\title{
WestVirginiaUniversity
}

THE RESEARCH REPOSITORY @ WVU

Graduate Theses, Dissertations, and Problem Reports

2019

\section{The Politics of Drug Courts}

Jeffrey Chris Moss

jmoss4@mix.wvu.edu

Follow this and additional works at: https://researchrepository.wvu.edu/etd

Part of the Political Science Commons

\section{Recommended Citation}

Moss, Jeffrey Chris, "The Politics of Drug Courts" (2019). Graduate Theses, Dissertations, and Problem Reports. 7426.

https://researchrepository.wvu.edu/etd/7426

This Dissertation is protected by copyright and/or related rights. It has been brought to you by the The Research Repository @ WVU with permission from the rights-holder(s). You are free to use this Dissertation in any way that is permitted by the copyright and related rights legislation that applies to your use. For other uses you must obtain permission from the rights-holder(s) directly, unless additional rights are indicated by a Creative Commons license in the record and/ or on the work itself. This Dissertation has been accepted for inclusion in WVU Graduate Theses, Dissertations, and Problem Reports collection by an authorized administrator of The Research Repository @ WVU.

For more information, please contact researchrepository@mail.wvu.edu. 
The Politics of Drug Courts

\author{
J. Chris Moss \\ Dissertation submitted \\ to the College of Arts and Sciences \\ at West Virginia University
}

In partial fulfillment of the requirements for the degree of

Ph.D. in

Political Science
John Kilwein, Ph.D, Chair Jeff Worsham, Ph.D. Shauna Fisher, Ph.D. Corey Colyer, Ph.D.

Department of Political Science

\title{
Morgantown, West Virginia 2019
}

Keywords: Political Science, Public Policy, Diffusion, Implementation, Drug Courts Copyright 2019 J. Chris Moss 


\section{ABSTRACT \\ The Politics of Drug Courts}

\section{J. Chris Moss}

This study examined drug courts from a public policy and political science perspective. The first portion of the study focused on the history of sentencing policy from the 1970s through the drug court movement. The second chapter addressed gaps in the policy literature about how drug courts were created and how they evolved. Another focal point was determining how state-level actors such as legislators, state supreme courts, and bureaucratic agencies regulated drug court policy in each particular state. From this data, a continuum was formed to determine which states operated from a top-down management style for drug courts and which states operated from a bottom-up management style. This data allowed me to empirically test whether certain political science, criminal justice, and structure variables could account for the amount of state-level regulation into drug court policy. Partisan politics was associated with the amount of state-level regulation into drug court policy, and method of judicial selection was weakly associated with the amount of state-level regulation. In the final empirical chapter, drug courts from a bottom-up management state and a top-down management state were selected for case study analyses. Members of drug court teams were interviewed to determine the similarities and differences between the two disparate styles of management. Members of the drug courts teams who had not received as much scholarly attention were also interviewed such as treatment counselors, prosecutors, defense attorneys, and members of law enforcement to share their views on drug courts and describe their official duties. Finally, in light of the current opioid epidemic, members of the drug courts discussed how heroin and prescription pain killers are affecting their counties and what the drug courts and other entities can do to alleviate this problem. 


\section{Acknowledgements}

This dissertation is dedicated to the memory of Rob Hardy. You were there guiding me through the whole long and grueling process. I would like to thank my parents: Jeff and Brenda Moss. Without your love, support, and dedication none of this would have been possible. To Amy Bean: I'm sure hearing me complain about the dissertation subtracted years from your life, but I'm glad you were there when I needed love and support. I would also like to thank all of the members of my committee. Special thanks is due to Dr. Kilwein. You breathed life into this dissertation and your ideas and guidance made this product significantly better. To Dr. Worsham, Dr. Fisher, and Dr. Colyer: you all provided excellent feedback and played a big role in making this dissertation better. To all of my friends who have also been there for me when it counted, I could not have accomplished this goal without support from each and every one of you. 


\section{Table of Contents}

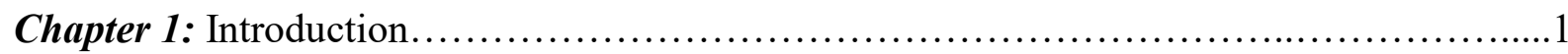

Chapter 2: Morality Policy and the Formation of Drug Courts in a Punitive Era..............7

Morality Policy........................................................... 7

Punitive Sentencing and the War on Drugs....................................... 9

Drug Courts, Diffusion, and Policy Implementation...............................23

Table 2.1: Cost Per Day Per Client in each of the Programs..........................28

Policy Implementation and Street-Level Bureaucrats................................ 31

Chapter 3: A Comprehensive Examination of Drug Court Development........................34

Table 3.1: State Drug Courts Created by Year..................................... 37

Table 3.2: State Population and Number of Drug Courts (2017)........................ 39

Table 3.3: Initial Drug Court Creation.........................................41

Table 3.4: Universal Standards and Restrictive Legislation......................... 44

Table 3.5: State Supreme Court Involvement in Drug Court Policy.....................48

Table 3.6: Laws of Oversight Authority over Drug Courts...........................51

Table 3.7: Decentralized Drug Courts..........................................54

Table 3.8: State Commissions................................................... 55

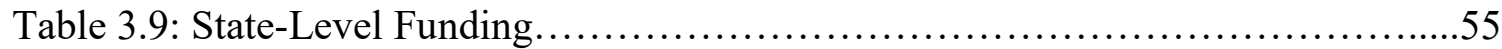

Table 3.10: Funds Allocated by State...............................................58

Table 3:11: Rank of Top-Down State Drug Courts................................61

Table 3.12: Rank of States Using a Bottom-Up Approach.........................62

Chapter 4:An Empirical Examination of State-Level Regulations into Drug Court Policy.....63

Dependent Variables.......................................................64

Independent Variables.......................................................66

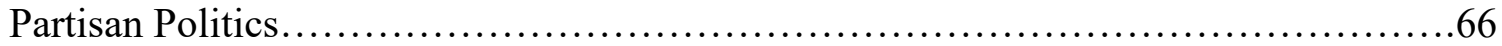

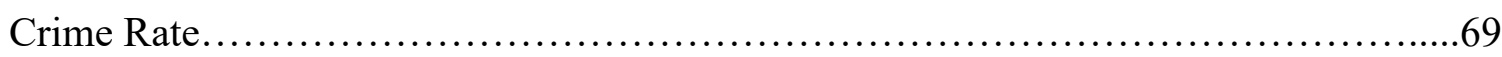

Method of Judicial Selection................................................ 71

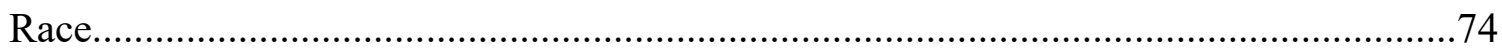

Statistical Analysis.......................................................... 74

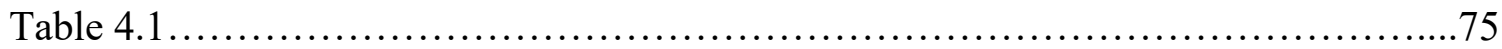

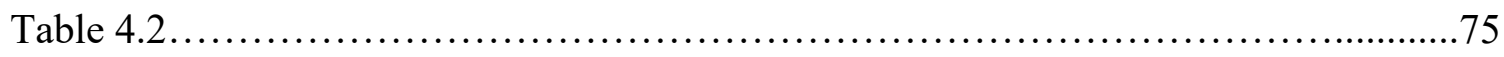

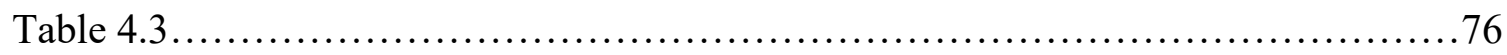

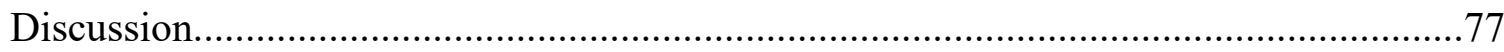

Chapter 5: A Qualitative Analysis of West Virginia and Pennsylvania Drug Courts.................80

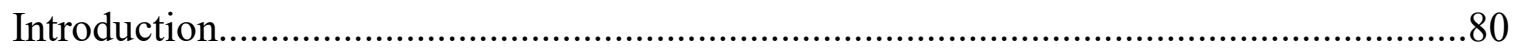

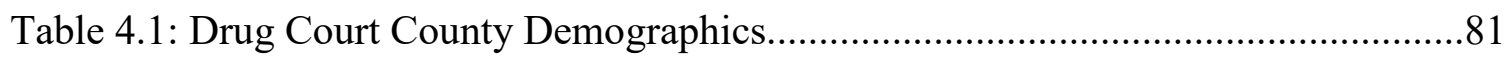

Top-Down vs. Bottom-up Drug Court Operations...................................................... 82 


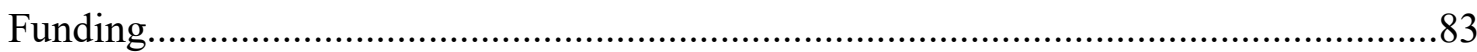

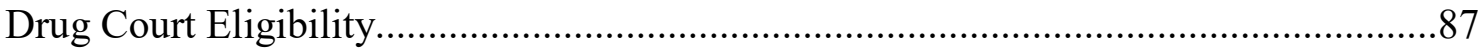

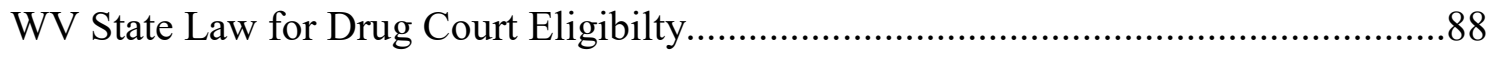

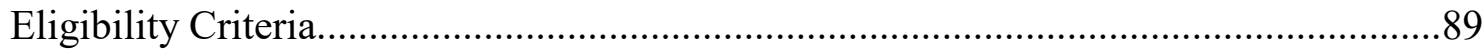

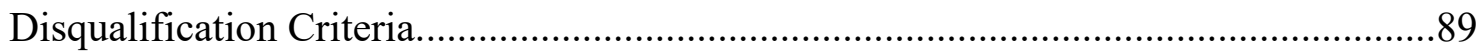

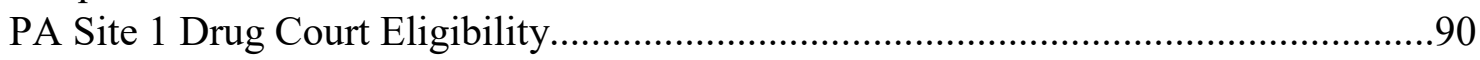

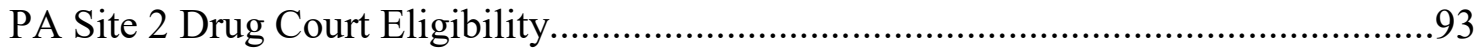

Drug Court Regulations, Evaluations, and Compliance...................................................97

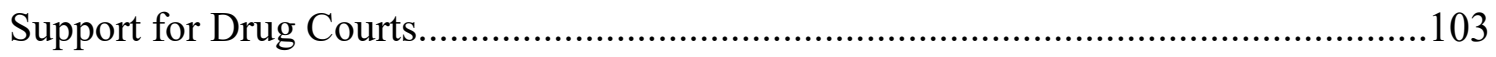

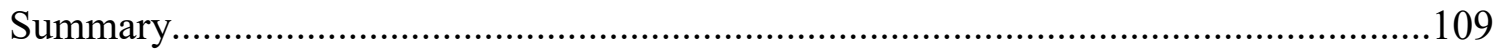

Chapter 6 Conclusion and Policy Recommendations...........................................................110

The Opioid and Heroin Crisis and Policy Recommendations........................115

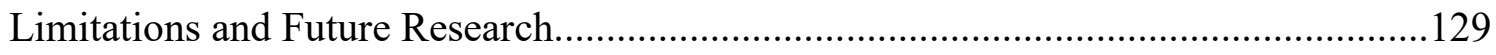

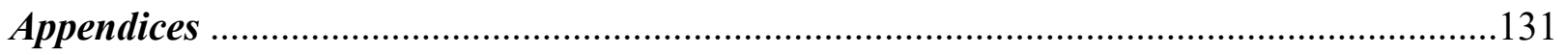

Appendix A State Drug Court Coordinator Questions.................................................131

Appendix B Questions for Drug Court Personnel......................................................132

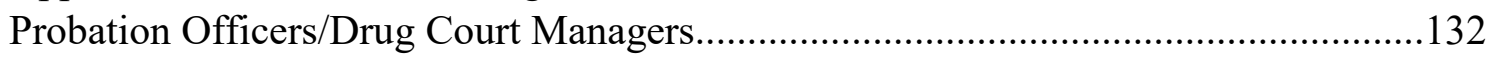

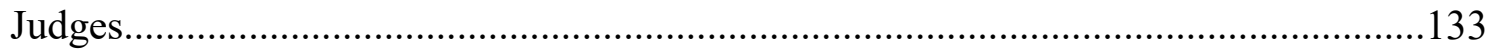

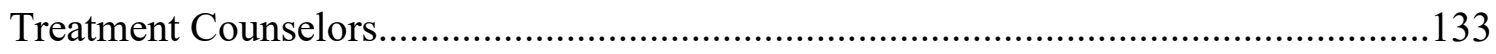

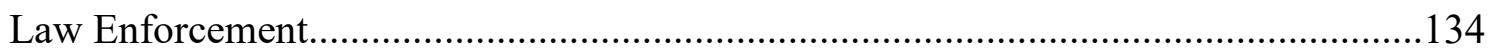

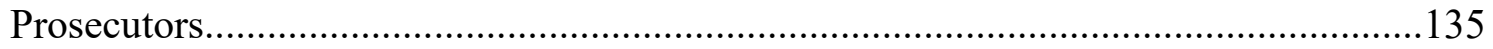

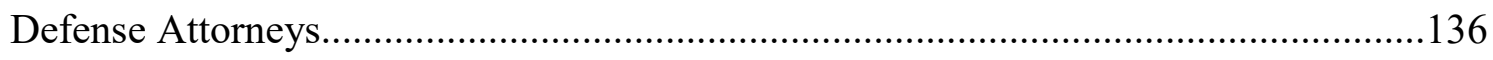

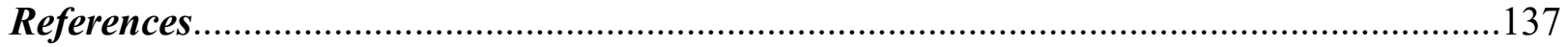




\section{Chapter 1: An Introduction to the Politics of Drug Courts}

Today, drug courts are arguably the most popular way to treat addicts who have committed drug-related, non-violent crimes. As of June 31, 2015, there were 3,133 drug courts operating in the U.S. and its territories (National Institute of Justice, 2017). The explosion of these types of specialty courts is nothing short of remarkable considering that their creation came at a time when criminal justice policies in the U.S. were largely defined by punitive measures. While there has been extensive criminal justice scholarship on drug courts, most of these studies have been narrowly focused on program graduation rates and recidivism. However, examining drug courts from a public policy and political science perspective offers many interesting avenues to explore.

In light of America's current opioid and heroin epidemic, drug courts could play a major role in alleviating this crisis, so it is important to understand more about the courts, what they are intended to achieve, and the ways in which policy is implemented. This study attempts to answer several important questions to increase our understanding of drugs courts. First, it is important to find out how these courts were created and evolved over time. By examining the diffusion literature, it is possible to determine if policy learning and imitation has been responsible for the spread of drug courts from both a vertical and horizontal diffusion perspective. Second, this study examines how state-level actors have influenced local drug court politics by analyzing legislation, state supreme court activity, and bureaucratic agencies. This is especially interesting from a judicial politics perspective since many studies involving federal and state appellate courts focus on judicial decisions, while largely ignoring the other ways judges can influence policy. Third, I argue that certain states have much more authority over shaping local drug court policies in a top-down fashion while the local drug courts in other states use more of a bottom-up 
approach. To understand what could possibly account for these disparate styles of management, it is important to determine whether certain political, criminal justice, or demographic variables can account for these differences. It is also imperative to understand if these two styles of management produce different implementation practices. This can be achieved by conducting case studies of states practicing these divergent styles of management. Fourth, understanding the specific roles played by key drug court personnel will allow me to determine whether these individuals believe in the drug court's goals and how that could affect successful implementation. Finally, to understand how the drug courts can better handle opioid and heroin addiction, it is necessary to ask drug court professionals for policy recommendations to improve an existing product. To begin answering these and other key questions, I have divided the study into five additional chapters.

In Chapter Two of this study, I offer a review of the relevant literature on drug abuse policy by first examining it through the lens of morality policy. I discuss how using drugs like opiates, cocaine, and marijuana went from a legal and socially acceptable practice to an illegal and morally reprehensible one. Certain factors such as race and social class played a large part in creating a moral panic in which immigrants and minorities were often blamed for creating the drug "problem" in the U.S. Policies were aimed at controlling members of these social classes and drug use was initially regulated at the federal level through acts such as the Harrison Narcotics Act of 1914 and the Marijuana Tax Act of 1937. Alcohol was first criminalized through the $18^{\text {th }}$ Amendment and federal polices such as the Boggs Act, the Controlled Substance Act of 1970, the Sentencing Reform Act, and the Anti-Drug Abuse Acts of 1986 and 1988 were federal laws that criminalized drugs. Many states passed legislation to criminalize alcohol and drugs both before and after federal policies. 
Before the 1970s, many factors were considered before sentencing an offender such as just deserts, rehabilitation, deterrence, and incapacitation. However, as both drug use and crime rose in the 1960s and continued into the 1980s, the goals of sentencing became centered on deterrence and incapacitation. Chapter Two discusses some of the factors that led to this dramatic shift in criminal justice policy and the consequences such as The War on Drugs, a meteoric rise in the incarceration rate (which disproportionately affected minorities) and resulted in tremendous financial cost to taxpayers.

Drug courts were developed as a way to reduce the backlog of drug cases burdening the criminal court system, but they soon evolved into a way to treat addicts, while maintaining an image of a tough but fair criminal justice program. Republicans were in favor of drug courts because they saved the taxpayer money and appeared to reduce crime in comparison to incarceration. Democrats viewed the program as more humane than prison and a way for addicts to get treatment.

While drug courts have continued to expand throughout the U.S. and the world, more needs to be understood from a public policy perspective. This chapter discusses diffusion and how it is relevant to drug courts. Drug courts began at the local level through an administrative court order by a Florida judge. These ideas then spread to other locations in various states. Eventually, both state and federal governments became involved in shaping drug court policies, as these specialty courts spread to every state by 2017 and many other countries around the world.

Chapter 2 concludes with an examination of the relevant bureaucratic literature concerning principal-agent theory and street-level bureaucrats. It then offers guidance as to how certain principals such as state-level policymakers and bureaucrats try to shape the policies of 
local drug courts through acts such as legislation, state supreme court rules, and policy evaluation procedures.

In Chapter 3, diffusion is a key factor in explaining how and why drug courts spread throughout the country. Several key data points are carefully mapped out by researching drug court creation and evolution in each of the 50 states. Factors such as initial state drug court development, the number of state drug courts per capita, legislation, state supreme court involvement, creation of commissions, development of best practice standards, and funding are all examined to develop a typology of drug courts. These drug courts range from top-down to bottom-up in their styles of management, with the former indicating significant state-level regulations are being used to manage these courts, while the latter indicates that the local drug courts have a larger degree of autonomy to develop and manage policy.

Chapter 4 builds on the knowledge gained in Chapter 3 by developing an understanding of factors that could account for variation in the way states choose to regulate drug courts. Three models were constructed to demonstrate whether certain political science, criminal justice, and demographic variables could account for state-level regulations. The first model determines whether variables such as partisan politics, method of judicial selection, the violent crime rate, and race can explain state adoption of restrictive drug court legislation. The next model analyzes whether these independent variables increase the likelihood that state supreme court judges will write rules to govern local drug courts. This has implications for judicial politics, especially if it can be determined that elected judges are more likely to intervene in politically popular programs such as drug courts. The goal of the final model is to determine if the independent variables can explain the variation in total state-level regulations.

Chapter 5 of this study uses a qualitative approach to determine how drug court policy is 
implemented in the state of West Virginia (a top-down state) and Pennsylvania (a bottom-up state). I analyze data collected from personal interviews with drug court team members from three sites, including judges, drug court coordinators, probation officers, law enforcement officers, prosecutors, and defense attorneys. The first goal of this chapter is to determine what, if any, differences exist in management practices between top-down and bottom-up drug courts. I use the relevant bureaucratic politics literature as a guide to explain how state-level actors are attempting to control the local drug court agents in a top-down model versus the bottom-up style of management, and if this control produces different policy products in terms of drug court funding mechanisms, drug court eligibility, and program evaluations. I also examine whether or not this affects compliance and if there is any evidence that certain state-level regulations could attempt to upend local drug court cultural norms and lead to shirking or sabotage.

Next, I examine support for drug courts by asking drug court team members to, first, discuss their own level of support for the mission of the program and, second, to shed light upon the support of other members of the community. By determining the level of support for the program, I am able to see if the bureaucrats are supporting the goals of the program or if divergent goals exist that could negatively impact policy implementation.

The last section of this chapter offers a glimpse into the jobs of lesser researched drug court team members such as probation officers, prosecutors, defense attorneys, and law enforcement officers. This is important because little research has been conducted to ascertain the duties of these street-level bureaucrats in a drug court context. The lion's share of these drug court professionals work in their primarily in their traditional jobs and the drug court is only a part-time position. It will be interesting to understand their transition from one job to another and if that has changed their views on drug control policy. For example, law enforcement officers 
have been traditionally in favor of punitive sanctions for drug offenders over the last several decades. Would working within the drug court system help to soften these views? If so, in what ways? Also, do differences among drug court professionals exist in terms of how they view the program? Do they all believe that the drug courts are the best avenue to treat drug offenders? These and other queries will be answered in this section.

Chapter 6 will conclude this study by summarizing the findings from each of my chapters. However, it goes a step further by discussing the current opioid/heroin epidemic and offering policy solutions to help alleviate this public health and criminal justice problem by improving drug court practices. West Virginia and Pennsylvania have suffered more than other states in terms of overdose death rates and public health problems, which makes studying the problem in these states especially relevant to public policy. West Virginia ranked first in overdose death rates and Pennsylvania ranked third in 2017 (CDC, 2019). The final section will address the limitations of this study and provide scholars with a roadmap to conducting future research on this topic. 


\section{Chapter 2: Morality Policy and the Formation of Drug Courts in a Punitive Era}

This chapter has several important goals. The first of which is to provide a review of the literature concerning the history of drug control policy in the United States. Morality policy will be used as a guide to discuss the reasons for drug prohibition throughout American history, including scapegoating, fear mongering, and the criminalization of once legal substances. Second, political motivations for these policies will be explored. Third, drugs courts will be examined using the diffusion literature as a potential explanation for the drug court movement. Finally, an inclusion of the relevant literature concerning principal-agent theory and street-level bureaucratic theories will be used to examine drug court implementation practices.

\section{Morality Policy}

Though it might appear unfathomable to someone unfamiliar with the history of U.S. drug policy, illicit drugs such as cocaine, opium, marijuana, and even heroin were all once legal and largely unregulated (Belenko and Spohn, 2015). However, beginning in the late 1800s concerns over the impacts of drug use arose. These were based on widespread fear described as moral panics, where the severity of the problems associated with drug use are often overblown and punitive policies are enacted based on these knee-jerk reactions (Belenko and Spohn, 2015). Similar to moral panics, scapegoating is a way in which politicians and interest groups are able to assign blame for drug-related issues by associating certain racial and ethnic groups with the abuse of certain substances, which are deemed to undermine society as a whole (Provine, 2007).

A good way to begin examining the history of some of these policies is to explore morality policy and discuss its relevance to drug policy. In a seminal work on the subject entitled The Politics of Sin, Meier (1994) developed a theoretical explanation to examine public policy by exploring how the interactions of political forces, citizen forces, industry forces, bureaucratic forces are used to shape legislation, implementation, and ultimately produce policy outcomes. 
Meier (1994) argued that morality politics is the way one section of society uses the government to shape societal values. Morality policy is either one-sided or two-sided: two-sided policies issues such as abortion and gay rights are issues where two legitimate viewpoints can exist, and citizens compete to redistribute values (Meier, 1994). On the other hand, one-sided policies are deemed to be sinful. Generally, there is universal opposition to these types of acts such as murder, drunk-driving, and drug abuse. Policy entrepreneurs often take the lead in shaping these polices without serious political opposition or without the assistance of bureaucratic expertise. These policies are usually poorly designed and result in policy failures (Meier, 1994). This, as I will demonstrate in this chapter, is particularly the case with U.S. drug policy. The goal of policy regarding sin is to punish and deter these behaviors. Politicians always believe that there is more support for being tough-on-sins like drug use than actually exists (Meier, 1999).

Mooney (2001) also made significant contributions to morality policy by describing the conditions necessary for it to exist, why it becomes salient, and how it results in high levels in public participation. In 2001 , he argued $(2001, \mathrm{p} 4)$ that "a policy is classified as a morality policy based on the perceptions of the actors involved and the terms of the debate among them. If at least one advocacy coalition involved in the debate defines the issue as threatening one of its core values, its first principles, then you have a morality policy." Some characteristics are indicative of morality policies. For example, the policies can be marked by high degrees of public salience (Mooney, 2001). In 1989, 27 percent of Americans believed drug abuse was the most important problem facing the country (Gallup, 1989). Morality policies are simple and clear policy value statements, and they are generally known to have higher levels of participation among members of the public, in part, because there is not a need for citizens to understand technical aspects of the policy (Mooney, 2001). Presidents are particularly effective in shaping 
public opinion on drug abuse policies by elevating the salience of the issue as I demonstrate when discussing Reagan's drug war.

Political ideologies can also influence morality policies (Omori, 2013). Tatalovich and Daynes (1998) claimed that public opinion on moral issues is generally conservative. Drug policy is particularly viewed as a Republican issue, even though most presidents were conservative in their speeches and policies regarding drugs and crime control after the Nixon era (Oliver, Hill, and Marion, 2011). Morality policies can also change after a period of time. This occurs after the issue is reframed to avoid the "sin" label. An excellent example of this occurred during Prohibition, when alcohol use was considered a sin (Schwartz and Tatalovich, 2018), but was later repealed as it was viewed through an economic lens (Belenko and Spohn, 2015), making it a two-sided policy issue.

In the following section, I discuss drug policy history, incorporating lessons learned from morality policies. I begin examining drug policy changes in the late 1800 s. I describe how several moral panics and episodes racial scapegoating led to various drug-control policies. I also examine how political ideology, issue salience through political rhetoric, and interest groups helped shape these policies.

\section{Punitive Sentencing and the War on Drugs}

America's first war on drugs actually began with alcohol and its eventual prohibition. As certain medical professionals such as Benjamin Rush warned about the dangers of spirits, church leaders sounded the alarm over the moral dangers of alcohol and equated its consumption with sin. This led to a change in public attitudes and the formation of several interest groups aimed at banning alcohol use. Among these groups were the Women's Christian Temperance Union in 1874 and the Anti-Saloon League in 1893 . These groups were instrumental in advancing the $18^{\text {th }}$ 
Amendment and supporting politicians who favored its passage (Belenko and Spohn, 2015).

Immigrants were also blamed for the alcohol scourge. They included the Irish and the Germans, and drinking soon became un-American (Rorabaugh, 1996). America's entry into World War I also after provocation from Germany further flamed the fans of scapegoating German immigrants. In 1918 Wisconsin's Lieutenant Governor, John Strange gave a speech chastising Germans: "We have German enemies across the water. We have German enemies in this country, too. And the worst of all our German enemies, the most treacherous, the most menacing, are Pabst, Schlitz, Blatz and Miller. They are the worst Germans who ever afflicted themselves on a long-suffering people (White, p1, 2018)." Many states had already banned the use of alcohol, and President Woodrow Wilson and members of Congress began to increase their support for Prohibition (White, 2018). In 1919, America passed the $18^{\text {th }}$ Amendment to the Constitution and it was ratified a year later; it essentially banned the manufacture, sale, and transportation of alcoholic beverages (Belenko and Spohn, 2015).

Despite the ban, Prohibition became difficult to enforce, especially in the immigrant communities (Provine, 2007). Other criminal justice issues began to arise as well. For example, bootlegging and organized crime flourished during this time. This created a rise in general crime, especially violence, as mobsters solved their problems with Tommy guns instead of relying on the police (White, 2018). By the time of the Great Depression, the rise in crime and violence coupled with a need for tax revenue, led interest groups such as the American Legion and the American Bar Association to change their views on the $18^{\text {th }}$ Amendment and support repeal. President Roosevelt campaigned against Prohibition, and members of the Congress also saw the political gains to be made and passed the $21^{\text {st }}$ Amendment, repealing Prohibition. It was ratified 
in 1933 and the issue of temperance and control of drinking quickly faded from the spot it once dominated on the national stage (Provine, 2007).

Alcohol policy during and after Prohibition has provided many parallels to our understanding of drug policy. For instance, moral panics and racial scapegoating were evident in many of the drug scares throughout the $20^{\text {th }}$ Century. In 1875, San Francisco passed one of America's first drug ordinances, making it illegal to own or visit an opium den (Belenko \& Spohn, 2015). These opium dens were operated by Chinese immigrants and they catered to young white men and women. It was feared that these young people were from respectable families could lose their morals while under the influence and be subject to sexual acts of perversion by Chinese men (Fisher, 2014).

The racial scapegoating continued into the $20^{\text {th }}$ Century, when African-Americans were portrayed by the media as violent cocaine "fiends" who could withstand bullets from a police officer's gun (White, 2014). In terms marijuana usage, Mexicans bore the brunt of the hateful propaganda. For example, the Los Angeles Times wrote a headline about marijuana-linked violence in 1918 that read "Crazed Mexican Runs Amuck and Creates Reign of Terror in Plaza District (White, p. 1, 2014)."

Negative propaganda helped fuel support for both state and federal action intended to first regulate and later ban certain drugs. An 1885 Ohio law banned smoking opium and selling cocaine without a prescription became a crime in Illinois in 1897. The federal government eventually entered the political fray by passing its own legislation to regulate and criminalize drugs in the following decades (Belenko and Spohn, 2015). First, the Harrison Act of 1914 was passed by Congress and signed into law by President Wilson. This law taxed the people who both made and distributed opium, coca leaves, and their derivates; it also required doctors and 
pharmacists to be licensed. While the Harrison Act did not criminalize drug use, it created a chilling effect in which the doctors were not allowed to prescribe maintenance drugs to addicts to prevent them from going through opiate based withdrawal (Belenko and Spohn, 2015). In some cases, doctors were even arrested for violations (Meier, 1994). As a consequence of this act, addicts were further marginalized and now forced to obtain their drugs via the black market, usually in high crime areas such as brothels (Belenko \& Spohn, 2015). The U.S. Treasury Department gained tremendous power to enforce the Harrison Act, and it used its discretion to distort the extent of the actual drug problem, mischaracterize the success of the bureau's impact at solving the drug problem, abuse citizens in the form of excessive arrests with little regard for procedural rights, and commit corruption (Meier, 1994).

The Marihuana Tax Act of 1937 was characterized by many of the same problems seen in the Harrison Act. For instance, Henry Anslinger, the newly appointed Commissioner of the Federal Bureau of Narcotics (FBN), led a false and misleading campaign against marijuana (Belenko and Sphon, 2015). The Federal Bureau of Narcotics portrayed marijuana as a scourge causing criminal and violent behavior (Meier, 1994). As with the aforementioned attempts at prohibition, minorities were blamed (Belenko and Spohn, 2015). Anslinger's agency portrayed the marijuana problem to be particularly troubling in black and Hispanic communities, and that approximately 50 percent of the violence occurred in these communities where marijuana use was “purportedly” rampant (Meier, 1994).

In 1936, the film Reefer Madness made its debut. It portrayed majuana use as causing hallucinations, rape, and eventually murder; it was also depicted as a gateway drug (Pagano, 2018). The film coupled with Anslinger's propaganda assault shaped opinion on marijuana and paved the way for state legislation regulating the drug's sale and usage as well as producing an 
appetite for legislation at the federal level (Meier, 1994). In 1937, the Marihuana Tax Act was passed. This legislation required those who grew pot to pay an annual tax from $\$ 1.00-\$ 24.00$ per year. Written records of all transactions per ounce of marijuana transferred between citizens was required (Belenko and Spohn, 2015). This largely stamped out of the legal marijuana industry.

In the years following the Marihuana Tax Act, the FBN continued to flex its might in shaping and enforcing federal drug policies. For example, legislation such as the Poppy Act of 1942, regulated cultivation of opium poppies (Meier, 1994), and the Boggs Act of 1951, introduced mandatory sentences for drug offenses (Pagano, 2018). Congressional hearings in the 1950s attempted to link drug use to crime and warn of the increasing usage of drugs, which helped to spur additional punitive sanctions in the form of both federal and state legislation aimed at increasing penalties for an array of drug offenses (Meier, 1994). Anslinger stiffly opposed any opposition from the medical and legal communities to the harsh penalties enacted for violations of drug offenses.

The decade of the 1960s saw an increase in both violent crime and drug use. Events such as tension from the long war in Vietnam, the Civil Rights Movement, and the birth of a new counter-cultural movement of hippies led to both social and political unrest. This would eventually play out in the political and criminal justice arenas in the form of reduced judicial discretion, fewer opportunities for alternative sentences to prison, and increased forms of punitive punishments. Beginning with Progressive Era in the 1920s up through the 1970s, the U.S. relied on a multifaceted set of sentencing goals for crimes, including rehabilitation, deterrence, retribution, and incapacitation (Spohn, 2009). These goals were based on the belief that structural factors such as environment, heredity, and other social circumstances contributed to criminal behavior (Alschuler, 2003). 
Beginning in the 1920s, criminal justice reformers placed a greater reliance on experts during policy implementation (Morone, 1998). Psychologists, doctors, and social workers, worked to inform and assist judges and other legal professionals in sentencing and treating criminal offenders (Tiger, 2013). Judges were advised to consider environmental and social factors in their sentencing practice (Bortner in Tiger, 2013). The reformers developed their own specialized courts to treat certain categories of offenders who needed help (Tiger, 2013).

Juvenile courts became popular and spread to many areas of the country because reformers were mobilized, little political opposition existed, and there was a prevailing belief that these courts would save money (Baum, 2011). The public was sympathetic to the plight of children, who were viewed differently than adults and especially deserving of rehabilitation and a general second chance (Tiger, 2013). There are striking similarities between juvenile courts and today's drug courts, particularly the notion that both juvenile offenders and drug addicts are different from normal offenders and could benefit from individualized treatment (Tiger, 2013).

Some other important criminal justice policies were developed in during this time frame, including probation and parole (Alschuler, 2003). With probation, a judge can sentence a criminal offender to supervision under the professional guidance of a trained probation officer. This is usually an option for criminals who have committed less serious crimes (Spohn, 2009). Parole, on the other hand, is an option given to prisoners who have exhibited good behavior while incarcerated, and their release is not seen as a threat to society (Tiger, 2013). The theory behind these two alternatives to incarceration posits that extensive time in prison would be detrimental to the offender's rehabilitative progress (Alschuler, 2003).

A reliance on experts and a preference for rehabilitative punishment would remain the dominant practices in sentencing policy until they were challenged in the 1970s and 
systematically dismantled in the following decade and beyond. During the 1960s, a rise in violent crime and drug use led some theorists and politicians to question prevailing criminal justice policies (Blumstein and Piquero, 2007). Research conducted during the 1970s was critical of both rehabilitation and judicial discretion (Tiger, 2013). Martinson (1974) found that prior research on rehabilitation failed to demonstrate a reduction in recidivism, and concluded that none of the current programs worked. Former federal judge turned researcher, Marvin Frankel, surveyed active judges, presenting them with the facts of hypothetical crimes and offender characteristics, then asked them to render a sentence based on that information. Frankel found wide variation in the application of sentences among the judges and concluded that sentencing practices needed to be more systematic and fair (Frankel, 1973). A return to earlier philosophies, such as deterrence and retribution gained popularity among theorists and with politicians (Andrews and Bonta, 2010). For example, James Q. Wilson (1975) argued harsher penalties for crimes would create a greater deterrent effect and increase public safety by incapacitating perpetrators.

From the late 1960s into the 1970s, marijuana became a prominent symbol of the counter-culture movement and greater law enforcement efforts to curb this drug's use were implemented (Meier, 1994). Marijuana arrests increased significantly from 1965-1974. At first marijuana arrests threatened to affect minorities and people living in impoverished communities, but this actually led to a large increase in the percentage of whites being arrested (Meier, 1994). States began to roll back some of the penalties for marijuana possession, and the Nixon administration had initially supported rehabilitation as a policy goal to curb drug use (Massing, 1998). However, this changed when certain Republican politicians saw an opportunity to transform their policy preferences into law (Stith and Cabranes, 1998). For example, state 
governors, like New York Republican Nelson Rockefeller, campaigned on tougher drug laws, including mandatory minimum sentences (Massing, 1998). Rockefeller's punitive rhetoric resonated with the public, which helped to shift national policies away from a focus on rehabilitation to a focus on law enforcement. The Nixon administration responded to this new political pressure and initiated mandatory sentences for low-level offenders. Again, this contrasted with the previous policies of his administration, where treatment and a model of harm reduction were implemented to fight drug abuse (Massing, 1998).

Democrats, like Ted Kennedy, were also supportive of the tougher penalties for drug offenders; however, Kennedy's main sentencing goal was to limit judicial discretion (Spohn, 2009, Stith and Cabranes, 1998). Kennedy used Marvin Frankel's study as ammunition to promote legislation to limit judicial discretion and make sentencing more fair and systematic, thereby reducing the potential for racial bias (Stith and Cabranes, 1998). Senator Kennedy formed a coalition with key Republicans, including President Reagan and Senator Strom Thurmond, to pass the Sentencing Reform Act of 1984. What had begun as a liberal-based movement to reform sentencing with this bill gained bipartisan support from Thurmond and Orrin Hatch as they were able to gain some of their policy preferences by creating a system that would theoretically deter crime by making penalties certain and severe (Stith \& Cabranes, 1998).

This law created a seven person sentencing commission. The commission developed a 900-page set of sentencing guidelines (Miller and Wright, 1999). The guidelines were based on two factors: seriousness of crime and criminal history. Seriousness of offenses ranged from 1-43, while criminal history ranged from 1-6, where higher scores in either category meant a longer sentence. This scoring mechanism eliminated judicial discretion by removing factors such as age, 
community ties, and life circumstances as choices a judge could use to reduce a convict's sentence (Stith and Cabranes, 1998).

Before the sentencing commission had completed its set of guidelines, President Reagan was busy implementing harsh sentencing practices as part of his War on Drugs agenda. Policies such as the 1984 Comprehensive Crime Control Act, the 1986 Anti-Drug Abuse Act, and later, the 1988 Anti-Drug Abuse Act represented an attempt by Congress to get-tough-on-crime by curbing drug use and detering future crime (Hora, Schma, and Rosenthal, 1998). The Democrats, especially during the 1984 legislation, did not want to give the Republicans sole possession of the drug issue, and they created a competition with Republicans for who could support the “toughest” anti-drug polices (Meier, 1994).

The most significant piece of legislation to address drug crimes was the Anti-Drug Abuse Act of 1986 (Beaver, 2010), which was boosted by the focusing event (Birkland, 1998) of the death of Maryland basketball star Len Bias, who overdosed on crack cocaine before he could begin what most sports pundits agreed would be a stellar NBA career (Spohn, 2009). This increased the salience of the issue in the eyes of the public (Meier, 1994). This Anti-Drug Abuse Act established mandatory minimum sentencing for a host of drug offenses. For example, being convicted of possession of 100 plants or 100 kilos of marijuana would result in a mandatory 5year prison sentence for the first offense and a 10 year sentence for a second offense (Davies, 2010). However, certain disparities were placed within this law. The most notable being the crack/powder cocaine disparity of 100 to 1 . Possession of 500 grams of powder cocaine carried with it a 5 year sentence for the first offense, which was the same as possession of 5 grams of crack cocaine (Spohn, 2009). 
The topic of crime in general (Marion and Oliver, 2003) and drug abuse in particular (Baumgartner and Jones, 1993) remained hot political agenda items into the mid-90s. The trend also remained almost completely one-sided in favor of more punitive sanctions (Spohn, 2009). There are at least two important reasons why this occurred. The first has to do with the actual and perceived political repercussions that policy makers face when advocating for more sensible measures (Massing, 1998; Tonry, 1995). A few notable examples are worth mentioning here.

In the 1988 presidential election, Democratic candidate Michael Dukakis suggested that to reduce prison crowding and crime rates, it might be prudent to re-think some of the mandatory sentencing policies and integrate law enforcement policies with other treatment-based policies. George H.W. Bush quickly pounced on these comments and painted his opponent as being "soft on crime." Dukakis' poll numbers dropped, and he lost the race by a substantial margin (Marion and Oliver, 2003). Learning from Bush's playbook, former President Clinton campaigned on a tough-on-crime platform as a Democrat by proposing tough sentences and greater use of capital punishment and he defeated President Bush (Marion and Oliver, 2003). In an example from the judicial branch, Brace and Hall (1995) found that in districts where judges are selected via popular election, liberals were more likely to be in favor of capital punishment than in districts where they are appointed.

Besides electoral politics, another reason why a serious opposition to punitive sentencing was never mounted in the past several decades is because of interest group domination by oneside. Fairchild (1981) found that professional groups, especially those representing law enforcement interests, had the most influence over criminal justice policy. However, her research only focused on the area where legislation was directly involved. Fairchild did not explore any of the other functions of interest groups. For instance, lay interest groups in the area of domestic 
violence were influential in educating the public and influencing lawmakers by testifying at hearings prior to the enactment of legislation (Stolz, 1999).

Miller (2008) conducted a study in which she coded all of the witnesses at Congressional hearings involving crime issues from 1946-2002. She found that hearings on crime became much more prevalent. For instance, crime hearings grew from .25 percent of all Congressional hearings in 1946 to 1.78 percent of all hearings in 2002. The salient issues have varied over time, but from 1980 to 2002, drugs became one of the most important issues at the crime hearings. During these years, illegal drugs issues constituted 30.1 percent of all crime hearings, which had risen sharply from 10.4 percent of all crime hearings from 1967-1980.

Like Fairchild (1981), Miller (2008) finds an overwhelming presence and influence being exerted by professional criminal justice groups. Professional organizations that included law enforcement or corrections groups accounted for over 30 percent of all the witnesses in over 85 percent of all hearings on crime. Single issue groups have also taken a much larger role in their attempt to influence Congress at these hearings. Victims' rights organizations and groups that represent women's rights and children's rights, along with the professional organizations, have became staunch advocates for more punitive punishments and harsher sentencing policies. However, broad-based citizen groups have been virtually excluded from these hearings. As a result, the impact of crime policies that affect a disproportionate number of minorities and the poor have been largely ignored (Miller, 2008). The few groups that have formed, such as Mothers Against Mandatory Minimums, have had minimal direct influence on Capitol Hill, but are expanding through various editorial media outlets to reach citizens (Siebert, 2010).

As a result of potential political repercussions (Marion and Oliver, 2003), power interests being able to keep their opponents off the political stage (Bachrach and Baratz, 1962), and the 
perceived electoral advantage of being tough on (drug) crime (Mayhew, 1974), policy continued to shift in favor of punitive sanctions into the decade of the 1990s.

After his win in the 1992 Presidential election, in which he campaigned to ensure that crime-control was not just a Republican issue, President Clinton made good on his promises to get tough on crime, and was able to elevate the 1994 Crime Bill onto the agenda, which instituted mandatory minimum sentences for more drug crimes and pledged to add 100,000 new police officers to the street (Marion and Oliver, 2003). However, Clinton's bill also included funding for drug courts (Mackenzie, 2006), an important break from the punitive tradition, which I will return to shortly. Meanwhile, at the state level, punitive policies spread from California via diffusion to other states. These included more mandatory drug sentencing policies, truth-insentencing, which limited parole, and three-strike laws that enabled the sentencing of offenders to 25-life for the conviction of a third serious felony (Frase, 2007).

While the law enforcement community was in favor of these harsh sentencing policies because it meant more money and resources for them (Miller, 2008), the judicial branch had suffered a tremendous loss in terms of autonomy and authority (Skogan, 2008). Departures from the Sentencing Reform Act's guidelines were rare and discouraged, especially for downward departures. Where judges lost a tremendous amount of discretion, prosecutors gained it. Prosecutors picked up power in terms of charging a defendant, plea bargaining, and downward departures for defendants willing to provide substantial prosecutorial assistance. The sentencing guidelines also put a severe constraint on probation, allowing it in only 15 percent of all federal cases in the 5 years after the law was implemented (Stith and Cabranes, 1998).

Many negative results accompanied these punitive sentencing policies, and would eventually pave the way for policy learning and new ideas in the form of alternative based 
sentencing and treatment, which will be discussed in the drug court section. However, it is important to first discuss some of the consequences of punitive sentencing. In the aftermath of strict sentencing for drug offenses and general crime, the length of federal prison sentences increased, opportunities for parole were reduced, and fewer individuals received probation (Spohn, 2009). Similar punitive policies were also implemented in large part by the states. Most states adopted some form of strict sentencing and a set of either mandatory or advisory sentencing guidelines (Zimring, 2007). As a result, America's incarceration rate exploded. By 2008, the rate of incarceration had risen to 753 out of 100,000 from 110 per 100,000 in 1973 (Schmidt, Warner, Gupta, 2010).

Roughly one-quarter of the people incarcerated committed drug crimes that did not involve violence (Schmidt et al., 2010). "The percentage of state prisoners incarcerated for a drug offense nearly quadrupled from 1980 (6\%) to $1996(23 \%)$. Similarly, the percentage of federal offenders serving time for a drug offense increased from $25 \%$ in 1980 to $60 \%$ in 1996 (Spohn and Holleran, pg. 330, 2002)." This rapid increase in prisoners has taken up a tremendous amount of financial resources. By 2011, the states collectively spent $\$ 51.7$ billion on corrections, while the federal government added more than $\$ 5$ billion in annual expenditures. The federal government's criminal justice spending has risen by 925 percent from 1982 to 2003 (Barkow, 2012). Despite the higher rate of incarceration, nearly 67 percent of criminals will be re-arrested within two years of release from prison. The recidivism rate for drug offenders is even higher (Petersilia, 2003). For example, Spohn and Holleran (2002) conducted a study that compared drug offenders that received prison to non-drug offenders in prison. They found that the recidivism rate for drug offenders was 82 percent compared to only 57 percent for non-drug offenders. 
The high rate of incarceration has created a tremendous strain on law enforcement in general, and corrections officials in particular. The massive gain in the prison population has far outpaced the construction of new prisons. Research has indicated that jail crowding is conducive to increased misconduct and violence among inmates (Gaes and McGuire, 1985; Wooldredge et al. 2001). However, Franklin, Franklin, and Pratt (2006) found that jail crowding alone was a weak direct predictor of inmate misconduct, but prison crowding can have a more indirect effect in terms of how the prison staff functions. For instance, many prisons are understaffed and poorly trained to handle the vast number of inmates and the problems inherent in some of the special inmate populations, such as drug addicts (Gido, 2002).

Obtaining funding for rehabilitation programs in correctional settings is difficult politically. Therefore, most facilities are forced to operate with a limited staff that does not have proper training, such as mental health and substance abuse professionals (Steadman, Morris, and Dennis 1995). This is especially troubling when one considers that there are large numbers of inmates with some form of a substance abuse problem. For instance, the Governor's Commission on Prison Crowding in West Virginia (2009) estimated that 85 percent of all West Virginia inmates have a substance abuse problem. The lack of proper rehabilitative treatment in correctional institutions can lead to an increase in criminal recidivism (Aos, 2006).

Race relations have also been negatively affected by the war on drugs. Despite an effort to reduce racial disparity in sentencing by establishing a system of sentencing guidelines, minorities now make up a greater percentage of the prison population today than they did before the guidelines were enacted. African Americans and Hispanics averaged 41 percent longer sentences than whites in the six years after the guidelines (Stith and Cabranes, 1998). Recent figures indicate that African Americans are the most disproportionately affected group in terms 
of incarceration rate. While African Americans make up only 12.4 percent of the population, they account for an incredible 38.2 percent of the prison population (Bureau of Justice Statistics, 2009). Examined in terms of males incarcerated in all federal and state prisons, the trend of disproportional penal population for blacks becomes even more disturbing. Spohn (2009) cited a Bureau of Justice study from 2007 that reported 1 out of 33 black men were incarcerated compared to 1 out of 79 Hispanic men and 1 out of 205 white men. Laws like the one passed by Congress in 1986, created a crack to powder cocaine sentencing disparity of 100 to 1 . In other words, possession of 500 grams of powder cocaine carried with it the same sentence as possession of 5 grams of crack cocaine (Stith and Cabranes, 1998). Crack cocaine is a drug that is more prevalent in certain subsets of the black community, particularly in impoverished inner cities (Tonry, 1996).

The high rates of incarceration and recidivism, back-logged court systems, onerous financial costs, and jail crowding were all factors that paved the way for a different criminal justice approach (Nolan, 2001; Tiger, 2013). However, lawmakers had become leery of supporting rehabilitative policies for fear of political backlash (Marion and Oliver, 2003), and the drug court movement began as a result of frustrated judges who decided to take action (Baum, 2011; Nolan, 2001). The following section will examine the development of the drug court movement and describe how these new reformers were able to offer an innovative approach to punishment through a combination of past criminal justice solutions. This will cover the relevant literature pertaining to why drug courts were developed, while also examining some of the shortcomings of this research.

\section{Drug Courts, Policy Learning, and Implementation}

To understand how and why drug courts were formed, it is important to understand their 
creation from a diffusion perspective. Simmons, Dobbin, and Garrett $(2006,787)$ offered the following definition: "Policy diffusion occurs when government policy decisions in a given jurisdiction are systematically conditioned by prior policy choices made in other jurisdictions." In this particular study, I examine policy diffusion both horizontally and, to an extent, vertically. In other words, I am concerned with how policy in one or several states influences policy in other states, but I am also interested in determining how drug court policy at the federal level has influenced state-level policy, as well as how state-level policy has influenced local drug court policy.

To examine how policy diffusion works, it is imperative to understand how learning occurs. According to Gilardi (2016, p 10), "learning is a process where policies in one unit are influenced by the consequences in other units." Learning is based on policy success, which can be determined by achievement of stated goals, implementation, and political support (Gilardi, 2016). Scholarly examples of this include Volden (2006), who concluded U.S. states were more likely to attempt to replicate medical insurance programs for impoverished youths from states that were able to keep the cost of insurance low but increase the overall health insurance coverage rates. Learning was also demonstrated in a political context, in the case where reelection could be conducive to adopting successful policies (Gilardi, 2010). Other types of diffusion focus on competition and emulation. Competition is when a particular state tries to look ahead or react to the moves of another state to gain or keep certain resources such as tax revenue (Basinger and Hallerberg, 2004). Emulation, on the other hand, is based more on symbolic policies that can garner high acceptance regardless of whether or not they actually work (Gilardi, 2016). 
To begin my assessment of learning, it important to mention the formation of the drug courts in the context of some of the negative consequences of punitive sentencing polices, which were mentioned at the end of the previous section. The earliest drug courts did not focus on treating drug offenders. Instead, they were intended as a way to redirect drug offenders to a new court to alleviate the strain that the increasing number of drug cases was placing on traditional criminal courts (MacKenzie, 2006). As drug courts evolved, they changed their focus from merely expediting the court dockets attempting to treat the underlying causes of the drug crime (Hora, Schma, and Rosenthal, 1999). The first actual drug-treatment court was created in MiamiDade, Florida in 1989 through a judicial order issued by a proactive state-level circuit judge named Gerald Wetherington. Here, the judge became frustrated by the ineffectiveness incarceration and probation had on reducing recidivism (Hora et al., 1999). This was a major concern of many judicial actors, treatment providers, and other criminal justice professionals as I demonstrate more clearly in Chapter 5. Judge Wetherington's ideas would eventually spread throughout the country through avenues of diffusion, which are examined in Chapter 3.

Before diffusion is discussed further, it is important to understand the nature of the drug courts, including how they differ from traditional courts, what policy concerns they attempt to address, and the degree to which they have been effective. Unlike traditional criminal courts that follow the adversarial model in which the prosecutor and defense attorney are competing against each other, while the judge plays the part of impartial umpire, drug courts are run in a cooperative manner (Nolan, 2001). Judges, prosecutors, defense attorneys, probation officers, and treatment counselors work together to reach a common goal: reduction of drug use and criminal recidivism (MacKenzie, 2006). The judge is the central figure in the court (Baum, 2011), and plays the key role in implementation and oversight of the program (Nolan, 2001). 
Depending on the drug court, judges ultimately decide whether eligible defendants enter into a pre-plea or post-plea agreement (Tiger, 2013). In pre-plea agreements, prosecutions are deferred and charges are dismissed if the defendant successfully completes the program. In postplea agreements, the defendant must plead guilty, but can have the sentence suspended or charges expunged if he/she graduates from the program (Tiger, 2013). If, however, the defendant fails to complete the program, charges can be filed or sentences can be imposed (Gottfredson, Najaka, and Kearley, 2003). To be eligible for participation in the drug court, the defendant generally has to be charged with a drug crime or a crime closely related to drug abuse, such as stealing to support a drug habit (MacKenzie, 2006). Violent criminal offenders (Gross, 2010) and those who have committed sex offenses (Weatherburn et al., 2008) are often ineligible to participate in drug courts.

Once an offender has been cleared to enter into the drug court, the judge sets the terms of treatment (Nolan, 2001), and a plan is developed based on an intake assessment conducted by members of the court, such as probation officers and treatment professionals (Wenzel, Longshore, Turner, and Ridgely, 2001). The philosophy behind treatment is based on coercive sanctions, which is a sort of "tough-love" approach to justice (Nolan, 2001). This approach combines some of the ideas and practices used in past criminal justice programs discussed in the previous section. For example, proponents of the drug courts view drug offenders as addicts who are different from "normal" defendants, just like their predecessors who developed the juvenile courts and advocated for children to receive special treatment (Tiger, 2013). These new reformers believe that the best way to change the behavior of addicts is through therapeutic treatment (Tiger, 2013). However, unlike the past treatment program that emphasized 
rehabilitation, the drug courts rely on a system of rewards and punitive sanctions to maintain compliance (Nolan, 2001).

Judges are in a unique position as both a mentor, who can encourage, praise, and reward individuals for good behavior, and an authority figure with the power to sanction offenders for non-compliance, such as failed urine tests, not showing up for meetings, and commission of new crimes (Nolan, 2001). Rewards and sanctions are often issued during scheduled hearings. The number of mandatory hearings is more frequent early on in the program, but as the offender progresses to different phases of the program, the frequency of hearings decline (Marlowe, 2010). The rewards can be simple, like praise for attending all hearings; they can also be tangible, such as movie vouchers for successfully completing each phase of the program. Sanctions are issued for non-compliance in the program (Tiger, 2011). Depending on the offense, sanctions can be mild or severe (Lindquist, Krebs, and Lattimore, 2006). For example, the judge can verbally admonish a drug court participant for showing up late for treatment, or they can sentence the participant to a day or two in jail for repeatedly failing urine tests. For extreme noncompliance, such as getting arrested, the judge has the authority to terminate the participant from the program (Tiger, 2011).

It is important to also discuss some of the roles of the other members of the drug court. Prosecutors and defense attorneys are mostly involved in the initial proceedings to determine if the drug court is an appropriate option; they can also participate in drug court meetings and hearings, but often do not (Nolan, 2001). Probation officers are more involved in the day-to-day monitoring of offenders; they inform the judges of an individual's progress in the program and make recommendations for either rewards or sanctions based on the individual's actions (Lindquist et al., 2006). The treatment specialist is usually a counselor or social worker who has 
been professionally trained to treat addiction (Olsen et al., 2001). The treatment usually involves programs, such as individualized cognitive behavioral therapy, group therapy sessions, and 12step meetings (Nolan, 2001).

Many of the prior studies on drug courts have focused on graduation rates, whether the courts have been effective at reducing recidivism compared to incarceration or probation (Marlowe, 2010), or how these two measures of success vary by race, age, gender, drug of choice, prior criminal history, mental illness, education, and employment. The vast majority of these studies have been quantitative. In the nearly twenty-five years of drug court existence, researchers have developed many important insights from numerous policy evaluations. Marlowe (2010) reviewed five separate meta-analyses of drug court evaluations, totaling 276 drug court studies in all. Each of these meta-evaluations resulted in an overall reduction of recidivism for drug court graduates compared to control groups; the average of all of the studies was a $10-15 \%$ reduction in future crime. The courts with more structured implementation demonstrated a greater reduction in recidivism (Marlowe, 2010). Shaffer (2011) criticized some of these meta-analyses, and used a sample of 82 drug courts that used more rigorous methods, such as random assignment, proper comparison groups, and control variables. The results of this study showed a smaller reduction in recidivism of 9-10\%. However, not all drug court evaluations have yielded positive outcomes (Tiger, 2013). For instance, a meta-analysis of five drug courts from a five-year multisite study showed no statistically significant reduction in recidivism for drug court participants compared to non-participants (Drug Policy Alliance, 2011 in Tiger 2013).

Prior research has demonstrated that certain types of drug court participants are more likely to graduate from the program and less likely to recidivate. For example, adult drug courts 
have produced more successful outcome measures than juvenile drug courts (Stein, Deberard, and Homan, 2012). In general, research has indicated that drug court participants who are white (Belenko, 2001; Gray and Saum; 2005; Senjo and Leip; 2001; Stein et al., 2012; Schiff and Terry, 1997;), female (Dannerbeck, Sundet, and Lloyd, 2002; Gray and Saum, 2005; Liang and Long, 2013), educated (Hartley and Philips, 2001; Mateyoke-Scrivner et al., 2004; Peters, Haas, and Murrin, 1999) employed (Dannerbeck et al., 2006; Hickert, Boyle, and Tollefson; 2009; Peters et al., 1999), and not mentally ill (Hickert et al., 2009; Gray and Saum, 2005) are more likely to succeed. Those who have little to no prior criminal records (Hartley and Philips, 2001; Mateyoke-Scrivner et al., 2004) and do not use cocaine are also more likely to experience successful drug court outcomes.

Drug courts have been lauded by some politicians as offering considerable financial savings over regular incarceration. Much of the savings has been attributed to a reduction in the costs of housing, medical treatment, and food, which is provided to offenders who are incarcerated (Carey and Finigan, 2004). For instance, a study of the Broward County Florida correctional system compared jail to drug courts and other forms of alternative sentencing. The following table is a comparison of the cost per day for offenders who are incarcerated vs. those who are enrolled in a drug court.

Table 2.1. Cost Per Day Per Client in Each of the Programs.

\begin{tabular}{|lcccccc|}
\hline & $\mathbf{2 0 0 5}$ & $\mathbf{2 0 0 6}$ & $\mathbf{2 0 0 7}$ & $\mathbf{2 0 0 8}$ & $\mathbf{2 0 0 9}$ & $\mathbf{2 0 1 0}$ \\
\hline Jail & $\$ 88.45$ & $\$ 91.27$ & $\$ 103.92$ & $\$ 106.66$ & $\$ 114.97$ & $\$ 107.71$ \\
\hline Drug Court & $\$ 7.40$ & $\$ 7.35$ & $\$ 8.09$ & $\$ 10.35$ & $\$ 10.01$ & $\$ 10.33$ \\
\hline
\end{tabular}

According to these data, the costs of incarceration were greater than 11 times the cost of drug courts (Piquero, 2010). Marlowe's (2010) investigation yielded an average savings of $\$ 3,000$ to 
$\$ 13,000$ per drug court offender, depending on the individual court. Newer data also demonstrate that drug courts offer a very high return on investment savings of between 200 to 400 percent, saving communities between $\$ 3,000$ to $\$ 22,000$ per individual when compared to prison (Marlowe et al., 2016).

It is worth noting that current incarceration rates are slowly shrinking from 753 per 100,000 in 2008 (Schimdt et al., 2010) to 698 per 100,000 in 2015 (Walmsley, 2015). A few reasons have been offered for this downward trend. First, the Supreme Court decisions of Blakely v. Washington (2004) and U.S. v. Booker (2005) rendered mandatory sentencing guidelines unconstitutional at the state and federal levels respectively, however, advisory guidelines were still deemed acceptable (Marcus, 2005). Second, politicians have been more amenable to criminal justice reform e.g. the Fair Sentencing Act by U.S. law in 2010, which reduced the aforementioned crack/powder cocaine sentencing disparity from 100 to 1 to 18 to 1 (Graham, 2011). States, however, have varied widely in the actions they have taken to reduce their incarceration rates. For example, California and New York both passed legislation to reduce the classification and sentencing for certain drug offenses (The Sentencing Project, 2017). States like Louisiana and Georgia have incarceration rates higher than 1,000 per 100,000 (Wagner and Walsh, 2016).

Finally, specialty courts in general and drug courts in particular are thought to reduce incarceration. Since drug courts are shown to reduce recidivism and provide an alternative to prison (Marlowe et al., 2016), they should, at least in theory, be able to reduce the incarceration rate. Research on this front has offered a mixed result: in a meta-analysis of drug courts compared to other community based corrections programs, drug courts significantly reduced the incidence of incarceration, but when examining pretrial or post-entry amount of time spent 
incarcerated, drug court participants saw no aggregate reduction in time served (Sevigny, Fuleihan, and Ferdik, 2013). To my knowledge, there have been no studies that actually try to gauge the exact role, if any, drug courts have played in reducing the overall jail and prison population.

In addition to concerns over drug courts and the incarceration rate, which goes beyond the scope of my study, public policy issues need to be addressed. In Chapter 3, I seek to determine how drug courts were formed, how they evolved, and which political actors played roles in the development of these policies. I also develop a typology of drug courts: top-down and bottom-up. States who manage their courts in top-down courts are heavily involved in policy creation, implementation, and evaluation practices. On the other hand, drug courts in bottom-up states have a large degree of autonomy to craft and manage drug court policy in their jurisdictions. I also examine drug courts in a top-down state and a bottom-up state in Chapter 5. To better understand how policy implementation works in these settings and to develop ways to examine the policy processes within these disparate drug courts, a review of the relevant policy implementation literature is needed.

\section{Policy Implementation and Street-Level Bureaucrats}

One of the most common concerns in public policy is whether principals control agents. However, thinking about it in those black and white terms severely limits the many intricacies involved in the process. A better way of framing the question would be to ask: In what ways do principals control agents? Traditionally, scholars have attempted to answer this query by examining how members of Congress can better control agencies within the federal bureaucracy. However, state and local governments are responsible for the majority of policy implementation 
in the United States, and a better understanding of these actors will improve overall knowledge of public policy.

There are two main approaches used to study this type of policy implementation: topdown and bottom-up. Theorists examining public policy from a top-down approach are concerned with how policy is controlled and shaped from the central level (Matland, 1995). For top-down policy to be effective, Sabatier and Mazmanian (1979) described several conditions that needed to be met: 1.) clear objectives; 2.) causal theory; 3.) legal structure of implementation process; 4.) committed officials; 5.) supportive interest groups; 6.) no undermining of socioeconomic conditions. While the top-down approach is good at offering generalizability, it focuses more on legislation and legislators, not those responsible for implementation at the locallevel (Cerna, 2013).

The bottom-up approach focuses on workers at the civil service level and illustrates their efforts in crafting and carrying out public policy (Matland, 1995). In his ground-breaking study, Lipsky (1980) examined the roles that public servants such as teachers, police officers, judges, and social workers play in implementing and shaping public policy. He referred to these workers as street-level bureaucrats. These individuals shape policy by determining who is eligible to participate in a program, the allocation of benefits, monitoring of compliance, and sanctioning those who do not comply (Meyer and Vorsanger, 2003). These types of activities are particularly relevant in drug treatment courts where judges and prosecutors have the authority to decide who can participate in treatment, and judges have the power to both reward participants for compliance and sanction them for non-compliance (Nolan, 2001). Probation officers or program managers are often tasked with monitoring compliance (Tiger, 2013).

Several findings from scholars who studied the issue of policy control using these 
frameworks are worth mentioning. For instance, political control of the legislature can affect front-line workers (Keiser, 1999), but political control is limited to highly visible activities such as the number of inspections (Winter, 2000). However, when studying policy implementation within the context of prison educational programs, Lin (2000) found that it was difficult to monitor activities such as disciplinary actions against inmates who missed class or slept through it. When rules are too complex and detailed they are difficult to enforce (Simon, 1983). Services can sometimes be rationed when resources are scarce (Lipsky, 1980). Finally, Brehm and Gates (1997) find that symbolism and cultural norms are some of the most powerful indicators that determine whether street-level bureaucrats work, shirk, or engage in sabotage against the organization. If the rules were consistent with shared beliefs and values, then workers were far more likely to work, not engage in shirking or sabotage (Brehm and Gates, 1997).

Many of the lessons from these studies can be applied to an examination of drug courts in top-down and bottom-up states. After determining what constitutes a top-down or bottom-up court in Chapter 2, I chose two states from this list: West Virginia, a top-down state, and Pennsylvania, a bottom-up state. I use the policy implementation literature to guide my research to determine what differences top-down and bottom-up states have in carrying out policies such as drug court eligibility, funding, implementation, evaluations, and compliance. I also examine the level of support among these bureaucrats, hoping it will shed some light on the culture and norms within drug court teams. 


\section{Chapter 3: A Comprehensive Examination of Drug Court Development}

The overarching aim of this chapter is to determine how drug courts were formed and implemented across all fifty U.S. states. I use diffusion policy to explain the most salient findings in this chapter. To gather the data for this portion of the study, I contacted the drug court coordinators from each of the fifty states. I also supplemented my findings by examining state court websites, research articles on state drug courts, and specific state legislation pertaining to drug courts. I chose to contact these policy actors after correspondence with personnel from the National Association of Drug Court Professionals (NADCP), the biggest pro-drug court interest group in the country and the marquee group responsible for developing drug court policy at the national level.

The NADCP was founded in 1994 by a group of drug court judges. The organization is the only national organization to provide training, offer membership, and support to local drug courts and other types of specialty courts (The Treatment Court Movement, 2019). Each year the NADCP hosts an annual conference for drug court professionals, addiction specialists, public health workers, law enforcement officers, judges, attorneys, and anyone else who is interested in learning more about treatment courts. At this conference, educational workshops, training, and networking is available (NADCP RISE 19, 2019).

Many drug court teams send their members here for training, especially startup drug courts. For example, the Monongalia County, WV Drug Court Coordinator (2017) said, "We have sent members of our team to these drug court conferences, where we were able to be trained on how drug courts should be modeled. Team members learned skills to enable them to more effectively perform their duties." A drug court coordinator from a newly formed drug court in Somerset, PA, also discussed the role of NADCP training as it pertained to her drug court. "We follow certain standards outlined by the NADCP, and our drug court judge even attended a 
recent national conference in Reno, NV, which he indicated was very useful in determining how to set up our court and better define the roles and expectations of team members." This provides an example of diffusion in the form of policy learning on a vertical level, as drug courts within states are being trained on how to start a court and the proper roles of personnel. Local drug courts within states are being groomed to adopt a national and more uniform approach to creating their courts and implementing policy as I will demonstrate.

The NADCP is a large, national interest group that helps shape federal policy and creates funding opportunities. The NADCP also sponsors many research projects that examine drug courts and other types of treatment courts. Some of the most utilized research that serves as a guide to state drug courts are the two NADCP Best Practice Volumes. Volume I was originally published in 2013 and Volume II in 2015. Both were revised in 2018 (NADCP, 2019). The "Ten Key Components of Drug Courts" were written by the NADCP and serve as a broad-based model for how drug courts should be structured and operated. For example, it emphasizes that drug courts need to use a non-adversarial approach, set up a system for determining offender eligibility, monitor individual drug abstinence, establish evaluation procedures, and forge partnerships within the community. A majority of the drug court coordinators interviewed in this study indicated their states utilize the Ten Key Components to facilitate drug court policy implementation. The NADCP also advocates for both federal and state legislation to fund and improve drug courts.

According to Courtney Brochious (personal communication, November 23, 2017), a former researcher at the National Center for State Courts, "The federal government is really pushing compliance with the Best Practice Standards and the 10 Key Components. They are tying this to funding to get states to comply." A couple cases demonstrate how this occurs at the 
state level. First, New Mexico's drug court coordinator indicated this his state received funding to implement the NADCP's Best Practices Volume I and II from the Bureau of Justice Assistance (Bochert, J, personal communication, March 26, 2016). The drug court coordinator in Vermont offered a similar assessment: “All of our treatment court practitioners are trained by the NADCP on Best Practice Standards Volume I \& II, which are being implemented into required Vermont Practice Standards.” These cases demonstrate clear evidence that top-down, vertical policy diffusion occurred, as the federal government in coordination with the NADCP has influenced local drug courts in the form of training and guidance. They also influenced statelevel drug court policy by providing funding to implement NADCP policy standards. Many states, like Vermont, are codifying these standards into law.

When I discussed my project with members of the NADCP, they indicated drug court coordinators would be the best source to initially contact for information on a particular state's drug court (NADCP, 2015). I used a combination of telephone interviews and open-ended email surveys to gather information from the coordinators. These questions can be found in Appendix A. Some of the drug court coordinators played a larger role in overseeing their state's drug court program than others and were able to provide more detailed information than their counterparts. Again, to compensate for this shortcoming and to confirm my data, I reviewed the secondary sources mentioned previously.

This study addresses major gaps in drug court literature. First, no study has offered a comprehensive explanation of the formation of drug courts. Scholars such as Nolan (2001) and Tiger (2013) found that the first drug courts were created by local judges who ginned up support among other criminal justice professionals to create the first drug courts. While I agree with the conclusions of these scholars, I argue that this process has evolved over time to include other 
institutional actors at the state level. I again use diffusion to explain how these courts were created and evolved into their present form. Table 3.1 tracks the year each state created its drug court.

Table 3.1: State Drug Courts Created by Year

\begin{tabular}{|l|l|}
\hline $\begin{array}{l}\text { Year of Creation } \\
\text { Number Created })\end{array}$ & States \\
\hline $1989(1)$ & Florida \\
\hline $1991(2)$ & California, Oregon \\
\hline $1992(4)$ & Arizona, Massachusetts, Michigan, Nevada \\
\hline $1993(3)$ & Alabama, Kentucky, Missouri \\
\hline$* 1994(9)$ & $\begin{array}{l}\text { Arkansas, Colorado, Delaware, Georgia, Illinois, Maryland, New } \\
\text { Mexico, Ohio, Washington }\end{array}$ \\
\hline $1995(7)$ & $\begin{array}{l}\text { Connecticut, Kansas, New York, North Carolina, Oklahoma, Texas, } \\
\text { Utah }\end{array}$ \\
\hline $1996(6)$ & Indiana, Iowa, Minnesota, Montana, New Jersey, Wisconsin \\
\hline $1997(6)$ & Louisiana, Nebraska, Pennsylvania, Tennessee, Virginia, Wyoming \\
\hline $1998(1)$ & Idaho \\
\hline $1999(2)$ & Maine, Mississippi \\
\hline $2001(2)$ & Alaska, South Carolina \\
\hline $2002(3)$ & Hawaii, Rhode Island, Vermont \\
\hline $2003(1)$ & West Virginia \\
\hline $2004(1)$ & New Hampshire \\
\hline $2007(1)$ & South Dakota \\
\hline
\end{tabular}

*In 1994, the Violent Crime and Law Enforcement Act was passed and federal funding was first available to drug courts.

The first drug court opened its doors in Miami-Dade, Florida in 1989; it was the result of a judicial order from a circuit judge (Nolan, 2001). South Dakota became the last of the fifty states to develop a drug court in 2007 (Eckrich and Loudenburg, 2012). From 1989-1993, ten states had initiated drug courts: Florida, California, Oregon, Arizona, Massachusetts, Michigan, Nevada, Alabama, Kentucky, and Missouri. Each of these states shared one thing in common with their Florida predecessor, their drug courts were initiated via local judicial efforts. I discuss the reasons for this in greater depth in Table 3.3.

The year 1994 marked a turning point in drug court expansion with the passage of the 
Violent Crime and Law Enforcement Act. The legislation provided federal funding for drug treatment courts for the first time (Marion and Oliver, 2003). This funding was used to jump start many drug court pilot projects, such as Arkansas in 1994 (Powers, 2012) and New Jersey in 1996 (C. Venditto, personal communication, June 15, 2016). From 1994-1997, twenty-eight additional states added drug court programs with nine occurring in 1994 alone: the most of any year. As the number of states offering drug courts expanded after the passage of the 1994 Crime Bill, the ways in which drug courts were created became more diverse. The states of Louisiana, North Carolina, Connecticut, and Vermont all created their drug courts via legislation, a theme that I will examine more carefully in Table 3.3.

After the drug court boom from 1994-1997, the eleven states that developed drug courts were states with low populations and mostly rural settings. Several reasons could plausibly be behind this trend. State budgetary issues may offer a partial explanation for this trend, as New Hampshire, Hawaii, and South Carolina spend the least amount of money on correctional programs per capita and Maine and West Virginia rank among the bottom ten states in per capita correctional spending. None of the states, except for the outlier of Alaska rank in the top-half of states in terms of correctional spending per capita (BJS, 2015). Political factors such as the makeup of state legislatures and governors did not account for drug court creation as these states were comprised of a mixture of Democratic, Republican, and split controlled legislatures from 1998-2007 (NCSL, 2019).

Sticking to the theme of population and drug courts, Table 3.2 provides data for each state's population, shows the number of drug courts in each, and ranks them by most courts. This also demonstrates how numerous drug courts have become in the U.S. over the last three decades. 
Table 3.2: State Population and Number of Drug Courts (2017)

\begin{tabular}{|c|c|c|}
\hline State & Population in millions & Drug Courts (Rank) \\
\hline California & 39.144 & $210(1)$ \\
\hline Texas & 27.469 & $144(3)$ \\
\hline Florida & 27.271 & $118(6)$ \\
\hline New York & 19.796 & $159(2)$ \\
\hline Illinois & 12.860 & $103(8)$ \\
\hline Pennsylvania & 12.803 & $82(13)$ \\
\hline Ohio & 11.613 & $109(7)$ \\
\hline Georgia & 10.215 & $100(9)$ \\
\hline North Carolina & 10.043 & $42(31)$ \\
\hline Michigan & 9.923 & $141(4)$ \\
\hline New Jersey & 8.958 & $24(37)$ \\
\hline Virginia & 8.383 & $37(32)$ \\
\hline Washington & 7.170 & $84(12)$ \\
\hline Arizona & 6.828 & $74(16)$ \\
\hline Massachusetts & 6.794 & $24(38)$ \\
\hline Indiana & 6.620 & $62(23)$ \\
\hline Tennessee & 6.600 & $59(24)$ \\
\hline Missouri & 6.084 & $130(5)$ \\
\hline Maryland & 6.006 & $33(33)$ \\
\hline Wisconsin & 5.771 & $69(19)$ \\
\hline Minnesota & 5.490 & $81(14)$ \\
\hline Colorado & 5.457 & $72(17)$ \\
\hline South Carolina & 4.896 & $32(34)$ \\
\hline Alabama & 4.859 & $100(10)$ \\
\hline Louisiana & 7.671 & $68(20)$ \\
\hline Kentucky & 4.425 & $94(11)$ \\
\hline Oregon & 4.290 & $63(22)$ \\
\hline Oklahoma & 3.911 & $76(15)$ \\
\hline Connecticut & 3.591 & $5(50)$ \\
\hline Iowa & 3.124 & $46(28)$ \\
\hline Utah & 2.996 & $45(29)$ \\
\hline Mississippi & 2.992 & $52(26)$ \\
\hline Arkansas & 2.978 & $70(18)$ \\
\hline Kansas & 2.912 & $14(45)$ \\
\hline Nevada & 2.891 & $47(27)$ \\
\hline New Mexico & 2.085 & $65(21)$ \\
\hline Nebraska & 1.896 & $25(36)$ \\
\hline West Virginia & 1.844 & $45(30)$ \\
\hline Idaho & 1.655 & $59(25)$ \\
\hline Hawaii & 1.432 & $16(42)$ \\
\hline New Hampshire & 1.331 & $9(47)$ \\
\hline Maine & 1.329 & $12(46)$ \\
\hline
\end{tabular}




\begin{tabular}{|l|l|l|}
\hline Rhode Island & 1.056 & $7(48)$ \\
\hline Montana & 1.033 & $29(35)$ \\
\hline Delaware & .946 & $16(43)$ \\
\hline South Dakota & .858 & $19(41)$ \\
\hline North Dakota & .757 & $20(40)$ \\
\hline Alaska & .738 & $15(44)$ \\
\hline Vermont & .626 & $7(49)$ \\
\hline Wyoming & .586 & $24(39)$ \\
\hline
\end{tabular}

Several interesting takeaways are observable from this table. First, eight of the ten most populous states also received a top ten ranking in terms of number of drug courts. For instance, the top five most populated states, California, Texas, Florida, New York, and Illinois, ranked first, third, sixth, second, and eighth, respectively. Pennsylvania and North Carolina were the exceptions. Pennsylvania was sixth in population and thirteenth in number of drug courts, which was not a major discrepancy; however, North Carolina was the ninth most populous state but ranked thirty-first in number of drug courts. North Carolina is an interesting case because it was a state that passed legislation to remove state funding from its drug courts (Woodhouse, 2016), which most likely has resulted in several drug courts closing their doors

The first way to measure level of state intervention is to determine how drug courts were created in each state. Table 3.3 paints this picture more clearly.

Table 3.3: Initial Drug Court Creation 


\begin{tabular}{|c|c|c|}
\hline Legislatively Created (4) & Local Effort (18) & $\begin{array}{l}\text { Local + Later Authorizing } \\
\text { Legislation ( } 28)\end{array}$ \\
\hline $\begin{array}{l}\text { North Carolina, Louisiana, } \\
\text { Connecticut, and Vermont }\end{array}$ & $\begin{array}{l}\text { Alaska, Colorado, Delaware, } \\
\text { Florida, Georgia, Indiana, } \\
\text { Iowa, Kansas, Maryland, } \\
\text { Massachusetts, Minnesota, } \\
\text { Montana, New Mexico, New } \\
\text { York, North Dakota, Ohio, } \\
\text { Rhode Island, South Carolina }\end{array}$ & $\begin{array}{l}\text { Alabama, Arizona, Arkansas, } \\
\text { California, Hawaii, Idaho, } \\
\text { Illinois, Kentucky, Maine, } \\
\text { Michigan, Mississippi, } \\
\text { Missouri, Nebraska, Nevada, } \\
\text { New Hampshire, New Jersey, } \\
\text { Oklahoma, Oregon, } \\
\text { Pennsylvania, South Dakota, } \\
\text { Tennessee, Texas, Utah, } \\
\text { Virginia, Washington, West } \\
\text { Virginia, Wisconsin, } \\
\text { Wyoming }\end{array}$ \\
\hline
\end{tabular}

As discussed earlier in the chapter, the earliest drug courts were created through a judicial effort. The first drug court in Miami-Dade was created via a judicial order from Chief Judge Gerald Weatherington of the 11th Florida Circuit (Hora et al., 1999) to help alleviate the severe backlog in drug related court cases. Courts in Florida and other states based their drug courts around this model where local judges and other criminal justice professionals adopted these specialty courts to not only relieve courtroom workloads but also to help reduce recidivism among drug offenders (Nolan, 2001).

For example, the drug court coordinator from Oregon indicated that Oregon's first drug court was created in 1991 from a local initiative by a judge who worked with other like-minded members of the legal community to offer an alternative to incarceration for drug offenders (Egbert, personal communication, June 16, 2016). The early states that were developing drug courts were engaging horizontal diffusion via policy learning by using the initial Miami drug court as model. The drug court coordinator in Massachusetts said, "Drug courts in Massachusetts were started after one judge visited the Miami drug court and brought the concept back here, and we were able to open our first court in 1992."

For the vast majority of the states, drug courts developed through local efforts. To my 
knowledge, however, no other studies have sought to determine whether every state created drug courts in this bottom-up fashion. By contacting state drug court coordinators and examining state court websites and previous state studies, I was able to ascertain the origin of drug court creation in all fifty states. In forty-six states, drug courts were initially created through a local effort that included some combination of judges, criminal justice professionals, mental health workers, and other interested members of the community.

The states of North Carolina, Louisiana, Connecticut, and Vermont stand in contrast in terms of drug court creation. These states created drug courts through legislative acts. The first drug courts to open their doors via legislation were in Connecticut and North Carolina in 1995. Nineteen states had created drug courts before that year, and the development of the Connecticut and North Carolina drug courts also came the year after the federal government first authorized funding legislation. The Connecticut law established a pilot program for drug addicted offenders where the chief administrator was responsible for finding a location, developing policies, and making recommendations to the legislature's judiciary committee in 1997 (Coppolo, 2006).

North Carolina's 1995 drug court law created the establishment of drug courts under the direction of the Administrative Office of the Court located within the North Carolina State Supreme Court. This law also established a state advisory committee, a local drug management committee, funding mechanisms, and required annual reporting (North Carolina Drug Court Treatment Act, 1995). In 1997, the Louisiana legislature realized that drug and alcohol related criminality had become a major problem, so they gave their district courts permission to create a diversion type of program to address these needs (Justia, 2016). This paved the way for the state's first five drug courts (Louisiana Supreme Court, 2016). Like North Carolina, the state 
supreme court in Louisiana is in charge of managing the drug courts, and they have broad authority (Louisiana Supreme Court, 2016).

Vermont was the final state to create drug courts through legislation. These drug courts were part of a three court legislative pilot initiative, with the first one opening in 2003 (Owens, K., personal communication, April 8, 2016). The pilot project was conducted in the same fashion as Connecticut's 1995 law. The drug court coordinator in conjunction with committees and other state partners provide some oversight (Owens, K., personal communication, April 8, 2016).

Though Connecticut, North Carolina, Louisiana, and Vermont are outliers in terms of drug court creation, they are not alone when it comes to legislative intervention into drug court policy. Twenty-eight states eventually passed authorization legislation. Authorization legislation is defined as a state legislature passing a law that gives local courts written permission to establish drug courts within their state's jurisdiction. States usually begin this type of legislation by defining drug courts. For example, South Dakota defined drug courts as a "court supervised alternative to incarceration and includes drugs, driving under influence, and other specialty court dockets aimed at increasing offender accountability and decreasing recidivism (Justia Law South Dakota Code 16-22-3, 2014)."

Similar to drug courts created by state legislatures, lawmakers in the states that later passed authorization legislation outlined broad policy goals. Alabama provides a good, example of the common types of goals enacted in authorization legislation:
Alabama Drug Court Law Alabama Code Title 12. Courts. § 12-23A-1
(1) Enhance community safety and quality of life for citizens.
(2) Reduce recidivism.
(3) Reduce substance abuse.
(4) Increase the personal, familial, and societal accountability of drug offenders.
(5) Restore drug offenders to productive, law-abiding, and taxpaying citizens.
(6) Promote effective interaction and use of resources among criminal justice and community agencies. 
(7) Reduce the costs of incarceration.

(8) Improve the efficiency of the criminal justice system by enacting an effective methodology.

While state legislatures in thirty-two states passed authorization legislation by either creating or approving drug courts, eighteen states have not passed any policy oriented legislation regarding drug courts. In some of these states the local drug courts operate with great autonomy, while others are constrained by supervision from state supreme courts and other entities (a greater discussion about this phenomenon will be offered later in this chapter). While authorization legislation in the majority of states helped to establish and expand drug courts, it sometimes worked to constrain them. Table 3.4 shows the states that have established universal drug courts standards and those that developed laws designed to restrict the authority of local drug courts.

Table 3.4: Universal Standards and Restrictive Legislation

\begin{tabular}{|l|l|l|}
\hline 10 Key Components/Best & Restrictive Legislation (23) & Both (18) \\
\hline Alabama, Arkansas, & & \\
California, Florida, Georgia, & Alabama, Arizona, Arkansas, & Alabama, Arkansas, Idaho, \\
Idaho, Illinois, Indiana, & Kentucky, Louisiana, Maine, & Illinois, Indiana, Kentucky, \\
Kentucky, Louisiana, Maine, & Michigan, Mississippi, & Nebraska, North Carolina, \\
Maryland, Massachusetts, & Nebraska, New Jersey, North & Oklahoma, South Dakota, \\
Michigan, Minnesota, & Carolina, Oklahoma, South & Tennessee, Texas, West \\
Mississippi, Montana, & Dakota, Tennessee, Texas, & Virginia, Virginia, Wisconsin, \\
Nebraska, Nevada, New & Utah, Washington, West & and Wyoming. \\
Hampshire, New Jersey, New & Virginia, Wisconsin, & \\
Mexico, North Carolina, & Wyoming & \\
Oklahoma, Oregon, & & \\
Pennsylvania, South Dakota, & & \\
Tennessee, Texas, Utah, & & \\
Vermont, Virginia, West & & \\
Virginia, Wisconsin, & & \\
Wyoming & & \\
\hline
\end{tabular}


The 10 Key Components of drug courts, which were created by the National Association of Drug Court Professionals in collaboration with the Bureau of Justice in 1997, are comprised of the following items:

1. Drug Court integrates alcohol and other drug treatment services with justice system case processing.

2. Using a non-adversarial approach, prosecution and defense counsel to promote public safety while protecting participants' due process rights.

3. Eligible participants are identified early and promptly placed in drug court.

4. Drug court provides access to a continuum of alcohol, drug and other related treatment and rehabilitation services.

5. Abstinence is monitored by frequent alcohol and other drug testing, including evenings and weekends.

6. A coordinated strategy governs drug court responses to participant's compliance.

7. Ongoing judicial interaction with each drug court participant is essential.

8. Monitoring and evaluation measure the achievement of drug court goals and gauge effectiveness.

9. Continuing interdisciplinary education promotes effective drug court planning, implementation, and operations.

10. Forging partnerships among drug court, public agencies, and communitybased organizations generates local support and enhances drug court effectiveness.

Adherence to these principles developed early on, because compliance became a requirement to receive federal grant funding (Nolan, 2001). This is another example of vertical diffusion at work, where the federal government used the power of the purse to compel states to comply with these policy standards. In terms of today's legislative rules, the 10 Key Components are the most common form of statutory drug court rules passed by state legislatures. The 10 Key Components were codified by statute, adopted through advisory committee rules, state supreme court rules, or other means in the states. Besides the 10 Key Components, the NADCP has also developed two volumes of Best Practice Standards to guide drug court operating procedures (NADCP, 2016). According to Marlowe et al. (2016), these publications have used scientific evidence to determine the most effective ways to implement drug court practices and train members of the 
drug court teams. A survey of the drug court coordinators indicated that thirty-six states were using at least one of the NADCP standards of the 10 Key Components or Best Practice Standards.

A couple of examples of how the states implemented these policies are worth mentioning. "We implement the 10 Key Components, and some of the Best Practices (especially paying attention to random drug testing). We also take on more clients that are higher risk and higher need as in Best Practices and provide mental health evaluations (Kubo, E., personal communication, July 9, 2016)." In Pennsylvania, the drug court coordinator indicated that for a local drug court to gain accreditation, they had to have an implementation plan approved for how they would use Best Practices and follow the 10 Key Components (Blackburn, K., personal communication, June 1, 2016).

While a state's adoption of NADCP standards indicates the power it has in influencing drug court policy, state legislatures have also passed legislation to curtail the authority of local drug courts. The term restrictive legislation best describes this phenomenon. Restrictive legislation limits the authority of local drug courts through explicit rules or by empowering other entities such as state Supreme Courts or bureaucratic agencies with rulemaking or oversight authority over drug courts.

One of the most common forms of restrictive legislation involved offender eligibility criteria that preclude certain individuals from entering a drug court program. The main reason why individuals are denied entry into drug courts is because they have committed certain previous criminal offenses, such as general violent crime, violent crime with a firearm, sexual offenses, and drug distribution, manufacturing, or trafficking offenses. Exclusion from drug courts because of violent offenses was among the most common forms of legislation passed by 
states. This is another example of vertical-diffusion being applied by the federal government. The evidence is provided in the 1994 Crime Control law. The federal government would only allocate grant money to states that complied with a rule that prohibited violent offenders from entering into a drug court program (Franco, 2010).

For example, Alabama law prohibits drug offenders with pending violent felony charges or convictions, including those where firearms or other potentially deadly weapons were used, to participate in drug courts (Alabama Code Title. Courts. § 12-23A-1). Other laws precluding violent offenders are not as stringent as the Alabama law. For instance, in West Virginia if a local court enacts a specific program to address violent offenders, then those who commit a violent felony as an underlying offense can participate in a drug court; however, prior violent felony convictions are grounds for exclusion (Drug Offender Accountability and Treatment Act, $\S 62-15-6$. Eligibility). Other states, like Maine, passed restrictive legislation but did not exclude violent offenders (Zeller, 2015).

Excluding violent offenders from drug courts can be traced at least as far back as the federal Omnibus Crime Bill of 1994 (Huddleston and Marlowe, 2011). However, it is widely known that drug and alcohol use can increase the likelihood for violent criminal behavior (Boles and Miotto, 2003; Grann and Fazel, 2004) and excluding this class of offenders from participation in treatment could inhibit their recovery. Scholarly work has demonstrated that violent offenders, when allowed to participate in drug courts, have performed just as well, if not better, than their non-violent counterparts (Carey et al., 2008; Saum and Hiller, 2008; Saum et al., 2001).

A final common piece of restrictive legislation that limited the authority of local drug courts came in the form of empowering other entities such as state supreme courts and 
bureaucratic agencies with oversight authority. The drug court coordinators indicated that the state legislatures in ten states have granted enumerated powers to their state supreme courts. They include the states of South Dakota, Louisiana, West Virginia, Nebraska, Kentucky, Arkansas, Alabama, North Carolina, Nevada, and Georgia. Some of these include the authority to create rules, implement policies, oversee court practices, and conduct policy evaluations. Various other states have created legislative committees to oversee local drug courts, and these committees often collaborate with other interested parties and government agencies to manage local state drug courts. To better understand the exact nature of drug court management, it best to begin by reviewing data on state supreme court involvement, and then examine the other entities involved in policy oversight. Table 3.5 shows the various types of involvement by state supreme courts in each state.

Table 3.5: State Supreme Court Involvement in Drug Court Policy

\begin{tabular}{|c|c|c|c|}
\hline $\begin{array}{l}\text { General State Supreme Court } \\
\text { Involvement (34) }\end{array}$ & $\begin{array}{l}\text { State Supreme Court } \\
\text { Rulemaking Capabilities } \\
(25)\end{array}$ & $\begin{array}{l}\text { No State Supreme Court } \\
\text { Involvement (15) }\end{array}$ & $\begin{array}{l}\text { No } \\
\text { Reporting } \\
\text { (1) }\end{array}$ \\
\hline $\begin{array}{l}\text { Alabama, Alaska, Arizona, } \\
\text { Arkansas, Colorado, } \\
\text { Connecticut, Florida, } \\
\text { Georgia, Idaho, Illinois, } \\
\text { Indiana, Kansas, Kentucky, } \\
\text { Louisiana, Maine, Maryland, } \\
\text { Michigan, Minnesota, } \\
\text { Mississippi, Missouri, } \\
\text { Montana, Nebraska, Nevada, } \\
\text { New Jersey, New Mexico, } \\
\text { North Carolina, North } \\
\text { Dakota, Ohio, Oregon, South } \\
\text { Dakota, Utah, Virginia, West } \\
\text { Virginia, Wyoming }\end{array}$ & $\begin{array}{l}\text { Alabama, Alaska, Arizona, } \\
\text { Arkansas, Georgia, Illinois, } \\
\text { Indiana, Kentucky, } \\
\text { Louisiana, Maine, Maryland, } \\
\text { Michigan, Minnesota, } \\
\text { Missouri, Montana, } \\
\text { Nebraska, Nevada, New } \\
\text { Mexico, North Carolina, } \\
\text { Ohio, Oregon, South Dakota, } \\
\text { Utah, Virginia, West } \\
\text { Virginia }\end{array}$ & $\begin{array}{l}\text { California, Delaware, } \\
\text { Hawaii, Iowa, } \\
\text { Massachusetts, New } \\
\text { Hampshire, New York, } \\
\text { Oklahoma, Pennsylvania, } \\
\text { South Carolina, Tennessee, } \\
\text { Texas, Vermont, } \\
\text { Washington, Wisconsin }\end{array}$ & $\begin{array}{l}\text { Rhode } \\
\text { Island }\end{array}$ \\
\hline
\end{tabular}

When discussing the roles of judges in courts of last resort and other appellate courts, most legal scholars and non-scholars would probably think of the "tasks those institutions 
perform as deciding appeals, writing opinions, and shaping the law and doctrines by which the legal system affects society (Shepard, p. 1535, 2006). However, many other aspects of the duties of state supreme courts have worked to help reform society. State supreme courts have created commissions to study and rectify societal problems, instituted educational and informational programs, and helped to develop therapeutic courts (Shepard, 2006). These latter duties have been understudied in the political science literature, particularly the role state supreme courts play in creating and implementing therapeutic courts.

According to the data in Table 3.5, at least thirty-four state supreme courts are involved in some aspect of drug court policy. This type of involvement of policy involvement can vary depending on the individual state. For example, the Alaska State Supreme Court created therapeutic courts to assist drug addicted and mentally ill defendants (Alaska Court System in Shepard, p. 1550, 2006). In other instances, the state supreme court is only tangentially involved. This is the case in Pennsylvania where the drug court coordinator's office is under state supreme court control, but the coordinator only serves to support the local state drug courts, not manage policy (Blackburn, 2016).

Other states find a sort of a middle ground where the supreme court is more involved in certain kinds of state drug courts but not others. Florida and New Mexico provide good illustrations of this point. In Florida, the Administrative Office of the Courts (located within the state supreme court) provides technical assistance to state drug courts, and this office also oversees the expenditures and performance of the eight adult post-adjudicatory drug court programs that are state funded (Grandal, J., personal communication, March 26, 2016). In New Mexico, the state supreme court has oversight authority over the magistrate-level drug courts, but the district courts operate independently of the structure, establishing their own rules (Bochert, J, 
personal communication, March 26, 2016).

In twenty-six states, the state supreme courts have the authority to create specific rules to govern local drug courts. In many cases, the types of rules or standards developed by the state supreme courts were not widely reported; however, it is imperative to discuss some of the common themes encountered. One of the rules imposed on local drug courts by state courts of last resort is the requirement to adhere to certification standards in order to establish a program and remain operational. For example, in Ohio drug courts must develop advisory committees, create drug court teams, provide treatment, and established a system of rewards and sanctions to ensure client compliance, and develop specific evaluation standards. Ohio's drug court coordinator also mentioned that Ohio is one of only five states that had mandated drug court certification as of 2015 (Worobiec, M., personal communication, September 14, 2016). Certain other general managerial tasks were mentioned by the drug court coordinators in other states. Specifically, administrative officials in the state supreme courts of West Virginia, Kentucky, and South Dakota work very closely with their local courts to help establish drug courts and train and advise staff. Kentucky's drug court coordinator stated that Kentucky's Administrative Office of the Court is also responsible for hiring and firing the drug court staff (Payne, C., personal communication, March 3, 2016).

In fifteen states, there was no state supreme court involvement over local drug court policy. These states either managed their drug courts entirely at the local level or involved other entities such as bureaucratic agencies and interest groups. 
Table 3.6: Laws of Oversight Authority over Drug Courts

\begin{tabular}{|c|c|c|c|c|}
\hline $\begin{array}{l}\text { Local Oversight } \\
\text { Only (12) }\end{array}$ & Court of Last Resort (33) & $\begin{array}{l}\text { Legislative } \\
\text { Committee } \\
\text { (13) }\end{array}$ & $\begin{array}{l}\text { Bureaucratic } \\
\text { Agencies (5) }\end{array}$ & $\begin{array}{l}\text { State Assoc } \\
\text { of Drug } \\
\text { Court } \\
\text { Professionals } \\
\text { (2) }\end{array}$ \\
\hline $\begin{array}{l}\text { California, } \\
\text { Delaware, } \\
\text { Florida, Hawaii, } \\
\text { Iowa, } \\
\text { Massachusetts, } \\
\text { New Hampshire, } \\
\text { New York, } \\
\text { Pennsylvania, } \\
\text { Rhode Island, } \\
\text { South Carolina, } \\
\text { Vermont }\end{array}$ & $\begin{array}{l}\text { Alabama, Alaska, } \\
\text { Arizona, Arkansas, } \\
\text { Colorado, Connecticut, } \\
\text { Georgia, Idaho, Illinois, } \\
\text { Indiana, Kansas, } \\
\text { Kentucky, Louisiana, } \\
\text { Maine, Maryland, } \\
\text { Michigan, Minnesota, } \\
\text { Mississippi, Missouri, } \\
\text { Montana, Nebraska, } \\
\text { Nevada, New Jersey, } \\
\text { New Mexico, North } \\
\text { Carolina, Ohio, } \\
\text { Oklahoma, Oregon, } \\
\text { South Dakota, Utah, } \\
\text { Virginia, West Virginia }\end{array}$ & $\begin{array}{l}\text { Arkansas, } \\
\text { Colorado, } \\
\text { Georgia, } \\
\text { Idaho, } \\
\text { Indiana, } \\
\text { Kansas, } \\
\text { Nevada, New } \\
\text { Jersey, North } \\
\text { Dakota, } \\
\text { Oregon, } \\
\text { Tennessee, } \\
\text { Texas }\end{array}$ & $\begin{array}{l}\text { Arkansas, } \\
\text { Oklahoma, } \\
\text { Tennessee, } \\
\text { Texas, } \\
\text { Wyoming }\end{array}$ & $\begin{array}{l}\text { Washington, } \\
\text { Wisconsin }\end{array}$ \\
\hline
\end{tabular}

Table 3.6 reveals the specific entities that have oversight authority over drug courts in their respective states. This type of oversight authority can include duties such as policy development, implementation, and policy evaluation. Through a combination of legislatively delegated and self-initiated authority, state courts of last resort are the most common overseers of local drug court policy, with thirty-three states reporting at least some form of state supreme court oversight authority.

In thirteen states, special committees created by either the legislature or state supreme courts are responsible for a portion of local drug court oversight. In the states of Oregon and Texas, the executive branch has given greater authority to agencies, like the Criminal Justice Commission (a legislatively created agency) in Oregon (Egbert, P., personal communication, July 14, 2016) and the Criminal Justice Division of the Governor's Office in Texas (Zammaron, 
D, personal communication, July 12, 2016). These entities share authoritative power with their respective Administrative Office of the Courts (AOC) to implement and oversee drug court policy. In Idaho, the state supreme court shares power with the Drug Court and Mental Health Court Coordinating Committee. In Georgia, state legislators created the Council of Accountability Court judges to make rules, set up funding, assist with technical support, and conduct peer evaluations. The Judicial Council and The AOC provide analytical and technical support to the Council of Accountability Court Judges (Jones, personal communication, June 24, 2016).

Besides working with committees, state supreme courts often partner with other agencies and interest groups to manage and support their drug courts. Louisiana provides an example of a state with legislatively created supreme court powers that has partnered with other agencies to better implement policy; it works with interest groups like the Louisiana Association of Drug Court Professionals and other governmental agencies such as the Office of Behavioral Health, the Department of Public Safety and Corrections, the Office of Juvenile Justice, the Department of Children and Family Services, and other state and federal partners to promote Best Practice standards and ensure accountability among current drug court programs (Louisiana Supreme Court, 2016). In Maine, the state supreme court and the Trial Court Chiefs work with each other to finalize drug court policy (Maine Courts, 2016).

In some states, other agencies are responsible for the management and oversight of drug courts. Oklahoma, Tennessee, and Wyoming all have entities other than state supreme courts who provide oversight. Here, governmental health agencies are responsible for providing the lion's share of policy oversight. For example, Wyoming's Department of Health's Substance Abuse Division assists with management, data collection, and it has adopted the following 
performance measures: 1.) graduation rates; 2.) sobriety; 3.) recidivism; and 4.) the units of service provided to each participant (Binning, J., October 5, 2016). In Tennessee, the Department of Mental Health and Substance Abuse services is responsible for managing the drug courts; however, they contain a committee made up of drug court professionals in which the AOC is included (Abbot, personal interview, March 2, 2016).

The fact that these states manage their drug courts through health agencies instead of through the criminal justice entities provides evidence that they may view addiction treatment primarily through the lens of a health issue, not a criminal one. This is interesting given that judges in individual drug courts have the authority to decide the fate of drug court clients, not treatment staff (Tiger, 2013).

Two drug court coordinators mentioned that the interest groups of state-level associations of drug court professionals played a salient role in their respective state drug courts. The state of Washington, for example, relies heavily on their independently elected judges. Their AOC provides guidance and consultation, but it has no authoritative oversight duties. Washington drug courts also receive educational insight from the Washington Association of Drug Court Professionals, an interest group modeled after the National Association of Drug Court Professionals. Like their national counterparts, these state-level organizations work to educate and train drug court operators, and they would host an annual conference (WSADCP, 2016). The Wisconsin Association of Treatment Court Professionals actually has authoritative policy management duties in that state (Gubbin, personal communication, March 15, 2016). This organization provides oversight for the state's drug court programs, and they also write standards for these courts to follow. These are largely based off of the National Best Practice Standards. Similar organizations have been developed in other states, but the coordinators did not discuss 
them as having policy oversight duties (Gubbin, T., personal communication, March 15, 2016).

So far, a descriptive analysis of drug court policy oversight has revealed the multiple ways in which drug courts in various states manage their programs. While enlisting a more centralized top-down approach to drug court policy management has become a reality for many states, there are still some states that operate in a more decentralized fashion, with local drug courts maintaining a greater degree of autonomy. According to the drug court coordinators interviewed, supplemented by state-level research, local drug courts provided the majority of management and oversight for their programs. For analytical purposes, I have divided these states into two camps. In the first category are drug courts that are managed entirely at the local level. The second category, is made up of local drug courts that are responsible for the majority of their management duties but received minor assistance from other agencies. These categories can be found in Table 3.7.

Table 3.7 Decentralized Courts

\begin{tabular}{|l|l|}
\hline Drug Courts with Complete Autonomy & $\begin{array}{l}\text { Autonomous Drug Courts with Some } \\
\text { Assistance }\end{array}$ \\
\hline $\begin{array}{l}\text { California, Delaware, Iowa, Massachusetts, } \\
\text { New Hampshire, Rhode Island, and South } \\
\text { Carolina }\end{array}$ & $\begin{array}{l}\text { Hawaii, New York, North Dakota, } \\
\text { Pennsylvania, Vermont, Florida, Washington }\end{array}$ \\
\hline
\end{tabular}

Table 3.7 shows that the drug courts in the states of California, Delaware, Iowa, Massachusetts, New Hampshire, Rhode Island, and South Carolina were managed entirely at the local level. In these states, each individual drug court was responsible for carrying out policy and providing oversight. The drug courts in these states appear to resemble the classic drug courts where the judge is the ultimate decision maker, and other team members such as case managers, probation officers, attorneys, and treatment counselors all have certain prescribed duties. These courts operate under their own individual standards. However, California and Massachusetts 
indicated that they incorporate Best Practice Standards, while New Hampshire plans to utilize these methods.

Hawaii, New York, North Dakota, Pennsylvania, Vermont, Florida, and to a certain degree Washington fall into the second category of states, which operate their drug courts mainly at the local level but indicate receiving support from other agencies. Two of the earliest states to initiate drug courts, Florida and New York, both receive some training and technical assistance through outside entities. Florida relies on its state supreme court for this assistance, while New York turns to its state drug court coordinator. In both of these states, the local judges have broad managerial authority over their courts. Like New York, the states of Hawaii, New Hampshire, Pennsylvania, and Vermont all reported their drug court coordinators as having some influence over managerial policy. In Hawaii, New Hampshire, and Vermont the state drug court coordinator shares oversight duties with local drug court judges; however, in Pennsylvania the drug court coordinator does not set any policy standards expect to ensure that the federal Best Practices guidelines are being met.

Table 3.8: State Commissions

\begin{tabular}{|l|l|}
\hline Commissions to Study Drug Courts (30) & No Commission Formed (20) \\
\hline Arkansas, California, Colorado, Delaware, & Alabama, Alaska, Arizona, Connecticut, \\
Florida, Georgia, Idaho, Iowa, Kansas, & Hawaii, Illinois, Indiana, Michigan, \\
Kentucky, Louisiana, Maine, Maryland, & Mississippi, New Hampshire, New Jersey, \\
Massachusetts, Minnesota, Missouri, & North Carolina, North Dakota, Pennsylvania, \\
Montana, Nebraska, Nevada, New Mexico, & South Carolina, Tennessee, Texas, Utah, \\
New York, Ohio Oklahoma, Oregon, Rhode & Washington, Wyoming \\
Island, South Dakota, Vermont, Virginia, & \\
West Virginia, Wisconsin & \\
\hline
\end{tabular}

The final area of management that merits discussion is policy evaluation. Here, drug court coordinators were asked if their legislators, state supreme courts, or any other entities with oversight authority had set up committees or otherwise initiated any evaluative studies into drug 
court effectiveness. The findings are provided in Table 2.8. In thirty of the fifty states, some form of state-sponsored commission or committee had been set up to study drug courts. It is worth noting that Texas reported being in the process of developing a commission, and Illinois mentioned its governor's office developed a commission on sentencing policy with some attention going toward problem solving courts.

The two most common types of commissions were formed by either state supreme courts or through legislation. For example, the Florida Supreme Court's Task Force on Substance Abuse and Mental Health Issues recommends strategies to ensure that the 10 Key Components are being implemented (Grandal, J., personal communication, March 26, 2016). Other state supreme courts have been more aggressive in developing advisory committees. Nebraska, Nevada, and New Mexico have all formed committees that advise their supreme courts on all issues pertaining to drug courts; they also work diligently to ensure policy is being implemented properly and conduct evaluations. Legislatively created commissions, like the one in Kentucky, perform many of the same duties as those created by the state supreme court (Payne, C., personal communication, March 3, 2016). These organizations often conduct research and report back to their respective state legislatures in the form of annual reports.

Generally, scholars who have conducted drug court evaluations primarily focused on whether or not drug treatment courts lower recidivism rates for those individuals who graduated from them. The other major factor examined by researchers was cost effectiveness. In other words, were drug courts a cheaper option than incarceration? Not surprisingly, the sample of state-sponsored studies that I examined were most concerned with recidivism rates and cost effectiveness. As I discuss later (see section on funding), most states use legislative appropriations to fund a significant portion of their drug courts, and every state, at one time or 
another, has taken federal funds to either initiate or improve drug courts. Since these types of funds are generated from taxpayer dollars, there is a natural incentive to demonstrate that these programs work by reducing criminal recidivism and alleviating the financial burden caused by the mass incarceration of drug offenders.

Table 3.9: State-Level Funding

\begin{tabular}{|c|c|c|c|}
\hline $\begin{array}{l}\text { Complete State } \\
\text { Funding (6) }\end{array}$ & Authorized State Funding (36) & $\begin{array}{l}\text { No State Funding } \\
\text { Legislation (14) }\end{array}$ & Unknown \\
\hline $\begin{array}{l}\text { North Dakota, } \\
\text { Hawaii, Louisiana, } \\
\text { Oklahoma, Idaho, } \\
\text { New Jersey }\end{array}$ & $\begin{array}{l}\text { North Dakota, Hawaii, } \\
\text { Louisiana, Oklahoma, Idaho, } \\
\text { New Jersey, Mississippi, } \\
\text { Alabama, Arizona, Georgia, } \\
\text { New Mexico, Florida, Nevada, } \\
\text { Tennessee, Utah, Connecticut, } \\
\text { Vermont, Massachusetts, Iowa, } \\
\text { Arkansas, Colorado, Ohio, } \\
\text { Missouri, California, Kentucky, } \\
\text { Wyoming, South Dakota, } \\
\text { Maryland, Alaska, Oregon, } \\
\text { Maine, Nebraska, Delaware, } \\
\text { Montana, Texas, West Virginia, } \\
\text { Minnesota }\end{array}$ & $\begin{array}{l}\text { Illinois, Michigan, Rhode } \\
\text { Island, Kansas, New } \\
\text { Hampshire, Wisconsin, } \\
\text { Indiana, Pennsylvania, } \\
\text { Washington, North } \\
\text { Carolina, New York, } \\
\text { Virginia, Washington, } \\
\text { South Carolina }\end{array}$ & Rhode Island \\
\hline
\end{tabular}

Table 3.9 provides another way to gauge state-level intervention into drug courts by measuring the way drug courts in each state are funded. In six states, the drug courts are fullyfunded through state appropriations. Drug court coordinators reported some variance in terms of which agency was charged with distributing funds. For example, North Dakota's adult drug courts are funded through the ND Department of Corrections, while the juvenile drug courts receive funding through the ND Supreme Court (Moe, 2016). The State Supreme Court of Louisiana is in charge of procuring funding for its state (Louisiana Supreme Court, 2016), while the Idaho legislature funds its drug courts through a combination of dedicated courts funds and substance abuse treatment funds (Ronan, personal communication, March 6, 2016). 
According to the data, thirty-six states receive at least some funding through legislative appropriations. Table 3.10 shows state funding for drug courts.

Table 3.10: Funds Allocated by State

\begin{tabular}{|l|l|l|}
\hline \multicolumn{1}{|c|}{ State } & State Funding Appropriations & $\begin{array}{l}\text { Funding Per Capita (Dollars } \\
\text { per 100,000 people) }\end{array}$ \\
\hline Alabama & $\$ 1,285,000$ & $\$ 26,500$ \\
\hline Alaska & $\$ 5,565,200$ & $\$ 756,757$ \\
\hline Arizona & $\$ 1,000,000$ & $\$ 13,699$ \\
\hline Arkansas & $\$ 500,000$ & $\$ 16,667$ \\
\hline California & $\$ 200,000$ & $\$ 502$ \\
\hline Colorado & $\$ 6,175,035$ & $\$ 106,897$ \\
\hline Connecticut & None & 0 \\
\hline Delaware & None & 0 \\
\hline Florida & $\$ 8,413,333$ & $\$ 258,333$ \\
\hline Georgia & $\$ 318,057$ & $\$ 3,200$ \\
\hline Hawaii & None & 0 \\
\hline Idaho & $\$ 7,734,468$ & $\$ 427,778$ \\
\hline Illinois & None & 0 \\
\hline Indiana & None & 0 \\
\hline Iowa & $\$ 520,150$ & $\$ 16,250$ \\
\hline Kansas & None & 0 \\
\hline Kentucky & $\$ 14,000,000$ & $\$ 311,111$ \\
\hline Louisiana & $\$ 17,100,000$ & $\$ 362,000$ \\
\hline Maine & $\$ 1,167,000$ & $\$ 92,307$ \\
\hline Maryland & $\$ 3,500,000$ & $\$ 57,377$ \\
\hline Massachusetts & $\$ 3,000,000$ & $\$ 43,478$ \\
\hline Michigan & $\$ 10,958,000$ & $\$ 110,000$ \\
\hline Minnesota & $\$ 2,364,000$ & $\$ 42,105$ \\
\hline Mississippi & $\$ 6,000,000$ & $\$ 200,000$ \\
\hline Missouri & $\$ 6,400,000$ & $\$ 104,198$ \\
\hline Montana & $\$ 1,000,000$ & $\$ 90,909$ \\
\hline Nebraska & $\$ 2,282,088$ & $\$ 121,053$ \\
\hline Nevada & None & 0 \\
\hline New Hampshire & None & 0 \\
\hline New Jersey & $\$ 54,000,000$ & $\$ 606,742$ \\
\hline New Mexico & $9,450,000$ & $\$ 452,381$ \\
\hline New York & None & 0 \\
\hline North Carolina & None & 0 \\
\hline North Dakota & None & 0 \\
\hline Ohio & None & 0 \\
\hline Oklahoma & $\$ 18,000,000$ & $\$ 456,000$ \\
\hline Oregon & $\$ 2,887,500$ & $\$ 68,801$ \\
\hline & & \\
\hline
\end{tabular}




\begin{tabular}{|l|l|l|}
\hline Pennsylvania & None & 0 \\
\hline Rhode Island & $\$ 1,250,000$ & $\$ 119,048$ \\
\hline South Carolina & $\$ 3,556,221$ & $\$ 70,588$ \\
\hline South Dakota & $\$ 3,000,000$ & $\$ 337,079$ \\
\hline Tennessee & $\$ 43,000,000$ & $\$ 632,353$ \\
\hline Texas & $\$ 7,500,000$ & $\$ 258,620$ \\
\hline Utah & $\$ 1,300,000$ & $\$ 40,625$ \\
\hline Vermont & $\$ 190,000$ & $\$ 30,159$ \\
\hline Virginia & $\$ 3,000,000$ & $\$ 34,884$ \\
\hline Washington & $\$ 8,000,000$ & $\$ 103,897$ \\
\hline West Virginia & $\$ 400,000$ & $\$ 22,222$ \\
\hline Wisconsin & $\$ 500,000$ & $\$ 8,620$ \\
\hline Wyoming & $\$ 4,340,415$ & $\$ 754,386$ \\
\hline
\end{tabular}

In thirteen states, no state-level funding was authorized by the state legislature. Several of these states, like New York, Illinois, and Pennsylvania have large populations with a high number of overall drug courts. This begs the question how do these states with minimal to no state funding operate drug courts? The answer is federal government funding available through appropriations and grants through agencies such as the Bureau of Justice and Substance Abuse and Mental Health Services Administration (Marlowe et al; 2016; Nolan, 2001; Tiger, 2013). Federal funding has its limitations, however. Many of the state drug court coordinators who reported receiving federal dollars indicated that this assistance was temporary and used to help start new courts, expand existing ones, and make specific improvements. For instance, drug courts received federal startup grants in states like Arizona and New Mexico. New York and Massachusetts reported receiving federal funding for enhanced services. A good example of these types of "enhanced" drug court services was evident in Maine where a SAMHSA grant improved the quality of client treatment services and case management (Madigan, 2016).

In other states, drug court funding is available through local or county funding, user fees, and special taxes. Thirteen states reported relying on some form of user fees, and seven states also reported creating special taxes or using money from asset forfeitures as a source of funding 
e.g., New Mexico uses a 1 percent liquor excise tax (Bochert, J., March 26, 2016), while Washington employs a 1 percent sales tax (Long, E., personal communication, February 25, 2016).

The figures in Table 3.10 also include a section on per capita funding. This illustrates how much money a state is willing to spend on drug court funding relative to its size. One finding worth noting is that several smaller, rural states like Alaska, Idaho, and Wyoming all rank in the top five for drug court spending per capita. These are also more conservative states, along with Tennessee, which also ranks in the top five for this category. State lawmakers in larger states, like New York, Illinois, and California have largely left the funding up to their local drug courts. Drug courts in these states also formed at or before the 1994 and have developed the infrastructure necessary to fund their operations.

The data in this chapter revealed the areas in which state governments have regulated local drug court policy. Efforts to manage these drug courts include authorizing legislation, restrictive legislation, the adoption of universal state drug court standards, state supreme court involvement, state supreme court rulemaking, oversight authority by each outside agency, state commission oversights, and funding. I calculated the number of these regulations by state and developed a formula to determine which states qualify as having either top-down or bottom-up management styles. In a top-down system, drug courts within a state are closely managed by lawmakers, state supreme courts, and other entities. Conversely, in bottom-up systems, drug courts have autonomy to operate largely without outside influences. To be considered a topdown state, the state must rank in the top ten of the states with the greatest number of state-level regulations. Bottom-up states must rank within the top ten states that are least regulated. There 
were several ties within these categories. To break these ties, I included the amount of state-level funding per capita.

Table 3.11: Rank of Top-Down State Drug Courts

\begin{tabular}{|l|l|l|l|l|}
\hline 1. Arkansas & 2. Louisiana & 3. Idaho & 4. Kentucky & 5. Oregon \\
\hline 6. West Virginia & 7. Nebraska & 8. New Jersey & 9. South Dakota & 10. Maine \\
\hline
\end{tabular}

Table 3.11 ranks the ten states that are the considered to be top-down states, according to the number of regulations imposed on drug courts by state-level actors. These ten states from Arkansas to Maine represent a top-down model of operation, which features significant central planning from states legislatures, courts of last resort, and other entities. Local drug courts in these states have certain authorities to develop and run their own courts, but they must do so within the parameters developed by other higher-level state government actors.

Table 3.12: Rank of States Using a Bottom-Up Approach.

\begin{tabular}{|l|l|l|l|l|}
\hline $\begin{array}{l}\text { 1. South } \\
\text { Carolina }\end{array}$ & 2. Rhode Island & 3. New York & $\begin{array}{l}\text { 4. New } \\
\text { Hampshire }\end{array}$ & 5. Delaware \\
\hline 6. Iowa & 7. Pennsylvania & 8. Hawaii & 9. Massachusetts & 10. Washington \\
\hline
\end{tabular}

In Table 3.12, the states from South Carolina to Washington are the bottom-up states. The drug courts in these states have minimal to no state-level interventions into drug court policies and have substantial independence to manage their own programs. To understand more about the similarities and differences in the development and implementation of drug courts using either top-down or bottom-up approaches, case studies must be conducted for each.

The case studies will take a closer look at certain drug court policies such as funding procedures, state legislation, drug court offender eligibility, policy evaluations and compliance. I 
use policy literature on management and street-level bureaucrats to explain the policy differences between top-down and bottom-up states. Two states will be examined. One state, Pennsylvania, will be a state that uses a bottom-up approach to drug policy management, while West Virginia is a state that uses a top-down approach to management. However, before the case studies are conducted, it is important to examine whether or not any political, criminal justice, or demographic variables can for account some of the most salient state-drug court interventions such as restrictive legislation, state supreme court rulemaking authority, and overall state-level regulations. In the following chapter, a quantitative analysis will be provided to determine the factors that affect these state-level regulations. 


\section{Chapter 4: An Empirical Examination of State-Level Regulations into Drug Court Policy}

The previous chapter examined how drug court laws and other administrative regulations were developed by state-level policy actors, including legislators, governors, and members of state supreme courts. The goal of this chapter is to determine if politics, crime, or extralegal variables could explain greater state-level regulations. As shown in Chapter 2, partisan politics can influence criminal justice policies. As the political parties realigned to be more congruent in terms of political ideology in the 1960s, Republicans have generally supported more punitive sanctions than Democrats (Tonry, 1999). The partisan divide over drug control policy became less pronounced through the 1980s and 1990s, however, and both Democrats and Republicans supported punitive measures as a means to control drug crimes (Meier, 1994). The drug courts provide a potential opportunity for both political parties to return to their ideological roots, and as Nolan (2001) argued, Republicans support drug courts because they viewed it as considered tough-on-crime program that also saves money over incarceration, Democrats are in favor of these therapeutic courts because they are more humane and offer the offender a chance to get treatment. Therefore, I expect Republicans to have a desire to pass restrictive legislation and additional regulations to reign in the authority of drug courts to ensure that the programs are not too lenient.

It is also important to examine how state supreme court judges can influence drug court policy regulations. As mentioned in Chapter 3, judges play additional roles in shaping policy other than deciding cases (Shepard, 2006). Judges are involved in initiating therapeutic courts and shaping and implementing policy (Shepard, 2006). Method of judicial selection could influence how state supreme court justices behave in terms of deciding when to regulate drug court policy. Elected judges may perceive a greater potential electoral benefit by becoming involved in a politically popular program. 
Variables such as crime and race could also affect drug court regulations. Drug crime, especially drug trafficking (Belenko and Spohn, 2015), has been linked to violence. It makes sense that states experiencing a higher rate in violent crime would be more inclined to intervene in drug court policies as a way to reduce drug-related crimes. Finally, throughout the country's history, racial scapegoating was a way to advocate for regulating and criminalizing drug use (Meier, 1994). This would later result in a great disparity in arrests and sentencing, with blacks more likely to be both arrested and sentenced to prison than whites (Belenko and Spohn, 2015; Stith and Cabranes, 1998). Race could be associated with a higher perceived level of dangerousness (Belenko and Spohn, 2015) and could lead to increased drug court regulations.

To begin examining how these political, criminal justice, and demographic variables are associated with increased state-level regulations, it is important to discuss the dependent variables, then add more substantive knowledge about the independent variables and why they are important to include in this study. Three statistical models will be developed using logistic and OLS regressions to analyze the data. Finally, the results and their meanings will be discussed.

\section{Dependent Variables}

The first dependent variable in this study is Restrictive Legislation. This is one of the most visible ways that state-level actors regulated local drug court policies. Restrictive Legislation limits the authority of local drug courts through explicit rules or by empowering other entities such as state supreme courts or bureaucratic agencies with rulemaking or oversight authority. This variable is dichotomous and coded 1 for states that passed restrictive legislation.

The second dependent variable to be constructed is State Supreme Court Rules. In specialty courts, like the drug courts, state supreme court members possess the ability to craft 
policy like writing rules to govern local drug courts. In a majority of the states, state Supreme Courts were either explicitly granted this power through legislation or took it upon themselves to write rules designed to shape drug court policy. This is a dichotomous variable coded 1 for states where the supreme court enacted rules to regulate drug courts.

The third dependent variable, State-Level Regulations, is a combination of the six statelevel regulations and ranges from 0 to 6, and includes: Enabling Legislation, a dichotomous variable coded 1 for states that have passed enabling legislation; Restrictive Legislation, a dichotomous variable coded 1 for states with legislation that limits the authority of local drug courts through explicit rules or by empowering other entities such as state supreme courts or bureaucratic agencies with rulemaking or oversight authority; Authorization Legislation, a dichotomous variable coded 1 for states that have passed legislation to authorize drug court funding; Supreme Court Rules, a dichotomous variable coded 1 for states where the state supreme court has enacted policy rules to govern drug courts; State Commissions, a dichotomous variable coded 1 for states that have created a commission or committee to study and make policy suggestions regarding drug courts; Universal Standards, variable coded 1 for states that have adopted universal standards, such as the Ten Key Components or other specific practices. The goal is to predict the variation in regulatory efforts by state-level actors.

Each of the dependent variables will be tested in separate models. To test what factors potentially influenced the dependent variables, I constructed four independent variables. The first two independent variables are intended to test political explanations for drug court regulations. The first measures political partisanship and the second method of judicial selection. For the next variable, I seek to determine whether the violent crime rate in each state is associated with any of the dependent variables. Finally, as I demonstrated in Chapter 2, the issue of race has influenced 
drug policies through moral panics and scapegoating many times in U.S. history, and it is important to examine whether race could impact the regulation of drug court policy. In the following section, I discuss my independent variables in more detail, which will allow me to construct testable hypotheses.

\section{Independent Variables}

\section{$\underline{\text { Partisan Politics }}$}

My first independent variable is partisan politics. To understand how partisan politics could possibly influence drug court policy, it is important to briefly revisit how partisanship has affected past criminal justice policies. A political and cultural shift toward more punitive criminal justice policies (Tiger, 2013), especially with regard to illicit drugs (Spohn, 2009), materialized in the 1980s. Beginning in 1964, Republicans took the lead in making crime control part of their national policy platform (Tonry, 1999), but during the 1980s, many of the most punitive laws passed, such as the Anti-Drug Abuse Laws of 1986 and 1988 (Beaver, 2010) and the Sentencing Reform Act of 1984 (Stith and Cabranes, 1998) had strong bipartisan support. During the 1988 presidential election, Michael Dukakis, the Democratic nominee, spoke of the ill effects of the War on Drugs, such as high incarceration rates, jail crowding, and lack of rehabilitation programs (Marion and Oliver, 2003). George H.W. Bush pounced on these comments, and labeled Dukakis as "soft-on-crime." Since then, elected officials have tried to avoid this label at all costs (Marion and Oliver, 2003). The solution became a shift away from rehabilitation as a goal of sentencing to one of deterrence and incapacitation (Marion and Oliver, 2003). State lawmakers also passed many mandatory minimum sentencing provisions as well as "three strikes" laws to punish repeat felony offenders (Marion and Oliver, 2003).

Drug courts, however, have been able to dodge the "soft-on-crime" label, in part, through 
its use of punitive sanctions (Nolan, 2001). From reading the title of the WV law, the Drug Offender Accountability and Treatment Act, one clearly sees the word "accountability" preceding "treatment." This certainly appears to be purposeful, insinuating that drug offenders must own up to their mistakes, and by doing so, they will receive an opportunity to receive treatment. This tough-love approach is also politically feasible because it has something that appeals to both political parties. For example, liberals who see incarceration for addicts as inhumane favor the drug treatment, while conservatives are generally in favor of the court's intense supervision and use of sanctions as a deterrent (Nolan, 2001).

While both parties are able to find things they like about drug courts, it is Nolan's (2001) aforementioned point about conservative's allure for intense supervision and sanctions that leads one to a logical conclusion about how political ideology could sway state-level action. From Goldwater's 1964 presidential platform (Tonry, 1999) to the present day Trump administration (RNC speech, 2016), the GOP has aligned itself with "tough-on-crime" policies and a "law and order" theme. In a study by Fox and Wolf (2004), when one judge was asked about drug courts, he stated, "The issue for me in a conservative southern state is: how do we embrace a program that is seen as warm and fuzzy? How do I sell that to law enforcement when Louisiana is No. 1 in per capita incarceration in the U.S.?" One of the ways to sell that program is by emphasizing sanctions and strict regulations. Louisiana is a state where the Supreme Court is given broad authority to implement drug court policy (Louisiana Supreme Court, 2016).

Studies of state-level politics and imprisonment have generally supported the notion that Republican politicians can influence sentencing practices (Stucky, Heimer, and Lang 2005). For example, Davey (1998) found that Republican governor's who were in favor of law and order politics were had much higher increases in incarceration than other surrounding states. Beckett 
and Western (2001) found that states with a higher percentage of Republicans in their state legislatures had higher incarceration rates. This is relevant to drug court politics because in states where conservatism is more prevalent, policy actors would be especially leery of being labeled soft-on-crime, and should be more likely to regulate the activities of local drug courts to ensure the program remains tough.

The first independent variable is a measure of state-level Partisanship (IV1). There are different ways to gain a sense of partisanship or ideology. One way that has become popular is through measuring DW-Nominate scores to test for ideology. This was originally done for state members of Congress, but in recent years, it has been conducted on state legislatures. While this method is good for determining the ideological makeup of a state's legislature over time, I do not believe it would be the best measure for this particular study. While specific types of legislation make up three of my dependent variables, the role of legislators is not as well established for the other variables. Other actors such as members of the state supreme courts and other bureaucrats account for things such as writing supreme court rules, forming commissions, and writing universal standards.

Therefore, it is my contention that a broader measure of a state's partisanship is more appropriate. According to the Lewis-Beck et al (2008), more Americans vote in presidential elections than in congressional or local elections. A more accurate depiction of a state's partisan leanings could be determined by measuring how its citizens voted for president over time. To measure this variable, I have calculated the number of times that a state voted for a Democratic presidential candidate since 1988 until the present. I chose 1988 as a starting point because the drug courts first formed in 1989, so this would capture the entire period of its existence. So, in the statistical analysis, the more times a state voted for a Democrat, the less likely that state 
would be to intervene in local drug court policies. This leads me to my first hypothesis:

H1: States that are more Republican are more likely to intervene in drug court policy.

\section{Crime Rate}

My second independent variable is the crime rate. The crime rate can have a major impact on criminal justice policy. For example, as drug use and violent crime rose in the 1980s, strict sentencing policies such as The Sentencing Reform Act of 1986, the Anti-drug Abuse Acts of 1986 and 1988, and various state-level legislation were enacted to reduce crime (Stith and Cabranes, 1998). One of the primary reasons drug courts have become popular is because they have been shown to reduce drug use and other types of criminal recidivism (Marlowe, 2010). Judges and other criminal justice professionals were strong advocates of drug courts because they wanted to solve the underlying causes of addiction to reduce recidivism (Nolan, 2001). It makes intuitive sense that said professionals and other political actors would take the crime rate into account when deciding to intervene in drug court policy.

While it would be ideal to include both the rate of drug use and addiction as well as the overall crime rate over time, longitudinal data for the individual state drug use rates was not readily available. The Substance Abuse and Mental Health Services Administration (SAMASHA) included state-level data on drug use rate since 2012; however, my descriptive data in the preceding chapter revealed that many states had already enacted drug court policies such as enabling legislation and supreme court rules before this date. To compensate for the lack of data on drug usage, I believe it would be appropriate to use the violent crime rate as a proxy measure for overall crime rate. I will spend the remainder of this section arguing that violent crime and drugs are both directly and indirectly tied together.

There has been substantial research on drug use and criminal behavior. Substance abuse, 
including both alcohol and illicit drug use, increase an individual's likelihood of committing interpersonal violence (Boles and Miotto, 2003; Grann and Fazel, 2004). However, certain drugs appear to influence one's propensity for violence more than others. For example, heavy use of stimulants such as cocaine and amphetamines is associated with irritability, psychosis, and ultimately violent behavior (Dawe, Davis, Lapworth, and McKetin, 2009; Haggard, Moller, Hallqvist, Thiblin, 2013). Individuals on parole who reported using methamphetamine, which has a longer lasting stimulant effect than cocaine, reported a greater propensity for engaging in violent behavior and general crime (Cartier, Farabee, and Prendergast, 2006). This study also found that those involved in the drug trade were more likely to commit criminal acts of violence.

It is important to understand that drugs do not have to be consumed to impact violent behavior. Criminal enterprises such as gangs or even individual drug dealers have a vested interest in protecting their products and drug manufacturing operations (Goldstein, 1985). Gangs and other outlaw criminal organizations are the chief peddlers of illegal drugs in the U.S. They are involved in the smuggling, manufacturing, and distribution of drugs, and these organizations are extremely violent (Department of Justice, 2005). Violent behavior is used to intimidate rivals, protect one's products and turf, and exact revenge on anyone who threatens the criminal organization's existence (DOJ, 2005).

This information allows me to construct the second independent variable in this study: Crime Rate (IV2). To calculate the value of a state crime rate, I examined data from the FBI's Uniform Crime Report. The UCR data is compiled annually by the FBI, and it is divided into Type I and Type II crimes. The Type I crimes are deemed to be the most serious type of offenses, while Type II offenses are less serious in nature. Certain UCR statistics are aggregated by crime type (either violent or property) and are available from 1985 to 2012 . This is 
appropriate for this study because drug courts were first formed in Florida in 1989, and the state to initiate a drug court was South Dakota in 2007. The FBI calculates its annual crime rates per 100,000 people. To account for this in SPSS, I computed the violent average crime rate by taking the raw number of violent crimes, dividing it by the state's population, then multiplying it by 100,000. I averaged the violent crime rate for each state using values from 1989 to 2012. This variable allowed me to develop my second hypothesis.

H2: States with higher average violent crime rates will be more likely to intervene in drug court policy.

\section{Method of Judicial Selection}

The next independent variable to be constructed is method of judicial selection.

Specifically, I want to determine if the method of judicial selection influences a state supreme court's decision to create rules for drug treatment courts. Before I can answer this query, it is important to briefly review some of the literature on method of judicial selection. Judges can be selected on the basis of gubernatorial appointment, partisan or non-partisan elections, or in a hybrid system known as the Missouri Plan (Segal, Spaeth, and Benesh, 2005). The notion judges may be swayed by public opinion makes intuitive sense because if their rulings were so far outside of the mainstream norms of society, there is a high probability that the laws would be rejected by the people (Epstein and Knight, 1997). Judges, like other human beings, are not immune from popular media and the views of the public, and they likely take it into account when making decisions (Baum, 1997; 2006). In terms of method of judicial selection, it makes sense that judges who have to face voters would be cognizant of how their actions could affect their chances of reelection.

While some scholars have concluded that method of judicial selection has little influence 
over how a judge generally decides a case (Benesh and Martinek, 2002; Segal et al., 2005), there is evidence that criminal justice issues can impact judicial decision making for elected judges (Cross, 2008). For example, when comparing judges appointed by state governors to those who must face the voters in elections, Uelman (1996) found that judges facing reelection were more apt to uphold previous rulings in favor of the death penalty, while reversing sentences in which the death penalty was not instituted. Brace and Hall (1995) and Hall (2001) also argued that judges facing reelection were more likely to favor the death penalty, even liberal judges were found to be more likely to support capital punishment when facing reelection compared to liberal judges who were appointed (Brace and Hall, 1995). A study by Hall (2001) showed evidence that the public does pay attention to crime, and will punish members of the judiciary if they do not produce results. For example, a ten percent increase in the murder rate resulted in a twentyone percent decrease in voter support for state supreme court justices (Hall, 2001).

These studies all demonstrated that death penalty and violent crime, issues that are generally salient among the public, can affect judicial decision making for elected judges. However, most of these studies examined judicial behavior in regards to more punitive action. For decades political actors have reaped benefits by promising to get "tough-on-crime" (Tonry, 1995). The examination of how punitive criminal justice policies, like capital punishment, affect judicial behavior provides an incomplete analysis of the ways judges behave when it comes to other criminal justice issues. I argue that politically popular programs, such as drug courts, also affect judicial behavior. While it is easy to see how supporting harsh sanctions against extremely heinous criminals, such as capital punishment for murderers could reap political benefits for judges and other politicians, it is unknown how supporting a program that offers coercive treatment could affect judicial behavior. 
The drug courts are a popular political program among both Republicans and Democrats (Nolan, 2001). At first glance, conventional wisdom would tell us that supporting a program that features treatment instead of incarceration might spell political suicide for judicial actors. However, with a high incarceration rate (Tiger, 2013), a high recidivism rate (Petersilia, 2003), and onerous financial costs because of mass imprisonment (Nolan, 2001), drug courts have provided a politically feasible alternative to punitive policies. It is my contention, that these treatment based programs can provide a way for judges to build their political profiles during reelection campaigns. Gaining a better understanding of this issue bolsters our general knowledge of political behavior by offering a clearer explanation of the ways judges act when they have to face voters. If this is true, it strengthens Baum's $(1997,2006)$ argument that judges take more than just legal factors into account when making decisions.

This relevant literature on judicial behavior allows me to construct my third independent variable: Method of Judicial Selection (IV3). This variable indicates whether or not a specific state selects its state supreme court justices by election or through a process of judicial appointment. Some states had changed their method of judicial selection since 1989, to account for this I set a threshold for the amount of time a state either elected or appointed judges. My threshold was 90 percent of the time a state had to be a certain way after they had adopted drug courts. This variable is a dichotomous variable where states that elect their judges receive a score of 1 , while states that select their judges through appointment receive a score of 0 . To test the notion of whether or not the election of judges influences judicial behavior at the state supreme court level, I offer the following hypothesis:

H3: Elected judges in state supreme courts are likely to involve themselves drug court policy 
decisions by writing rules.

$\underline{\text { Race }}$

The final independent variable in my study is race. This variable is especially relevant to drug policy because of how it has been used to shape past morality policies. Minorities have been used as scapegoats for problems associated with drug use and crime by politicians, bureaucrats, and members of the media. These scare tactics helped pave the way for legislation intended to regulate and later criminalize drug use (Meier, 1994). Some of the most draconian policies of the 1980s such as the SRA of 1984, and the Anti-Drug Abuse Acts of 1986 and 1988 disproportionately affected African-Americans by vastly increasing the likelihood of both arrests and incarceration for both possession and sale of drugs (Belenko and Spohn, 2015).

I constructed an independent variable to test if race played a factor in explaining the regulatory variables in this chapter. The final variable, Race (IV4), is based on the percentage of African-American's in each state from 1990 to 2017. Developing this independent variable allows me to offer my final hypothesis.

H4: States with a greater percentage of African Americans will be more likely to regulate drug court policy.

\section{Statistical Analyses}

Now that both the dependent and independent variables have been described and the hypotheses formed, it is time to test my first statistical model. It is important to first discuss a limitation of this study: the unit of analysis. Since the individual states are the units of analysis, this limits the number of cases to 50 . While this fact hinders the power of certain multivariate statistical analyses, there is still valuable information than can be extracted from this data. In the first model, I determine if the four IVs have any significant effect on DVI Restrictive 


\section{Legislation.}

Table 4.1

Multivariate Logistic Regression for Restrictive Legislation

\begin{tabular}{lllllll} 
& B & S.E. & Wald & df & p & Odds \\
\hline Partisan Politics (DEM) & -.277 & .116 & .825 & 1 & $.017^{* * *} .758$ \\
Crime Rate & -.001 & .002 & .563 & 1 & .453 & .999 \\
Method of Judicial Selection & .577 & .635 & .825 & 1 & .364 & 1.780 \\
Race (African-Americans) & .002 & .015 & .021 & 1 & .885 & 1.002 \\
* Indicates significance at the .05 level. & & & & & &
\end{tabular}

The overall model explained between 15 percent (Cox \& Snell R-Square) and 20.1 percent (Naglekerke R-Square) of the variance. Partisan Politics was associated with an increased likelihood for state legislatures to pass Restrictive Legislation. States that are more Democratic are .758 times less likely to pass restrictive drug court legislation than states that are more Republican. This supports the Partisan Politics hypothesis. The other variables did not affect the dependent variable in the way I predicted.

Table 4.2

Multivariate Logistic Regression for State Supreme Court Rules

\begin{tabular}{llllllll} 
& B & S.E. & Wald & df & p & Odds \\
\hline Partisan Politics (DEM) & -.153 & .106 & 2.093 & 1 & .148 & .858 \\
Crime Rate & .001 & .002 & .171 & 1 & .679 & 1.001 \\
Method of Judicial Selection & 1.430 & .667 & 4.608 & 1 & $.032 *$ & 4.181 \\
Race (African-Americans) & -.016 & .017 & .875 & 1 & .350 & .985 \\
* Indicates significance at the .05 level. & & & & & & &
\end{tabular}


According to the results from Table 4.2, the overall model explains between 18.8 percent (Cox and Snell R-Square) and 25.1 percent (Nagelkerke R-Square) of the variance. Method of Judicial Selection was the only variable in this model to demonstrate statistical significance. Judges who were elected were 4.181 times more likely to have the authority to write drug court policy rules than appointed judges. This provides support for H3: Method of Judicial selection hypothesis.

\section{Table 4.3}

Multivariate OLS for State-Level Regulations in Drug Court Policy

\begin{tabular}{|c|c|c|c|c|}
\hline & $(\mathrm{B})$ & Beta & $\mathrm{p}$ & R-Square (overall) \\
\hline Partisan Politics (Dem) & -.256 & -.352 & $.013 * *$ & .230 \\
\hline Crime Rate & -.001 & -.086 & .639 & \\
\hline Method of Judicial Selection & 1.076 & .238 & $.089 *$ & \\
\hline Race (African-Americans) & -.013 & -.145 & .401 & \\
\hline \multicolumn{5}{|l|}{ **Significant at the .05 level } \\
\hline \multicolumn{5}{|l|}{ *Significant at the .10 level } \\
\hline \multicolumn{5}{|c|}{ According to the R-Square, the overall model explained 23.0 percent of the variance in } \\
\hline \multicolumn{5}{|c|}{ determining what factors accounted for an increase in the number of combined state-level } \\
\hline \multicolumn{5}{|c|}{ regulations in drug court policy. Both Partisan Politics and Method of Judicial Selection were } \\
\hline \multicolumn{5}{|c|}{ significant variables that were associated with the DV. Partisan Politics was significant at the } \\
\hline \multicolumn{5}{|c|}{$\mathrm{p}<.05$ level, while Method of Judicial Selection displayed a weaker level of significance $\mathrm{p}<.10$. } \\
\hline \multicolumn{5}{|c|}{ Partisan Politics recorded a higher beta value (beta $=.352 \mathrm{p}<.01$ ) than Method of Judicial } \\
\hline
\end{tabular}




\section{Discussion}

The goal of this chapter was to attempt to explain the reasons why state-level actors have become more involved in local drug court policy over the past few decades. I chose three models based on variables that were relevant to political science and public policy. By using several different independent variables such as Partisan Politics, Method of Judicial Selection, the Violent Crime Rate, and Race to determine if any of them had an effect on the dependent variables: Restrictive Legislation, State Supreme Court Rules, and Combined State-level Regulations, I was able to test my four hypotheses. In the first model, Partisan Politics was associated with a change in Restrictive Legislation. As conjectured by Hypothesis 1: States that are more Republican are more likely to intervene in drug court policy. The Partisan Politics variable was significant at the $\mathrm{p}<.05$ level and showed a moderate level of explanatory power. Republican policy platforms have consistently included themes to crack down on crime, so it makes sense that states that are more Republican would contain legislators that would want to intervene in drug court policy by passing legislation to reign in the authority of the actors in local drug courts. This would allow them to ensure that the drug court program remains a tough program with an emphasis on offender accountability and not just a get out of jail free card.

In the second model, Method of Judicial Selection was able to explain why certain states were more likely to allow state supreme court justices to write rules governing drug court policies. States that elect their judges were significantly more likely to allow their justices to write drug court rules than states that selected their judges through the appointment process. This provides support for H3: States that use a system of partisan or non-partisan elections to select state supreme court justices will be more likely to have a state supreme court that is involved in writing rules that dictate drug court policy decisions. In the past, elected judges have been 
shown to support more punitive approaches to criminal justice policies, but this study shows that this could also extend to more politically popular criminal justice programs, too. However, more research will need to be conducted in the future to test for other alternative explanations.

In the final model, Partisan Politics was again significant at the $p<.05$ level, while Method of Judicial Selection was significant at the .10 level. This again lent support to H1: States that are more Republican are more likely to intervene in drug court policy. It could be argued that some support exists, for H3: Elected judges in state supreme courts are likely to involve themselves drug court policy decisions by writing rules. However, this could be controversial, since its significance was only at the $p<.10$ level of significance instead of the $\mathrm{p}<.05$. The overall model explained 23 percent of the variance, more than either of the models testing single dependent variables.

Partisan Politics was the strongest overall predictor out of all the variables. This is not surprising since criminal justice issues have taken a more conservative slant since the War on Drugs. Being viewed as tough-on-crime would be especially likely in more Republican states. Evidence to support this claim was found in several studies in relation to supporting drug courts (Fox and Wolf, 2004) and incarceration (Davey, 1998; Western, 2001).

My quantitative analyses showing that elected state supreme court judges were more likely to write drug court policy rules than appointed judges lends support to the theory offered by Baum $(1997,2006)$ that judges consider things other than just legal factors when making decisions. Drug courts are popular and visible programs and supporting them could reap electoral benefits. For instance, during West Virginia's annual Drug Court Day, former State Supreme Court Justice, Brent Benjamin, was one of the key speakers at the event. Benjamin lauded the drug courts as a way to save lives and save the taxpayers' money (WV Drug Court Day, 2015). 
Touting the program's success provided Benjamin with an opportunity to receive positive press coverage. 


\section{Chapter 5: A Qualitative Analysis of West Virginia and Pennsylvania Drug Courts} Introduction

This chapter offers a case study comparison between drug courts from a top-down and a bottom-up state to explore whether the differences in policy implementation in the areas of funding, participant eligibility, program implementation, evaluation, and compliance can be explained by the style of management. Recall, a top-down state was considered a state whose drug court policies were determined, in large part, by state-level actors such as state legislatures and state supreme courts. Bottom-up states are states whose drug courts operate largely autonomously. In order to understand these differences, I initially interviewed judges and drug court coordinators to discuss implementation issues, and then other team members such treatment providers, defense attorneys, prosecutors, and law enforcement officers to examine their level of program support.

Data for this portion of the study were collected through a combination of personal interviews and written responses to open-ended survey questions. The respondents included drug court professionals from three sites: drug court judges, drug court coordinators, probation

officers, drug court treatment counselors, law enforcement officers, prosecuting attorneys, and defense attorneys. Overall, sixteen respondents participated in this study. These included two judges, three drug treatment court coordinators, two probation officers, two treatment court counselors, two law enforcement officers, two prosecuting attorneys, and three defense attorneys. Table 4.1 shows demographic data for the counties in this study.

Table 4.1: Drug Court County Demographics 


\begin{tabular}{|l|l|l|l|}
\hline Demographic & $\begin{array}{l}\text { Mon County WV } \\
\text { Site }\end{array}$ & $\begin{array}{l}\text { Fayette County PA } \\
\text { Site 1 }\end{array}$ & $\begin{array}{l}\text { Somerset County PA } \\
\text { Site 2 }\end{array}$ \\
\hline Population & 106,420 & 130,441 & 73,952 \\
\hline Race (\% White) & $90.1 \%$ & $92.7 \%$ & $95.6 \%$ \\
\hline $\begin{array}{l}\text { Median Income per } \\
\text { capita }\end{array}$ & $\$ 29,285$ & $\$ 24,247$ & $\$ 23,877$ \\
\hline Persons in Poverty \% & $17.3 \%$ & $17.9 \%$ & $12.6 \%$ \\
\hline $\begin{array}{l}\text { Bachelors Degree or } \\
\text { Higher (Age 25+) \% }\end{array}$ & $39.8 \%$ & $15.4 \%$ & $15.7 \%$ \\
\hline Unemployment Rate & $3.9 \%$ & $5.6 \%$ & $5.2 \%$ \\
\hline $\begin{array}{l}\text { Partisanship } \\
\text { (\% Trump 2016) }\end{array}$ & $51.2 \%$ & $64.4 \%$ & 76.5 \\
\hline
\end{tabular}

The West Virginia court has also been in operation since 2009 and has undergone structural changes both locally and at the state-level. This is in stark contrast to the Pennsylvania drug courts that are both in their first year of operation. In terms of economic makeup, the West Virginia site is located in one of the most affluent counties in the state, and has a median per capita income of $\$ 29,285$ compared to $\$ 24,247$ in Fayette County and $\$ 23,877$ in Somerset County. Likewise, Monongalia County's unemployment rate is 3.9 percent compared to Fayette County at 5.6 percent and Somerset County at 5.2 percent. In terms of the poverty rate, Somerset County, PA had the lowest at 12.6 percent, compared to Monongalia County, WV at 17.3 percent and Fayette County at 17.9 percent. Monongalia County had a substantially higher rate of individuals aged 25 and older with a bachelor's degree at 39.8 percent, compared to Fayette County at 15.4 percent and Somerset County with 15.7 percent. This is not surprising as Monongalia County is home to WV's flagship university, a thriving healthcare industry, and the headquarters of Mylan Pharmaceuticals.

The politics in this particular West Virginia county trend more Democratic than the two Pennsylvania counties as evidenced by support for Donald Trump in the 2016 election. President Trump won 52 percent of the vote in Monongalia County (the lowest of any WV county), 
compared to Fayette County in which he won 64.4 percent of the vote and Somerset County in which he secured 76.5 percent of the vote. However, each of the counties in this study are still more Republican than the nation as a whole. The geographic locations of these courts are very similar, as these are bordering states with less than 50 miles separating each of these sites. The drug trends for these states are also akin to each other, with heroin and opioids mentioned as the most problematic drugs in these areas. The CDC (2018) reported that West Virginia had the highest overdose death rate in 2017 while Pennsylvania was number three in this dubious category. These areas of Appalachia are often thought of as ground-zero in the current opioid crisis, which makes studying the drug court's role in managing this issue all the more salient.

\section{Top-Down vs. Bottom-up Drug Court Operations}

West Virginia was classified as a top-down state, ranking $6^{\text {th }}$ in terms of state-level regulations, while Pennsylvania ranked $7^{\text {th }}$ in the bottom-up category. Given this disparity between the two states in terms of their methods of drug court policy implementation, these states make for an excellent comparison between the top-down and bottom-up approaches.

I begin my comparisons of top-down and bottom-up states by examining how drug courts are funded. From the data collected in Chapter 2, I learned that top-down states have a centralized funding operation that often involves specific funding legislation. Therefore, I expect to find that West Virginia has passed legislation to allocate drug court funding, and a bureaucratic agency is in charge of funding oversight. Pennsylvania drug courts should have more freedom in deciding how to fund their operations. I am also interested in examining the West Virginia drug court's compliance with its funding legislation. For example, are the funding regulations overly burdensome, or are those rules simple and easy to follow?

\section{Funding}


The standards for funding West Virginia courts were laid out in the West Virginia Drug

Offender and Treatment Act (2009). §62-15-11 of this law states the following:

(a) Each drug court with the guidance of the Supreme Court of Appeals may establish a schedule for the payment of reasonable fees and costs necessary to conduct the program;

(b) Nothing in this article shall prohibit local advisory committees or drug court teams from obtaining supplemental funds or exploring grants to support drug courts.

(c) Nothing in this article shall be construed to supplant funds currently utilized for drug courts.

The Act has been updated to feature an additional section related to funding. $§ 62-15-9 \mathrm{a}$

creates an adult drug court participation fund, and it reads as follows:

(a) There is created within the State Treasury a special revenue fund designated the Adult Drug Court Participation Fund to be administered by the West Virginia Supreme Court of Appeals.

(b) The fund shall consist of moneys received from individuals participating in an adult drug court program.

(c) All moneys deposited into the State Treasury and credited to the Adult Drug Court Participation Fund shall be used to pay the costs associated with maintaining and administering the court's adult drug court programs.

(d) All moneys collected by the Administrator of the Supreme Court of Appeals for participation in the court's adult drug court program shall be deposited into the Adult Drug Court Participation Fund. Expenditures from the fund shall be for the purpose set forth in subsection (c) of this section and are not authorized from collections but are to be made only in accordance with appropriation by the Legislature and in accordance with article three, chapter twelve of this code and upon fulfillment of the requirements of article two, chapter eleven-b of this code: Provided, That for the fiscal year ending June 30, 2017, expenditures are authorized from collections rather than pursuant to appropriation by the Legislature.

While the local drug courts in West Virginia are technically still able to obtain funding through additional means, this has been limited in practice. According to the drug court coordinator from the WV Site, "There are new drug court policies since the state Supreme Court's department of probation took over in 2012. Money is given by the state based on the 
people that our drug court currently has. We operate on a per capita/per diem fee rate, which basically means we are paid by the head and by the amount of days.

In some instances, the changes in funding practices have not been well received. "One of the biggest changes to our court system was funding," said the judge from the WV Site. "We have to turn over the money we have raised to the state. The state tells you what you can use the money for, how much you can use, and how you can use it. This has made it more difficult for the drug court coordinator to do her job." The drug court coordinator also implied that some of the other avenues in funding that came from local partnerships are not being utilized as they once were. "Our county has had a drug court foundation, which has accepted contributions when the need has arisen, mainly to assist with purchasing things, such as personal items and medicine for court participants. However, the Supreme Court is now in charge of most of the funding." The foundation solicits funds and donations to provide incentives for drug court participants such as restaurant coupons and gift certificates. In addition to the items mentioned by the drug court coordinator, the foundation also provides emergency food, shelter, transportation, and clothing. They can also assist participants in finding employment as they progress in their treatment (WV Site County Drug Court Foundation, 2013). Charitable foundations such as the one mentioned here serve as a great resource for the participants and limiting their services would be short sighted, as they have the ability to not just aid participants directly, but they can also raise community support for the court and help offenders reintegrate back into society." In sum, funding in this top-down setting is set by the state supreme court through legislation. This has streamlined the process but also affected funding from outside sources. To demonstrate how the bottom-up courts are funded, I examined the two counties in Pennsylvania.

Both of the Pennsylvania drug courts reported getting startup assistance from the state, 
but no continuous stream of state funding was available. Both drug court coordinators also stated that their counties were responsible for funding their drug courts. This is part of the correctional budget the county allocates to the courts. According to the drug court coordinator from PA Site 1, "One of the ways we will be able to keep the court funded is through saving money by not having to incarcerate as many addicts."

While both Pennsylvania county drug teams had approved drug court manuals discussing the rules and regulations of their respective courts, PA Site 2 was the only drug court to explicitly write a plan for sustainability in its drug court manual. This was a financial plan that included efforts to obtain additional funding through application of state and federal grants as well as through establishing outside partnerships within the community. The cost savings discussed by the PA Site 1 drug court coordinator were, however, similar to what was written for PA Site 2's sustainability plan. For example, PA Site 2's court plans to save on its direct costs through a reduction in crime, fewer arrests, lower rates of incarceration, and a less burdensome court docket (PA Site 2 County Treatment Court Policy and Procedure Manual, 2016). The section on sustainability also encourages other options to obtain funding such as "state/federal grant funding, participants incurring daily costs, and the service providers/treatment court team collaborating with the treatment court coordinator to seek funding from local foundations; such as the United Way, service organizations, Community Foundation, and others (PA Site 2 County Treatment Court Policy and Procedure Manual, 2016).”

When asked about trying to obtain funding other than the original startup funding offered by the state and county funding, the drug court coordinator from PA Site 2 said, "We will consider efforts to increase funding. We will be looking into state grants, such as the Pennsylvania Commission of Crime and Delinquency. Groups such as members of Drug Free 
Coalition, the SCA advisory board, school personnel, and business people have been supportive, and the newspaper has promoted the court and told of the days and times for the public to come and see the court. While none of them have offered to provide us with additional funding or resources, they have not yet been asked." After initial startup assistance, the Pennsylvania courts are both funded through the county budget through corrections allocations. It is important to understand the differences in funding mechanisms and what it means for management practices.

Funding in the top-down state is much more centralized than in the bottom up one. The legislation and implementation by the West Virginia Supreme Court streamlined funding mechanisms, but it also left members of the local drug court feeling frustrated because it limited their ability to seek additional avenues of revenue. Yet, the WV Site has had a long standing relationship with community partners to assist them in receiving funding, even if the court does not rely on these practices as much as they once did. In contrast, the Pennylvania counties in the bottom-up courts mostly rely on county funding and tout the cost savings from incarceration as a way to fund their courts. Neither have partnered with other local entities such as charities, although they are considering these avenues in the future. The Pennsylvania courts may need to be more innovative in the future, because if their counties do not see a major reduction in cost savings from the drug courts, the funding could dry up. According to the drug court coordinator from PA Site 2, "I wish the state would continue to fund the court after startup operations." When studying drug court policy implementation in the future, there are several key takeaways from examining funding in a top-down and bottom-up state that should allow public policy researchers to make predictions as to the differences in management. First, top-down states are more likely to pass legislation to fund drug courts. Second, if funding legislation is enacted, state supreme courts or other bureaucratic entities will be tasked with determining how 
the funding is allocated and set rules in which drug courts are expected to follow to obtain funding. However, it would be short-sighted to assume that funding legislation could stifle or discourage forging community partnerships to obtain additional funding in other top-down states. More research would be needed to draw those types of conclusions.

The rules that were enacted through legislation and enforced by the West Virginia Supreme Court did leave the judge and drug court coordinator feeling frustrated. These rules were not overly complex and difficult to follow, but it did reduce the West Virginia drug court's independence to obtain additional funding. While members of the drug court felt the funding regulations restricted their ability to raise revenue, there was no evidence that they failed to comply with these regulations. As predicted by previous implementation research, compliance with regulations is more likely if the rules are simple and easy to understand (Simon, 1983). West Virginia's funding regulations were not complex, and since the allocation and reporting of funding is a highly visible activity, it is easier to monitor (Winter, 2000), and this reduces the likelihood of noncompliance.

\section{Drug Court Eligibility}

As discussed in chapter 2 , one of the major ways in which states have influenced local drug court policy is through enacting legislation to develop eligibility standards for participation in drug courts. West Virginia is a state that has passed legislation to develop these standards, while Pennsylvania has not. In this section of the study, I will determine what kinds of eligibility standards exist in these states, and if the state-level legislation passed in West Virginia is different than the local standards developed in the two drug courts in Pennsylvania.

In 2009, the West Virginia legislature passed the Drug Offender Accountability and Treatment Act, which was enacted with the goals of aiding the creation and facilitation of drug 
courts in the state (Justia, 2014). In section 7 of this code, the eligibility requirements for participants were written to include the following prohibitions to participation.

\section{West Virginia State Law for Drug Court Eligibility}

“(a) A drug offender shall not be eligible for the drug court program if:

(1) The underlying offense involves a felony crime of violence, unless there is a specific treatment program available designed to address violent offenders;

(2) The underlying offense involves an offense that requires registration as a sex offender pursuant to the article twelve, chapter fifteen of this Code;

(3) The drug offender has a prior felony conviction in this state or another state for a felony crime of violence; or

(4) The drug offender has a prior conviction in this state or another state for a crime that requires registration as a sex offender pursuant to article twelve, chapter fifteen of this Code.

(b) Eligible offenses may be further restricted by the rules of a specific drug court program.

(c) Nothing in this section shall require a drug court judge to consider or accept every offender with a treatable condition or addiction, regardless of the fact that the controlling offense is eligible for consideration in the program.

The main restrictions found in the state law are the prohibitions for violent felons and sex

offenders, which were also the most common eligibility restrictions all 50 states according to the data in chapter 2 . While providing some definite restrictions, the legislation does provide plenty of room for the West Virginia drug courts to create their own eligibility restrictions. According to the drug court coordinator from WV Site, the drug court team is currently in the process of creating a new standard of eligibility requirements to meet the evolving needs of their drug court.

The following is a list of eligibility requirements originally written for the WV Site in 2008:

\section{Drug Court Eligiblity}

1. Adult ( 18 years of age or older) with a felony offense

2. Resident of the Morgantown area whose offense(s) occurred in Monongalia County 
3. An identifiable substance abuse problem, as determined through the screening and assessment process

4. No more than three prior felony convictions and/or juvenile adjudications

\section{Disqualification Criteria}

1. Violent offenses, sexual offenses, or offenses that involved the use of a dangerous weapon

2. Previous convictions for violent felony offenses or sexual offenses

3. Pending offenses in other jurisdictions (unless waived by the Drug Court team)

4. Refusing to cooperate with Drug Court procedures and/or refusing to abide by program rules

5. Any condition that would prevent an offender from being able to actively participate in the program

6. Use of Methadone or Buprenorphine outside of an approved clinical treatment program.

When asked about the eligibility restrictions specific to the WV Site, the drug court coordinator stated, "An offender cannot be a violent felon, and they must live in this county. We want non-violent offenders, no sex crimes, and the offender must be a drug addict." The judge from the WV Site described some additional restrictions and discussed the crimes of violence. "Most crimes of violence are prohibited, such as your aggravated assaults and crimes involving weapons. Depending on the circumstances, however, some misdemeanor crimes such as simple battery can be excused. We also will not accept people charged with gun crimes."

Both the drug court coordinator and judge were adamant about the type of addicts that they have chosen to accept into the program during risk assessment. "We accept offenders who are high risk/high need," said the judge. "Drug courts should only take the high risk/high need individuals. However, I've heard of some laws excluding high risk individuals, which fails the population." When asked the dangers of mixing the high risk/high need offenders with those who have either low risks or low needs, the drug court coordinator said, "The high risk individuals tend to negatively affect the low risk ones."

High risk/high need offenders are "(1) substance dependent and (2) at risk of failing in 
less intensive rehabilitative programs (Marlowe, p. 2, 2012).” Many early drug court programs limited their eligibility to the low risk individuals to avoid the soft on crime label, but drug court experts encourage the programs to now focus on the high risk/high need individuals to offer the best results in terms of crime reduction (Marlowe, 2012).

When asked what should be done to treat individuals who are low risk/low need, the judge believed that less intense measures would suffice. "Probation would be more effective for these individuals. Some are recreational users. Some have jobs. They normally require less intensive supervision and treatment than those fully dependent upon substances."

\section{PA Site 1 Drug Court Eligibility}

Both of the Pennsylvania drug courts in this study had constructed their own rules to govern drug court eligibility. The following set of guidelines is from PA Site 1's drug court manual:

\section{$\underline{\text { Legal Eligibility }}$}

After receiving an application, the application will be processed within (five) 5 days to determine legal eligibility.

1. The lead charge needs to be related to drug use. Both misdemeanors and felony will be considered however it is to the discretion of the District Attorney's office and presiding judge to determine who is an appropriate candidate for the program. Trafficking charges may be considered but will be at the discretion of the District Attorney's office and presiding judge.

2. No past violent or sexual offenses including juvenile adjudications may be permitted including but not limited to;

a. Criminal Homicide, b. Manslaughter, c. Rape, d. Aggravated Assault, e. Aggravated Assault with a Weapon, f. Robbery, g. Sexual Assault, h. Aggravated Indecent assault, i. Indecent Sexual Assault, j. Indecent Exposure, k. Involuntary Deviate Sexual Intercourse, 1. No Prior Violent Felony Convictions, m. No Prior Firearms Convictions, n. Assault by Prisoner, o. Strangulation, p. Incest, q. Escape, r. Arson, s. Incest

3. No prior Megan's Law offender will be eligible for the Adult Drug Court Program 
4. The participant must be 18 years at the time of offense

5. The defendant must be a resident of the County

6. After the successful graduation of the Adult Drug Court Program, the participant's attorney may petition the Court to have the charges dismissed. The dismissal of charges will be at the discretion of the presiding Adult Drug Court Judge.

7. Driving Under the Influence of a Controlled Substance will be considered for Adult Drug court if it is the offender's first, second or third Driving Under the Influence offense.

Many of the prohibitions on offender eligibility that are present in West Virginia state law and in the WV Site local regulations also exist in regulations of PA Site 1. For example, both of these courts are adamant about preventing violent offenders and sex offenders from entering into their respective programs. However, both programs will allow misdemeanor cases of violent crimes to proceed, depending on the circumstances. According to the drug court coordinator from PA Site 1, "We do not accept violent felons, but simple battery is okay." Both of the programs also require offenders to be residents of their counties.

The two Pennsylvania drug courts have also adopted somewhat different rules regarding the type of offender eligible. The drug court coordinator from WV Site stated the offender "must be an addict," while the Pennsylvania Site Drug Court rules read that the lead charge needs to be related to drug use. This leaves open the possibility offenders in WV Site can commit a crime, such as petit larceny, which the judge from WV Site indicated was common among addicts trying to support their drug habits, and still be eligible to receive admission into the drug court. This could potentially allow a greater portion of WV Site's addicted population to receive treatment, while limiting the options for some of the addicted offenders in PA Site 1.

Another disparity between these two courts is that the WV Site's court targets felons according to part of its mission statement "The target population is felons living in the county." However, according to the eligibility requirement, no more than three prior felony adjudications 
will be tolerated. In contrast, the first eligibility requirement for PA Site 1 states that "Both misdemeanors and felonies will be considered however it is to the discretion of the District Attorney's office and presiding judge to determine who is an appropriate candidate for the program." But a deeper analysis shows that many of the subsequent restrictions in section 2 of PA Site 1's eligibility regulations consist of common felonies, particular those governing both violent and sex offenses.

Section 2 of PA Site 1's regulations also leaves the door open to allow drug traffickers to enter the program with district attorney and judicial approval. However, according to the drug court coordinator from this site, "We do not allow offenders charged with possession with the intent to distribute to enter our program." The incongruence between this adopted rule and the rule as it relates to practical use could potentially be explained by information obtained in the previously in this chapter. For instance, the drug court coordinator from PA Site 1 had indicated that both "the probation officer and district attorney were reluctant about drug courts at first." Limiting admission to those offenders who had only been charged with simple possession of drugs, not distribution or possession with the intent to distribute, could have been a way to gain support for the program from the district attorney, the probation officer, and other law enforcement officers who may have been skeptical of the program. For example, when discussing the program with the PA Site 1 drug court coordinator, she mentioned those actors were reluctant about the drug court, at first. At the same time, the rule to allow those offenders who have been charged with drug distribution to enter into the program technically remains on the books. This is something that could be revisited again in the future if the district attorney and others begin to soften their position over time.

In West Virginia, the program is targeting addicted offenders with the greatest risk to 
commit future crime if not treated with rehabilitative programs under greater supervision. However, PA Site 1 seems to accept a mixed bag of offenders, even though their target population is also one of "high risk offenders," according to their drug court manual. By not allowing offenders in the program with the charge of possession with the intent to distribute, the court could be undeserving a key group in need of rehabilitation. The issue of drug distribution is more intricate, though. For example, many of those charged with distribution or possession with intent to distribute are addicts themselves, who sell drugs to support their own addictions. By looking at each drug court case individually, weeding out the heavy drug traffickers, and allowing those charged with low-level distribution to enter the program, a greater portion of the at risk population could be served with the possibility of a reduction in both drug use and other criminal behaviors.

\section{PA Site 2 Drug Court Eligibility}

The following guidelines are from PA Site 2's drug court manual:

\section{ELIGIBILITY CRITERIA}

The following criteria have been established to identify individuals who may be eligible for admission to the Somerset County Court of Common Pleas Treatment Court:

- Legal residence of the United States

- County resident, age 18 years or older

- Non-violent criminal history

- Offender commits an offense related to substance abuse (not necessarily a drug offense)

- Individual voluntarily agrees to participate in, and be subject to rules, regulations and sanctions of Treatment Court

- Personal injury crimes after consultation with the victim(s)

PA Site 2, like its WV Site and PA Site 1 counterparts, generally prohibit both violent criminals and sex offenders from entering into the program. However, PA Site 2 makes exceptions for presumably lower crimes of violence after consultation with the crime victim. 
Consulting the victim before deciding upon drug court admission would be a good way to instill confidence in the system and could be a way to further the notion that the drug court is not a lenient program. Like the other drug courts, PA Site 2 requires that the offense needs to be related to substance abuse in some fashion and that the offender be a resident of the county. PA Site 2 also goes a step further by stating that the offender must be a resident of the U.S. The other programs have not explicitly written about that requirement, and while it is worth noting, a discussion of the immigration status of offenders goes beyond the scope of this study.

Both Pennsylvania sites identify particular areas of state law violations that would prohibit offenders from entering into the drug court programs. Again, many of these cover violent felonies and sex offenses. However, other mala in se crimes, such as arson, kidnapping, and extortion are also mentioned for both courts. PA Site 2 also prohibits those charged with the conspiracy to commit these offenses from entering into their program. Both Pennsylvania courts afford the prosecuting attorney veto power over entry into the drug court. When asked about the restrictions to entering drug court, the drug court coordinator from PA Site 2 responded, "All applications go directly to the district attorney's office, they have complete discretion, usually reject based on criminal history, certain charges, like out of county charges, out of county resident, very violent crime, and victim impacts."

While the prosecutor has an important role to play in the criminal charging of offenders, they only represent one member of the drug court team, and allowing them to exercise unbridled discretion over drug court admissions could have negative consequences. As discussed earlier in the study, the punitive era of criminal justice in the 1980s and 1990s resulted in a vast increase in prosecutorial power, while at the same time judicial power was limited (Stith and Cabranes, 1998). Too much prosecutorial power could result in fewer drug court admissions if prosecutors 
exercised their authority to recommend the traditional adversarial model instead of treatment for some of the higher risk offenders. Evidence of this practice in the PA Site 1 court already exists by prohibiting offenders charged with possession with the intent to distribute from entering the court. Again, this could limit the effectiveness of the program by not treating offenders who could benefit the most.

Another major distinction from WV Site's court and its PA counterparts is the risk/needs assessment practice. In WV Site, the drug court follows the high risk/high need model, which is favored by the National Association of Drug Court Professionals (Marlowe, 2012). Both PA drug courts use different approaches. For example, PA Site 1 does not mention the high risk/high need approach specifically in its drug court manual, although it recommends targeting “individuals who are at a high risk of reoffending." Yet, it allows those who have been charged with both misdemeanors and felonies into its program, but prohibits admission to anyone charged with any type of drug distribution. According to the drug court manual from PA Site 2, their drug court "targets primarily offenders who are medium/high risk/needs through an evaluation process."

When asked about their admissions practice the drug court coordinator from PA Site 2 indicated that the program has limited numbers so far and has been accepting individuals outside of the preferred realm of treatment. "Our drug courts are treating offenders with low and medium risks and high needs, but we do have some offenders with high risk/high needs. Unfortunately, only a small percentage of addicts are in treatment. We need to have a broader tent in some capacity and offer more high level offenders." From the coordinator's statements, it is clear that many of the criminal addicts are not getting treatment. This is most likely a combination of eligibility prohibitions and prosecutorial discretion. The current practices employed by PA Site 1 
and 2 could be problematic because they are mixing the types of offenders in the program. As mentioned earlier, the WV Site drug court coordinator and judge both believed this practice could negatively impact the low-level offenders in the program by exacerbating their addictive behaviors through exposure to high risk/high need addicts.

It is clear that the West Virginia drug court program has benefited from its experience, as it has been in existence for over a decade. This has helped them fine tune their admission practices and make decisions as a team, without affording too much discretion to one individual. As both drug court coordinators and many of the other drug court team members indicated during the interviews, their courts are still a work in progress and many things are being done by trial and error. West Virginia also has legislation dictating certain eligibility and funding requirements, and the state supreme court is also in charge of overseeing and assisting with the implementation of their drug court policies.

Though the West Virginia drug court had passed legislation to define drug court eligibility standards, this legislation did little, if anything, to change the eligibility standards already being practiced by the WV drug court. Those standards were also strikingly similar to the set of eligibility standards developed by both Pennsylvania drug courts. For instance, both the WV and PA Sites restricted sex offenders and most violent offenders, with exceptions being made for misdemeanor assaults and batteries. Therefore, in terms of the program eligibility standards enacted by all of these courts, there were not any appreciable differences between the top-down and bottom-up states. The WV Site targets felons as its main population and only admits high risk/high need offenders, while the PA courts target a mixed bag of offenders. According to Marlowe (2012), the target population should be high risk/high need. The WV drug court members indicated that mixing offenders could negatively impact those who are not yet 
classified as high risk/high need. Since the PA courts were just beginning their programs, it is more likely that the difference in the needs/risk assessment aspect of program eligibility could be because of lack of experience instead of a difference in management style. In the next section, the specific relationships between drug court professionals and their state supreme courts will be discussed regarding policy implementation.

\section{Drug Court Regulations, Evaluations, and Compliance}

In this section, I want to first determine if certain drug court regulations and evaluation practices are different in the top-down and bottom-up states. West Virginia, the top-down state, should have more extensive regulations and procedures for evaluation in place. Given the more centralized approach to drug court management, West Virginia should presumably provide a greater opportunity for me to analyze whether they have been compliant in adhering to statelevel regulations. One of the most common form of rules adopted by drug courts are the 10-Key Components of Drug Courts. West Virginia has codified these into law, while the Administrative Office of Courts led by the State Drug Court Coordinator has recommended that these components be used in Pennsylvania.

PA Site 1 and PA Site 2 have explicitly written the 10-Key Components into their local drug court manuals. When asked about the 10-Key Components and other rules and regulations that the state supreme court expects the local drug courts to follow, the WV Site drug court coordinator stated, "Legislation and the state supreme court requires certain rules. For example, treatment providers must be certain licensures. We have a drug court team and a judge (judge is the boss). We are required to keep a database entry and have a drug testing protocol. However, there is a mix between freedom to run our court and rules that we must follow."

The PA Site 1 drug court coordinator responded to the same question by stating, "The 
state supreme court requires evidence based practice, such as adhering to the 10 Key

Components. We must staff our court and they provide training. We are also required to go through accreditation, have a mission statement, and ensure our participants go through graduated phases of treatment. Other than that, we have lots of freedom to run the drug court. There are no other explicit rules from the state supreme court." The drug court coordinator from PA Site 2 stated, "In PA we have the Administrative Office of Pennsylvania Courts, there are best practices and training. There are NADCP Best Practices. These were given over a three-day period and the judge actually went to Reno for the conference."

While the state of West Virginia requires certain rules such as the 10-Key Components, the supreme court in Pennsylvania also requires those rules in the absence of legislation. There seem to be few differences in terms of these states when it comes to requiring NADCP standards. These standards have been in place since 1997 (Marlowe, 2016) and have become common place among drug court programs over the previous two decades.

One of the other main questions about local drug court policy is how drug court evaluations are implemented. Program evaluations will not only demonstrate whether or not the drug court polices are working, but they could also be influential in determining whether tax dollars are being spend effectively, which could eventually dictate future decisions about whether the drug courts are an effective program to combat recidivism and addiction. Examining the procedures for this data collection is important to ensure that the most accurate data is being collected.

In West Virginia, under 62-15-6a, standards for evaluation practices have been explicitly written. It contains the following regulations: 
(a) Drug courts shall collect and maintain the following information and any other information required by the Supreme Court of Appeals or its administrative office:

(1) Prior criminal history;

(2) Prior substance abuse treatment history, including information on the drug offender's success or failure in those programs;

(3) Employment, education, and income histories;

(4) Gender, race, ethnicity, marital and family status, and any child custody and support obligations;

(5) The number of babies, both addicted and healthy, born to female drug offenders during participation in drug court;

(6) Instances of relapse occurring during participation in drug court;

(7) Instances of recidivism occurring during and after participation in drug court. Recidivism shall be measured at intervals of six months, one year, two years, and five years after successful graduation from drug court;

(8) The number of offenders screened for eligibility, the number of eligible drug offenders who were and were not admitted and their case dispositions;

(9) The drug of choice and the estimated daily financial cost to the drug offender at the time of entry into the program; and

(10) The costs of operation and sources of funding.

(b) A drug offender may be required as a condition of pretrial diversion, probation, or parole to provide the information described in this section. The collection and maintenance of information under this section shall be collected in a standardized format according to applicable guidelines set forth by the Supreme Court of Appeals.

(c) To protect drug offenders' privacy in accordance with federal and state confidentiality laws, treatment records must be kept in a secure environment, separated from the court records to which the public has access.

As can be seen from these rules, there are regulations governing the collection of demographic data, offender drug of choice, instances of relapse, recidivism, acceptance or denial into the program, and financial information regarding program costs and funding. When asked about these regulations and whether it was difficult to comply with them, the drug court coordinator from the WV Site stated, "There is difficulty in complying with data entry because there is not enough personnel to perform these tasks. Some case managers have been lost because the grant funding ran out. They (the state supreme court) could be more helpful by granting more employees. More staff is needed."

The evaluation procedure is an example of top-down policy that is difficult to comply 
with because of a lack of resources. The principals, the West Virginia Supreme Court, had cut back on personnel whose job was to help with evaluations. While the drug court coordinator seemed frustrated by the new policy, there was no evidence of non-compliance. However, it is important to understand that this represents an area where it would be extremely difficult for policy managers to monitor compliance a la Lin (2000) who found it nearly impossible to monitor whether prisoners were punished for not attending or participating in prison educational programs.

The judge from the WV Site also offered his thoughts on the legislative mandates and state supreme court rules. "The legislative mandates have not been difficult; they have essentially followed local drug court models." Since there was not an abundance of new rules, and they were not overly complex (Simon, 1983), the WV Site did not have any issue with compliance. However, there appeared to be some conflict when the state supreme court first became involved in what had been local drug court domain. "Some of the state supreme court rules and protocols conflicted with what local courts had done in the past. There were some differences, but nobody has taken away our funding or said that we have done things wrong. The change in personnel at the supreme court has made things better over time."

When pressed further to provide concrete examples of the differences in policy between state and local drug courts, the judge seemed frustrated and said, "We do things the way we do things, the state supreme court did not affect the underlining principles we had established in our drug court. There are no real evaluation pressures. These are more perceived. We do have a level of independence to adapt." This provides supporting evidence for Lipsky's (1980) claim that street-level bureaucrats, in this case drug court team members, have substantial discretion to shape and implement policy, even in a top-down state. 
The legislation and oversight provided by the state supreme court has caused some burdens in terms of collecting data in the WV Site. This was mainly because the state had not provided a case manager to compile the data, presumably to save money. While there was some tension between the local courts and the state supreme court shortly after legislation was passed that gave the state supreme court oversight authority, compliance did not seem to be an issue. The judge and drug court coordinator both indicated that the local drug court maintained a great deal of independence to operate their drug courts.

In PA Site 1, no evaluation procedures were explicitly written in the drug court manual. When asked about evaluation procedures, the drug court coordinator from PA Site 1 said, "We keep data records and are faithful to the 10 Key Components, but there have been no explicit rules from the state supreme court. It is not tough to comply with anything the state supreme court has requested of us. However, getting the local team to meet and interact can be difficult because scheduling issues are a problem, and other members of the team have other responsibilities."

The drug court in PA Site 2 had adopted a local policy to collect data, which was written in its drug court manual (2016). It contains the following information:

In 2017, the Somerset County Treatment Court Team will begin tracking data using the computer program Problem-Solving Adult and Juvenile Courts Information System (PAJCIS), which is supported through the Administrative Office of Pennsylvania Courts (AOPC). The Treatment Court Coordinator/Somerset County Intern has the responsibility for the initial input of required PAJCIS data. The Probation Department will provide the Coordinator/Intern with updated information on a weekly basis.

Using the information collected through PAJCIS, the Treatment Court Coordinator will pull identified data on a quarterly basis. The purpose is to identify positive and negative trends and make any associated recommendations. The Treatment Court Coordinator will summarize the findings and recommendations, and review this information with the Team. The data will be 
used to create necessary goals and objectives that strengthen the functioning and outcomes of the Court.

While PA Site 2 has adopted a system to collect data, which is supported by the Pennsylvania Supreme Court, no legislation has been written, and the evaluation procedures have been left vague. When asked to describe some of the data that is collected the drug court coordinator said, "We collect information on race, gender, age, what kind of drugs the participant is addicted to, recidivism rates will also be collected." The drug court coordinator also indicated the relationship with members of the state supreme court is a good one. "The state has been very helpful with training and funding to start the court. They have done nothing to hinder our progress. The state data system is cumbersome but there has been money provided from the state for start-up costs."

When comparing the top-down and bottom-up drug courts, there does not appear to be major differences in terms of regulations. Both states use the 10-Key Components and Best Practice Standards to guide their policy decisions. Both West Virginia and Pennsylvania collect data for evaluations and both state supreme courts are involved in some fashion. However, West Virginia has passed legislation that establishes specific practices for data collection, and while they appear to be more involved than the local rules for the Pennsylvania Sites, a lot of the evaluation standards, such as demographics, recidivism rates, and drug of choice are required for each program.

In Pennsylvania, these are newer courts and the initial interactions with members of the state supreme court in terms of oversight is all they have known, and compliance was never an issue. In West Virginia, however, there does appear to have been some tension with the state supreme court after legislation was passed to give the state supreme court oversight authority. 
The tension seemed to be short-lived and while the court from the WV Site claims that some of the regulations are more difficult to follow, there are no indications that compliance has been an issue. Both the top-down and bottom-up courts indicate being able to exercise discretion in these areas. The WV Site has more explicit rules governing its actions in these areas, but these rules have not significantly deviated from past practices, which have resulted in a high-level of compliance. Again, compliance was with state-level regulations in West Virginia was more likely because the rules were not complicated (Simon, 1983), and the policy actors at the streetlevel still maintained a substantial amount of discretion (Lipsky, 1980), and the rules that were in place did not appear to deviate far from the cultural norms (Brehm and Gates, 1997) established earlier in the WV Site court. Taken together, this factors offer explanations as to why the members of the WV Site's drug court did not engage in shirking or sabotage.

In the next section of the study, support for drug courts is examined. Here, I can gauge whether drug court team members are on the same page in term of program goals. If not, it could negatively impact program implementation.

\section{Support for Drug Courts}

Nolan (2001) argued that drug courts were able to garner bipartisan support because they offered tangible incentives for both Republicans and Democrats. While these earlier studies demonstrated how drug courts were able to overcome political obstacles in their formative years, they did not examine the degree to which drug courts are supported by drug court personnel. In this section, the degree of support for drug courts among their own members, as well as how drug court team members perceive the level of support among the community, will be examined. I will also explore how efforts are currently being made to educate the public about drug courts. Examining the level of support is key to understanding if the members of these drug courts buy 
into the program, because when bureaucrats have a shared system of norms and beliefs, they are more likely to work to meet organizational goals and less likely to shirk or sabotage (Brehm and Gates, 1997).

The members of the drug court team are diverse in terms of their philosophical approaches to justice policy. One would expect that prosecutors and police officers to favor a more punitive approach to punishment, especially considering the increase in proactive policing (Belenko and Sphon, 2015) and the substantial authority gained by prosecutors (Spohn, 2009) during The War on Drugs. That philosophical approach is markedly different than an approach favoring rehabilitation, which is something I predict treatment counselors to support. It will be interesting to determine whether or not the actors have found common ground in terms of the drug court's mission or whether there are differences that could potentially hinder effective policy implementation.

Each of the participants in this study was asked to discuss the supporters and detractors of the drug court program and to describe any efforts made to garner more support for the program. The two most common themes mentioned among all members of the drug court teams were that the drug court community and legal community were the most supportive of drug courts. When asked about the public, however, many of the respondents indicated that those who knew about drug courts were supportive, but most of the public had no knowledge of the drug court's existence.

According to the drug court coordinator from PA Site 2, "The majority of those who know about drug courts are supportive. Everyone in the court system is supportive, most of law enforcement, probation and jail, family and friends of addicts, and the treatment community." The drug court coordinator from PA Site 1 offered similar views. "The district attorney and 
probation officer view drug courts as a tough but fair sentence. The judge is supportive as well as the treatment counselors (it increases the number of their clients), the public defender is supportive, too."

The WV Site drug court coordinator and judge both believed there was a large degree of support for the drug courts, but both acknowledged that the courts are not widely recognized throughout the community. "Drug courts are supported within the legal community where it is known," said the drug court coordinator from the WV Site. According to the judge from the WV Site, "In general, the community is supportive. However, a large part of the public is unaware of drug courts, but those who are remain supportive." The judge from PA Site 2 expanded upon the individuals who are supportive of the drug courts. "Supporters include families and friends of addicts, some members of the business community, some law enforcement officers, and the treatment professionals as a whole.”

When asked who the most vocal critics of drug courts were, law enforcement officers were the group most often cited. According to the drug court coordinator from PA Site 1, "Law enforcement officers still seem to be the biggest critics within the criminal justice community. Some have not tried to understand the program.” The drug court coordinator from PA Site 2 reiterated her counterpart's point by adding, "Some law enforcement are against it, but they are not familiar with the court, but the ones who are involved do support it."

The WV Site judge offered a similar view. "Some individual law enforcement officers have a few issues, especially with drug court clients, because some of these clients have large criminal histories and the officers know them." The judge from PA Site 2 also confirmed that some police officers were against the program. "While no person has voiced criticism to me personally thus far, what I have heard is that the most vocal critics are "old-school" law 
enforcement officers."

There have been efforts to assuage some of these concerns among the law enforcement community. For example, according to the drug court coordinator from PA Site 2, "Law enforcement and some of the attorneys who were opposed to drug court were invited to observe court hearings, as well as members of the public." The attorney from the site added, "Newspaper coverage has been positive, and this has helped to gain support."

The drug court coordinator from PA Site 1 offered her views about how greater support for the program can be achieved as the program continues to develop over time. "Law enforcement still seems to be the biggest critics within criminal justice. Some have not tried to understand the program. The probation officer and DA (district attorney) were reluctant at first, especially the DA who was used to the adversarial model. However, as more criminal justice folks discovered that the drug courts weren't a get out of jail free card, they became more supportive. I believe that as law enforcement receive more training and learn more about this new program over time, then their support will increase."

The judge from the WV Site said, "To have support for drug courts, you must get the DA and law enforcement on board and create a knowledgeable public. This segment of the public would not think the program is soft on crime if they knew the structure of the court."

The drug court coordinator from the WV Site illustrated some of the efforts that had been made to increase awareness of drug courts and garner support for the program. "Education is provided through the bar association to defense attorneys. We (the drug court team) go out to speak to the Rotary Club and faith based organizations to gin up support." When asked about support from the law enforcement community, the coordinator added, "Training has been conducted to educate law enforcement and other personnel to get them on board. We have also 
obtained a Bureau of Justice grant to go to the National Association of Drug Court Professionals annual conferences. A local police officer who became a probation officer was instrumental in bridging the gaps between law enforcement critics, so the drug court team now includes a city police officer."

When interviewing the law enforcement officers, both of them did seem supportive of the program. However, this comes with some caveats because they were both affiliated with the drug court team. For example, the officer from PA Site 1 said, "Without treatment the problem is a runaway train, poverty, crime in Appalachia, and drugs are rampant in this area."

The law enforcement officer from WV Site added, "I believe the community is limited in their knowledge of drug courts, therefore they are unable to be fully supportive of the court's efforts. There are many defense attorneys that do support our effort and recommend clients to participate in our program."

While two of the defense attorneys interviewed voiced support for the program. One of the private attorneys not affiliated with the drug court team, but who has had clients that have entered into the drug court system, was vehemently opposed to the drug courts. "This community largely is opposed to drug rehab facilities. Other out-of-county attorneys have commented on the area's hard line position on drugs such as the longer sentences. However, studies have shown over the decades that this approach has never affected crime rates. Therefore, it is nothing but a political hoax. Prosecutors normally run for judgeships and giving the impression of being hardline is nothing but a political ploy. Our county is losing thousands of dollars having to rent space in jail in other counties due to prison overcrowding. Our county now has developed drug courtvery hypocritical because it's all about money and not really about treating addicts."

Other members of the drug court team from WV Site offered some ideas about how to 
gain future public support for the drug court programs. "I believe there needs to be more community outreach requesting support in the form of job opportunities, community service opportunities, or monetary donations," said the prosecuting attorney. The treatment counselor added to this theme. "The drug court I worked on in Illinois was more supportive than this county. There were fundraisers, we actively helped participants find jobs and housing."

Overall, drug court team members in both West Virginia and Pennsylvania believed that most members of the drug court teams and the legal community were supportive of drug courts and its mission. These represent shared values and goals, which increase the likelihood of policy compliance and decrease the likelihood of shirking and sabotage (Brehm and Gates, 1997). Support for the mission of the programs has resulted in high rates of compliance, as evidenced in the previous section. However, certain law enforcement officers were not as supportive. West Virginia's drug court has been operating for more than a decade and were ahead of the two Pennsylvania drug courts, which were both in their first year of operations at the time of the interviews, in terms of alleviating some of the resistance to drug courts from law enforcement officers and others. This was achieved through education, federal grants, and allowing law enforcement officers on the team to bridge the divide to other police officers unfamiliar with drug courts. The Pennsylvania drug courts have identified the need to educate and train law enforcement officers and are beginning to do so by inviting these individuals to drug court hearings. Ensuring these practices are met will help to establish a culture and increase the likelihood that the programs will work toward meeting shared goals. West Virginia's drug court has also indicated conducting outreach to faith based organizations and other non-profits. However, better job placement and housing for offenders are areas in which both states could be improved upon. 


\section{Summary}

This chapter examined several important elements in drug court policy. First, an analysis of states using both a top-down and bottom-up approach to drug court management was provided. Drug court support, funding, offender eligibility, policy implementation, evaluation, and compliance were measured through qualitative analyses by examining both policy documents and personnel interviews. In terms of differences between top-down and bottom-up states, the top-down state is more likely to pass legislation and use a bureaucratic agency (in this case a state-supreme court) to enforce policy implementation and evaluations. The most pronounced difference between top-down and bottom-up states was in funding practices. However, there were few differences between these states in terms of drug court eligibility, policy implementation, and evaluation practices. Program compliance was not an issue in a topdown state, mainly because the state-level directives were not complicated and they did not significantly alter the local drug court's culture. Second, support for drug courts was high among drug court professionals, but a sub-section of police officers (not any that were directly involved with the drug courts) were still skeptical about treating addicts instead of incarcerating them. However, efforts to assuage concerns and gin up support were in place, which helps to form a culture in which shared goals and values are common and compliance is high. 


\section{Chapter 6: Conclusion and Policy Recommendations}

This study began with a literature review of morality policy and a history of drug sentencing policy and the political forces that drove it. Moral panics and racial scapegoating were catalysts for legislation that led to polices that regulated and criminalized both alcohol and drugs. Before the 1970s, sentencing policy was guided by many goals, including deterrence, just deserts, incapacitation, and rehabilitation. However, as the crime rate in general and drug use in particular began to rise, both scholars and politicians began to question the multifaceted approaches to sentencing policy. Federal legislation such as the Sentencing Reform Act of 1984 and the Anti-Drug Abuse Acts of 1986 and 1988 limited the authority of judges to make decisions about sentencing, while giving prosecutors gained greater discretion in this process. The goals of sentencing policy became deterrence and incapacitation. The states followed the federal government's lead, and passed mandatory minimum sentences for drug offenses and other crimes as well as three strikes laws. The result of these draconian sentencing policies led to massive incarceration and a substantial increase in spending at both the federal and state levels, while doing little to curb the addiction rate. Minorities were also much more likely to be incarcerated and serve longer sentences than whites after these policies were enacted.

Drug courts were originally adopted to alleviate the backlog of drug cases experienced in criminal courts. They soon evolved into a form of coercive treatment, where addicts were provided resources to treat their addictions. Individuals enrolled in this program had to stay clean and agree not to commit additional crime. They were rewarded for good behavior, but were sanctioned for breaking the rules. Some of these punishments included spending additional time in drug court, jail time, dismal from the program, and being forced to serve out the remainder of their criminal sentence. The program was lauded by politicians from both sides of the aisle. 
Republicans touted cost savings, while Democrats were in favor of treating addicts instead of sending them to prison. Much of the prior research into drug courts focused on program graduation rates, criminal recidivism, and financial savings compared to incarceration. However, few studies were dedicated to examining drug courts from a broader public policy or political lens.

In Chapter 3 of this study, I addressed some of these concerns. I demonstrated that both vertical and horizontal diffusion helped to explain the evolution of drug courts in the U.S. The primary data was obtained by contacting the drug court coordinators from all 50 states, and this was supplemented by archival research when needed. I initially examined drug court creation. The majority of states created their drug courts through local efforts where judges and other criminal justice professionals worked together to form these courts. Drug court coordinators in several states discussed how they modeled their initial courts from the original model in Miami, even sending judges down to observe that court. This provided an example of policy learning via horizontal diffusion.

The federal government passed laws to allocate drug court funding as long as states complied with certain participant eligibility requirements. The NADCP also worked to craft drug court policy and helped initiate and train drug courts throughout the U.S. They were also instrumental in crafting the 10-Key Components and two volumes of Best Practice manuals, in which 36 states have required their drug courts to implement. These were clear-cut examples of vertical diffusion at work.

Many state legislatures became active in the process by passing supportive legislation in favor of drug courts, and in many instances they provided funding as well. However, only four states actually created their drug courts through legislative initiatives. Legislators also passed 
legislation to regulate the drug courts. Twenty-three states passed restrictive legislation to further regulate their state's drug courts. This type of legislation included offender eligibility requirements such as denying participation to sex offenders and many violent criminals. Other government agencies have also become involved in shaping drug court policy. A majority of state supreme courts are involved in at least some degree with assisting drug courts, and they have the ability to formulate rules and regulations in twenty-five states. Other entities that have oversight authority into local drug court policy include executive agencies, legislatively formed commissions, and state drug court professionals.

The chapter concludes by creating a meaningful distinction between the types of drug courts based on the total amount of state-level regulations. The states with the least amount of state-level regulations were considered to be operating their drug courts using a bottom-up approach. Conversely, the states that had the highest number of state-level regulations were considered to be operating their drug courts from a top-down approach. Creating this continuum was important empirically because it allowed me to test whether or not certain political, criminal justice, and structural variables could account for the number of state-level regulations. It also provided me a basis from which to conduct case studies comparing two states that used these disparate styles of management.

Chapter 4 provided a quantitative analysis of whether certain independent variables were associated with Restrictive Legislation, State Supreme Court Rules, and State-Level Regulations. The independent variables used in this study included Partisan Politics, Method of Judicial Selection, the Violent Crime Rate, and Race. Partisan Politics predicted a state's likelihood to pass Restrictive Legislation, with Republican legislators more likely to limit the authority of local drug courts in this manner. In the second model, elected judges were more likely to write 
rules to govern drug courts. In the first model, Partisan Politics was associated with a higher number of state-level regulations at the p. $<.05$ level of significance, while Method of Judicial Selection was weakly associated the number of state-level regulations at the $p<.10$ level of significance.

In Chapter 5 of this study, I used case studies of three drug courts from two states to discuss top-down and bottom-up policy implementation. The first goal of this chapter was to compare drug courts from these states to identify key differences and similarities between topdown and bottom-up states. In terms of funding, the WV Site received legislative funding which was allocated by the state supreme court. They have also forged some local partnerships; however, members of their drug court expressed frustration because they believed that the statelevel regulations have hindered their ability to innovate in terms of raising funds. However, there was no evidence of shirking. In contrast to this, both of the PA Sites relied mostly on county funding. Since both of the PA drug courts were in their first year of operation at the time the data was collected, they indicated that they had not forged community partnerships, but would like to do so in the future. Members of these courts also believed they needed more help from their state government.

The next category of comparison was offender eligibility to enter into drug court programs. Here, there were more similarities than differences between top-down and bottom-up states. Like with funding, West Virginia had passed legislation to regulate this area, but it used very similar language to what the local WV Site adopted into its court's rules as well. Each of the drug court programs barred violent offenders and sex offenders from entering their programs. West Virginia admitted high risk/high need offenders, while Pennsylvania allowed a wider variety of offenders to enter their programs. The WV Site has been in existence for more than a 
decade and has had time to fine tune its rules more than the other courts, so this could account for differences in these policies.

There were no major differences between top-down and bottom-up drug courts in the areas of regulations, evaluations, and compliance. In terms of drug court regulations, the WV Site and both PA Sites have adopted universal standards such as the 10-Key Components. In West Virginia, these were codified into legislation, while in PA the state supreme court required it. When it comes to evaluating drug court practices, WV again has codified rules into legislation, while both PA courts use local rules and adhere to the 10-Key Components. The WV Site's evaluation practices were much more detailed than the PA Sites, but each of these sites kept records on demographics, recidivism rates, and the participant's drug of choice. In terms of compliance, the WV Site indicated that tension had existed between themselves and the state supreme court, especially after legislation was initially passed. However, this tension seemed to quell over time, and the members of the WV drug court team indicated that they still have wide latitude over how to govern their courts. The rules passed by the WV legislature and members of the state supreme court were not overly complex and did not create a rift in the culture that had been established, so non-compliance was not an issue. The PA Sites indicated that complying with regulations in their respective state supreme courts was not difficult to follow.

Drug court team members were largely supportive of drug courts and the belief in the mission. This was another factor that undoubtedly led to compliance with mandates from lawmakers and state supreme courts. However, certain members of law enforcement still remain skeptical of drug courts. Attempts to use education and outreach to convince members of the law enforcement community has been effective in West Virginia, and efforts to do the same are underway in Pennsylvania. The general public is largely unaware of the drug courts unless they 
have been affected by them; however, faith-based organizations and other non-profit organizations seem to be supportive of the drug court effort.

\section{The Current Opioid Crisis and Policy Recommendations}

One of the biggest political and policy problems of the last few years has been the opioid and heroin crisis within the United States. From 1979 through 2015, there were over half a million deaths attributed to drug overdoses (Burke and Buchanich, 2018). Opioids, syntheticopioids, and heroin have accounted for the lion's share of these deaths in the past decade, with large increases in heroin deaths from 2010-2017, and even larger spikes in terms of deaths related to synthetic opioids like fentanyl (NIH, 2018).

\section{Drugs Involved in U.S. Overdose Deaths, 1999 to 2017}

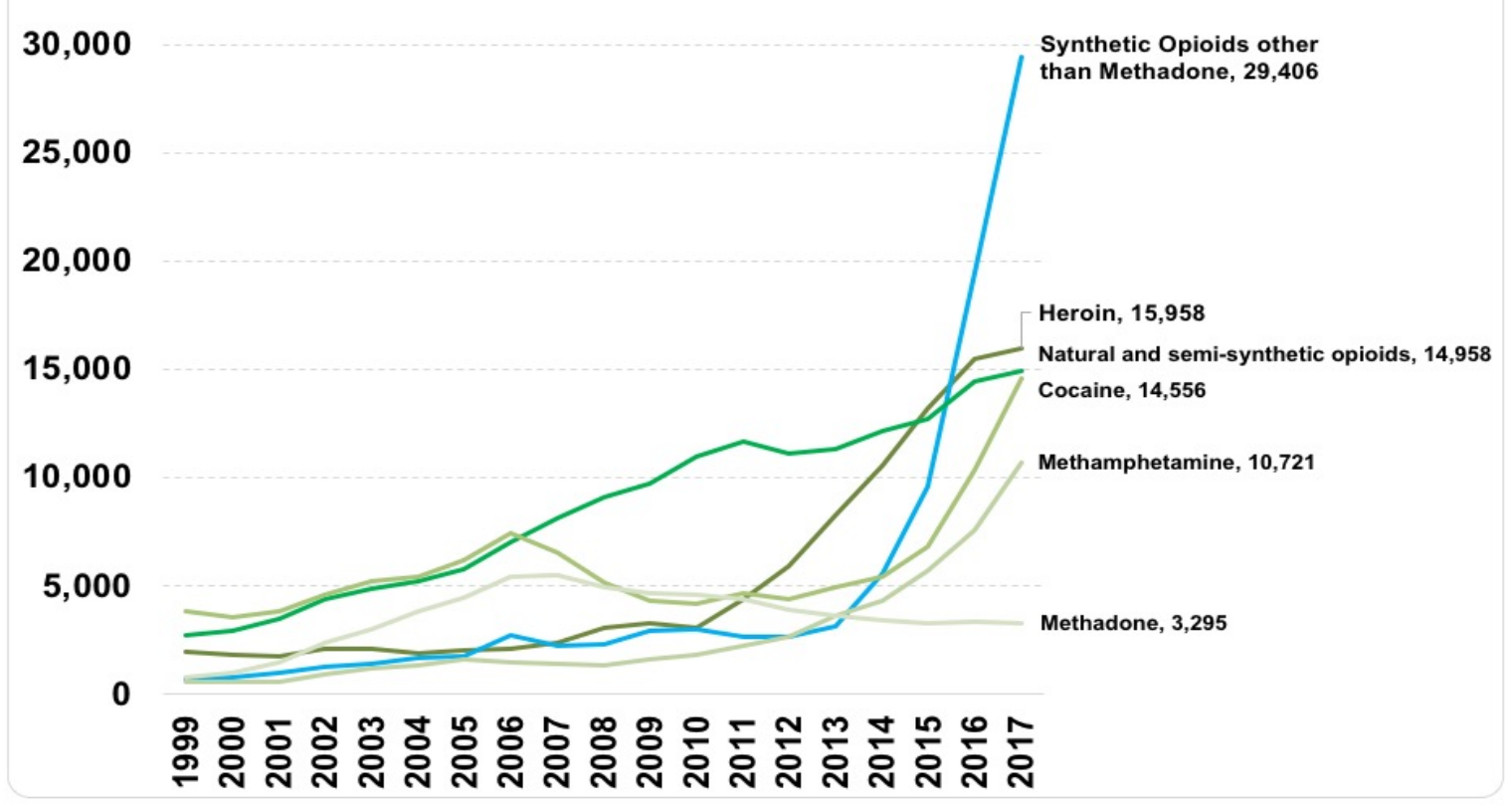

Drugs Involved in U.S. Overdose Deaths* - Among the more than 72,000 drug overdose deaths estimated in $2017^{*}$, the sharpest increase occurred among deaths related to fentanyl and fentanyl analogs (synthetic opioids) with nearly 30,000 overdose deaths. Source: CDC 
Both West Virginia and Pennsylvania, Western PA in particular, belong to the Appalachian region of the U.S., an area that has witnessed some of the highest overdose death rates in America (Burke and Buchanich, 2018).

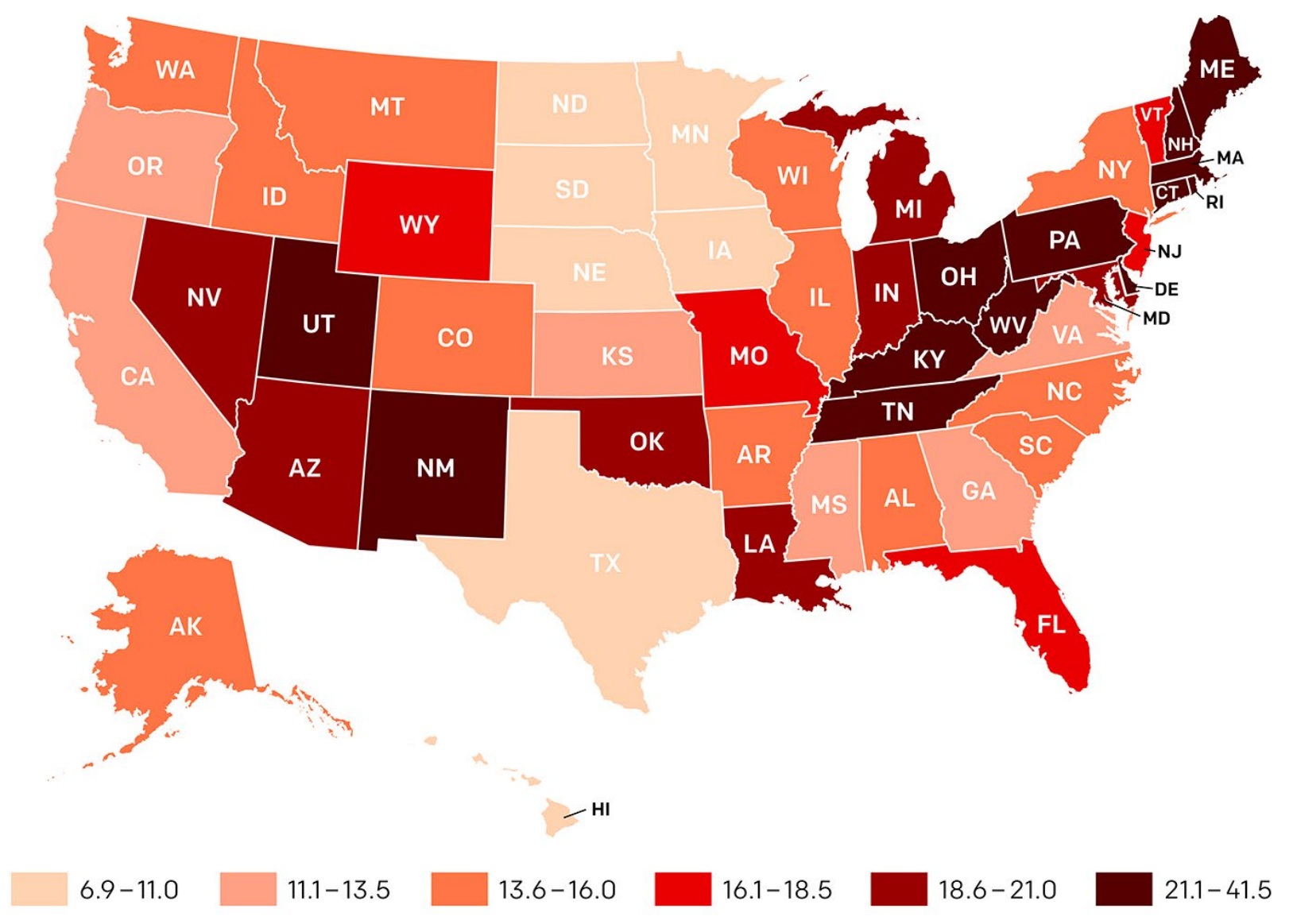

The CDC (2018) listed West Virginia and Pennsylvania rank number 1 and number 3, respectively, in drug overdose death rates for the year 2017. While overdose death rates often garner the most attention regarding the opioid crisis, this particular drug epidemic has created a host of other societal problems. According to many of the drug court professionals interviewed in this study, the healthcare system in West Virginia and Pennsylvania became overburdened by opioid addicts. Many areas lack the resources, treatment facilities, and funding to adequately address these type of issues. The criminal justice system is also strained as many addicts commit 
crime to support their addictions. Families are torn apart through neglect and lost productivity, and communities are searching for answers. The following section will tackle these issues in more depth by integrating current research with interviews from drug court professionals from West Virginia and Pennsylvania, and offering some insight into what kinds of policy ideas are needed to address the challenges of the opioid epidemic.

After speaking with drug court professionals across three courts and two states, it is clear that many drug courts are choosing to treat high risk drug offenders. According to the judge from WV Site, his particular court has chosen to only admit clients who are high risk/high need individuals. He believed that focusing on the individuals with high risk/high needs helps to treat the most severe cases. It also alleviates the chances for the high risk/high need individuals from negatively influencing other drug offenders who are not currently classified as high risk/high need. While the drug treatment court in PA Site 2 has only been in operation for less than a year, they have chosen to integrate individuals with both high and low risk assessments. "We have wanted to choose the low risk/high need model, but we have also admitted high risk individuals in the program as well." When asked if this posed a risk, the drug court coordinator from PA Site 2 stated, "This is a new program, right now there aren't a huge number of participants and certain things will be based on trial and error."

When asked which drug offenders posed the toughest challenges for drug court workers, all but two of the respondents indicated that individuals addicted to heroin or opioids were the most problematic. A defense attorney from the WV Site summed it up this way: "Because of the extremely addictive nature of the drug and the fact that it is cheap and easy to obtain makes it extremely hard to deal with from a law enforcement level. The same issues make it hard from a defense counsel perspective in trying to find ways to get one's clients off of it." 
When asked what kinds of problems the opioid and heroin epidemic has caused many of the respondents cited the same themes. First, addiction to opioids is difficult to treat because of the harsh physical symptoms that accompany attempting to stop using these drugs. For example, according to the treatment counselor from the WV Site, "Heroin and fentanyl are much stronger than other drugs. Stopping these drugs can cause severe physical withdrawal and make people extremely ill. Nobody wants to be sick, so they keep using. The initial euphoria from using drugs fades away, and it becomes more about feeling well, not about getting high." The attorney for PA Site 2 offered a concurring opinion when she stated that, "Opioid addiction is the worst drug problem we face. Unlike users of pot, who can hold down a job, heroin addicts do not. These individuals do not function well; they go into withdrawal and become sick."

A second, and more tragic, problem mentioned was the high rate of overdose experienced by users of heroin and opioids. A law enforcement officer from PA Site 1 said: "Synthetic opioids like fentanyl have made the overdose situation horrible.” These synthetic drugs are often added to heroin to increase its potency, often with deadly results. "Addicts begin to crave the stronger drugs, which has led to many overdoses."

"Heroin has been around here forever," said the prosecutor from PA Site 1. "It is only now getting a lot of attention because people are dying; it is affecting entire families." Opioid addiction also comes with a high rate of relapse, which can create deadly results. "When using heroin/opioids, the problem is that they (addicts) can become clean for a while, but then OD because they are still using the same amount of the drug w/o the tolerance they once had," said the Drug Court coordinator from PA Site 1. The drug NARCAN, which is an antidote for heroin overdose, has helped to save lives; its overabundance has also become problematic according to some law enforcement officers. The officer acknowledged that NARCAN has saved lives, but it 
has also made drug users bolder, because they know that officers are now required by law to save them.

A third common challenge is the additional crime that heroin/opioid addicts are engaged in. "Many new crimes are being committed as a result of heroin addiction," said the probation officer from PA Site 1. "The challenges (with heroin and opioid addiction) are too numerous to list adequately. As a prosecutor, the increased case load involving the commission of serious felony offenses is substantial," said the prosecutor from the WV Site. One way in which heroin users are especially dangerous is when they experience withdrawal. As a law enforcement officer from the WV Site points out, "They can become more desperate and violent when they are going through withdrawals, depending on the drug they have ingested, particularly heroin."

Withdrawals and lack of money to purchase additional heroin can result in other types of crimes, too. For example, according to the judge from the WV Site, "In order to support their drug habits, additional crime such as property crime and theft occurs. I have also seen an increase in robberies related to addiction." The prosecutor from PA Site 1 offered similar views as to the widespread nature of the offenses committed because of heroin addiction. "The crimes committed range from minor offenses to murder, burglary, stealing to get money and use robbing along the same lines, and child abuse, neglect, and sex crimes. In fact, we just had a drug-related homicide and many of them (homicides) involve drugs." Often, these crimes are not an isolated incident among addicts. "Crimes committed by addicts become a revolving door. The offenders are arrested for drug-related crimes, are eventually released from some form of custody, then start using (drugs) again and keep committing crimes," said the probation officer from WV Site.

A fourth problem caused by the opioid/heroin addiction is the disruption it causes to families. One way in which this occurs is through addicted mothers giving birth. "This is a 
complete crisis for the addicts, especially the babies of the addicts who are born going through withdrawal," said the drug court coordinator for PA Site 1. Since the start of the crisis there has been a five-fold increase in the number of babies born with Neonatal Abstinence Syndrome (Daley et al., 2018). Mothers who abuse opioids and other substances during pregnancy are at a much higher risk of other unwanted complications such as having a baby prematurely and giving birth to a child with fetal alcohol syndrome (Daley et al., 2018).

A main staple of the disruption that heroin and opioid addiction has caused to families is the high-level of child neglect and abuse. According to the judge from the WV Site, "It is overwhelming the court system in abuse and neglect proceedings. This is due to the addiction. For example, people are using these drugs and are found passed out in their vehicle in the parking lot of Walmart with their kids in the back seat." The prosecutor from the WV Site added, "Additionally, the civil abuse and neglect proceedings removing children from drug addicted parents or parents who are incarcerated is beyond a manageable point. The trickle down burden on DHHR (Department of Health and Human Resources) and the foster care system is never recognized with governmental support or funding and is rarely discussed in political arenas." This sentiment was shared by the judge from PA Site 2, who also expressed concern about female offenders. "Our jail, built in the 1980s, has space for about 120 males, but only about 25 females. Of course, the male to female ratio of addicts is more 1:1. Sometimes our jail struggles to place the females when they are sentenced. Moreover, there is the problem of what to do with the children of addiction and/or incarcerated females. Frequently, those cases end up in court too, often being necessary to place those children in foster care or group homes."

According to a study by Daley et al (2018), the abuse can take many forms such as physical, emotional, mental, or sexual abuse as a result of bad decisions made by intoxicated 
parents "Drugs affect everything!" said a law enforcement officer from PA Site 1, "I saw a violent crack and heroin fiend stab his girlfriend so many times that he cut his own fingers off." Violence and unpredictability of the addict often results in family members feeling insecure in regards to their safety (Daley et al. 2018). The abuse and neglect by addicted parents leads to many poor outcomes for their children. These children are more likely to be depressed, anxious, develop behavior problems, and perform worse in school than children whose parents do not have a substance abuse disorder (Daley et al, 2018).

One last theme uncovered by drug court personnel was the extreme strain placed on local and state-level resources as a result of the opioid/heroin epidemic. According to the treatment counselor from PA Site 1, "There are no beds available for inpatient treatment, and it is one of the biggest challenges to success for addicts." An attorney for PA Site 2 added, "There is only one treatment facility besides the drug court in the entire county." In an interview in the Dominion Post (a Morgantown, WV newspaper) in 2018, the chief of police in Morgantown, WV where the drug court from the WV Site resides indicated that most of the facilities only deal with addicts on a short-term basis. "Addiction is a type of disease and requires long-term treatment. But we do not treat addiction like that, typically. We get them clean in a 14 to 28 -day process, and we send them right back to the same circumstances where they were using or got addicted or were exposed to it, with the same people that were using with them, exposing them to it, and expecting them to stay clean because we dried them out for 28 days." Many of these individuals are not in drug courts and do not have the drug court support system to fall back on after their brief stay in rehab has ended. "Access to treatment is difficult for many," said the attorney from PA Site 2. "If the people have not committed crimes, then they have no access to drug court treatment." 
One of the most compelling findings in this study dispels the myths of yesteryear in which drug abuse was thought to be a largely inner-city problem, relegated to poor and minority communities. The spike in heroin abuse in the 1960s was largely viewed as a problem affecting minorities, and a hard-lined criminal justice response was viewed as the solution as evidenced by New York's draconian Rockefeller laws (Cohen, 2015). In the 1980s, the response to crack cocaine addiction and the perception of its users was viewed through a similar lens (ibid, 2015). At the time, powder cocaine use among affluent whites was often overlooked and even glorified to an extent (Spohn, 2009). Politicians declared crack to be a much more dangerous drug, often resulting in violent outbursts; this helped create a sentencing disparity of 100:1 for crack cocaine to powder cocaine possession in the 1986 Anti-Drug Abuse Act (Stith and Cabarnes, 1998).

Today's heroin crisis is viewed differently, however. The vast majority, nearly ninety percent, of those who tried heroin over the past ten years has been white (Cohen, 2015). "Heroin use has changed from an inner-city, minority-centered problem to one that has a more widespread geographical distribution, involving primarily white men and women in their late $20 \mathrm{~s}$ living outside of large, urban areas (Cohen, p. 1, 2015).” Many of the drug court team members from all three sites agreed that today's heroin epidemic has become more extensive. For example, according to the prosecuting attorney from PA Site 1, "The problem is widespread; race or socioeconomic status or the geographic areas do not matter. I knew a friend who overdosed and died recently from heroin. This person was from a rich family. Many of the people suffering from this addiction have money.” The drug court coordinator from PA Site 2 also agreed with that sentiment. "The problem is widespread and affects people from all walks of life. Over the last four years, this has changed from only a few isolated pockets of the area to include everywhere in the county." A private defense attorney from WV Site stated, "Many of 
my clients are from higher social economic levels. However, I believe the problem goes through all economic levels. It seems that the majority of addicts start with prescription drug abuse and that spirals on to heroin when pills become too expensive to obtain."

While a diverse array people have become addicted to heroin and opioids, it became evident that drug trafficking was most likely to occur in certain areas. "The drug hotspots are the low income housing areas, the trailer parks," said the law enforcement officer from PA Site 1; "However, the addiction itself knows no socioeconomic status." According to the treatment counselor from the WV Site, "All the drug court clients seem to know each other. The impoverished areas of the county are where many of the drugs are sold, and in many cases drugs are sold to keep one's addiction going."

In this section, I will examine the types of policy changes that could help to improve the outcomes for opioid and heroin addicts, while also improving drug treatment courts in a broader sense. Many of the drug court professionals indicated that for drug courts to maximize their success, there needed to be an expansion of inpatient treatment that preceded entry into the drug court program. According to the drug court coordinator from the WV Site, "The treatment availability is woefully low." While there has been some improvement in access to the initial medical detox phase of treatment, other initial recovery phases are lacking. "The 20-90 day beds are limited. There needs to be more encouragement for the community to get additional treatment beds for addicts in the acute phase of recovery." The judge from the WV Site expanded on some of these concerns. "We need more inpatient care followed by another layer, for how many number of days are deemed appropriate. The state needs to provide more beds and places to house offenders because these people do not have a good place to go back to." The drug court coordinator from PA Site 2 concurred with her West Virginia counterparts and offered 
some hope. "The offenders need to get the initial treatment to set them up for success. In this county, the rehab facilities are beginning to sprout up and there are more beds for addicts and many more on the way. Medical assistance are paying more for treatment and so are private insurers. So eventually there should be no financial excuse not to get treatment."

Some of the obvious concerns when implementing these policy changes deal with funding. Traditionally, offering support to criminals and drug addicts has not been politically popular. As evidenced by research from the first chapter in this study, politicians have run the risk of being labeled "soft-on-crime" for advocating rehabilitative programs. However, in today's political climate, there seems to be more of an appetite for treating addicts and moving away from mass incarceration. For example, Congress passed The First Step Act and President Trump signed it into law on December 21, 2018. The bill has reduced sentences for many federal inmates, including low-level drug offenders (Lau, 2018,). Obtaining federal grants to combat addiction has also become more prevalent in recent years. For instance, HHS awarded $\$ 1$ billion in grants in September to fight specific opioid related issues, and SAMASHA has awarded over $\$ 930$ million in state grants to increase access and treatment to opioid addicts (HHS Awards Over \$1 Billion to Fight Opioid Crisis, 2018). In sum, the political opposition is lessening toward treating addicts, and more money is being allocated to treat the problem

Setting drug court clients up for lasting success is another manner in which drug court policy can be improved. One way in which this can occur is by improving the current living situations of many of the addicts. As the drug treatment coordinator from the WV Site argues, "It is hard to take someone whose life is in chaos and think they will do really well, the majority will not." A financial hindrance to rehabilitation is also an issue, especially for those in West Virginia. According to a law enforcement officer from the WV Site, "Drug courts have always 
faced a challenge with finding available rehabilitation facilities that our lower income participants can attend upon initial entry into the program. Facilities throughout the state fill up very fast and the ones that are available, in many instances, they do not accept Medicaid." The judge from the WV Site also advocated for improving the living conditions of drug court clients. "There is a definite need to provide beds and places to house offenders because they do not have a good place to go back to." The drug treatment coordinator from PA Site 1 also emphasized the need for better conditions for drug court clients. "There is a definite need to provide greater housing for the addicts and additional facilities. More of a focus needs to center around re-entry into society. Transportation is also an issue, especially in rural counties where it is difficult for the individuals to travel to court for hearings and treatment."

A long-term commitment both during and after drug court treatment has been completed is something that the drug court professionals indicated would improve outcomes. According to the drug court coordinator from PA Site 1, "It takes a minimum of one year or longer for the brain to heal to pre-use state. Long-term clean time and living in recovery is needed to learn work skills, relationship skills, and to improve mental and physical health.” Another way to improve long-term outcomes would be to improve some things internally. For example, the law enforcement officer from WV Site asserted, "An increase in rehabilitation is needed, a wider variety of approved sanctions and incentives would help." Some of the incentives could involve adding activities to improve social skills and reintroduce addicts back into activities they once enjoyed without the use of drugs or alcohol. For instance, the treatment counselor from WV Site surmised, "There needs to be more sober activities within the group setting, like introducing a bowling night. This (drug court) is not an easy program to get through, so more fun things would help. The clients really need to participate in things being sober again." Finally, the judge from 
WV Site offered a community corrections approach to ensure long-term success. "You need to have the resources available so when clients have a relapse you offer options. You need a community based treatment with greater supervisions than probation, require offenders to check in, intensive outpatient therapy, random drug tests, but for some this isn't enough, they continue to use and relapse. Basically, there needs to be an additional level of treatment that the drug court cannot provide."

In terms of improving the drug court's actual structure, a few key ideas are worth mentioning. First, the program has come under some criticism in the past for trying to be a onesize-fits-all arena for addiction treatment. According to the prosecutor from the WV Site, "One of the problems with making a list of improvements is the belief that "drug court" is a cookie cutter program with a list of needs/resources to be checked-off for a participant to be successful. However, every individual is vastly different, the rules and regulations and constraints that exist within the bureaucracy developed around "drug court" prevent programs from addressing the individual needs of a participant. Services are limited to those that fit in a specific box and payment is restricted to unimaginable amounts so that needs of a participant with problems and difficulties that may never be duplicated by another participant or could never be imagined for the purpose of being placed on a list of approved services, can never be completely addressed." One way to address this is by allowing local drug court professionals to have more of a say in developing rules and regulations that govern the participants activities. In many cases, the drug court manuals can be rigid and more freedom to innovate could certainly benefit drug court participants. This could be more of an issue in top-down states where more rules and regulations are handed down by lawmakers and state-level bureaucrats.

Prior research has indicated that minorities fare worse in drug court outcomes than their 
white counterparts. Areas of improvement can come in the form of better access and treatment services. According to a national survey in 2008 , blacks constituted 21 percent of drug court participants compared with 28 percent of probationers and parolees, 39 percent of jail inmates, and 44 percent of prison inmates (Huddleston and Marlowe, 2017). Some ways to improve this would include ensuring the criteria for eligibility is race-neutral and fewer restrictions could be implemented to increase participation (Huddleston and Marlowe, 2017). In terms of treatment, minorities indicated that they felt uncomfortable with the Alcoholics Anonymous and Narcotics Anonymous formats and other group therapy activities, and they believed tools that helped to focus on education and job training would better serve their needs (Wolf, 2009). In fairness to the drug courts participating in this study, the overall population of minorities in these communities is scarce when compared to the national average and minority participation was beyond the scope of the questions asked during personal interviews; however, I believe it is important to include under policy improvements as it would be relevant on a broader scale to drug courts in general.

Another interesting point was that the drug court or at least its intensive supervision and structure could be beneficial to other people, not just those who have been in trouble with the criminal justice system. As the drug court coordinator from PA Site 2 indicated, "Only a small percentage of addicts actually receive treatment. There needs to be a broader tent in some capacity. Look at ways to help high-level offenders. There should also be efforts made to reach those who are suffering but haven't been arrested, whether it is through intensive therapy or some other means." While there are obvious risks involved with allowing high-level offenders into the current drug court programs, similar programs geared toward these individuals has the potential to improve outcomes and reduce recidivism. In terms of reaching other people in the 
community, the drug court structure could arguably benefit addicts in general. Getting them to adhere to the program via sanctions would be tricky, however, since they cannot be threatened with jail time because they have not been adjudicated for a crime. Certain incentives for voluntary treatment could work, though. For example, those who have prior criminal records could have their records expunged after successful completion of the program. Job training and certain educational benefits, such as obtaining a GED or learning a trade could also be added to the equation. These are things many addicts are lacking and which would help motivate them not only to beat their addictions, but also to become more productive citizens.

One worthy aim mentioned by several of the drug court professionals would be to stop addiction before it starts. In the late 1990s and into the 2000s, big pharmaceutical companies, like Purdue Pharma, flooded the market with Oxycodone and other prescription pain killers. These companies sought out doctors who seemed eager to over-prescribe these addictive drugs (Macy, 2018). A few of the drug court professionals mentioned that doctors and these companies should be held responsible in order to deter over-prescribing pain medication. For example, the judge from WV Site stated, "Pharmaceutical companies and doctors have become very problematic in prescribing pain killers. There is a tremendous potential for abuse. This needs to be better regulated." The law enforcement officer from PA Site 1 was more forceful when offering his solution to the problem, "The fucking doctors need to be prosecuted for overtreatment!" Tighter regulations governing the industry and increasing punishments for companies and doctors who recklessly prescribe drugs are warranted and could be pursued at both the federal and state levels. 


\section{Limitations and Future Research}

While this study was able to shed light on many areas important to public policy and political science, it was not without its limitations. First, the drug courts chosen for the case studies did not include drug courts from urban areas. Those courts presumably would have been larger and yielded different demographic information; however, since one of my main inquiries was to compare drug courts with different management styles, not including an urban court was not especially detrimental to this study. In the future, it would be interesting to compare an urban drug court to one from a rural area.

Another limitation of this study was to not be able to interview drug court participants. During preliminary discussions with drug court team members, I decided not to attempt to interview drug court participants. Privacy concerns from a research standpoint were an issue. However, the main issue was individual privacy concerns of the subjects. Several members of the drug court teams I spoke with also discouraged me from including drug court clients as part of my research. While including them would have been interesting in terms of learning about how to improve drug courts from a policy perspective, it did not limit my research in terms of comparing management styles, discovering the roles of drug court team members, or shedding light on how the drug courts are attempting to deal with the current opioid epidemic. Future research could examine ways in which drug court participants believe the courts are helpful to them and ways in which they believe the courts could be improved.

A final limitation to this study was not being able to include data on participant recidivism. First, this data was not readily available and I was unable to obtain permission to access it. Second, the two the PA drug courts were in their first year of existence, so not enough time had elapsed for the data to be meaningful. Third, an exhaustive amount of research has been 
conducted on recidivism rates of drug court graduates compared to recidivism rates of prisoners and probationers. Finally, much of the crux of my study where recidivism might have been relevant was focused more on policy implementation and not on the actual outcomes of the policy. Nevertheless, it would be interesting for future scholars to expand upon this work to determine if drug court management style makes a difference in terms of recidivism. 


\section{Appendices}

\section{Appendix A: State Drug Court Coordinator Questions}

1.) In what year were drug courts created in your state, and how were they created?

2.) Has drug court legislation been passed in your state? If so, where could I find these laws?

3.) How are the drug courts in your state funded? What does this consist of? i.e. federal, state, and/or private funding?

4.) Who provides policy oversight for the drug courts?

5.) Does your state's court of last resort have any managerial, oversight, funding, or additional responsibilities with drug courts?

6. Have any committees or commissions to study drug court effectiveness been developed in your state?

7. Have any universal operating standards or best practice methods been adopted by your state? If so, where I could I find these?

8. Have any outcome evaluations been conducted and/or published in your state? If so, would it be possible to gain access to a brief synopsis of the findings? 


\section{Appendix B: Questions for Drug Court Personnel}

\section{Probation Officers/Drug Court Managers}

1. Do you believe the community is largely supportive of drug courts? Who are these supporters and how do they help? Who are some of the most vocal critics of the drug court programs? Are there any attempts to address some of these concerns?

2. Are addicts who are dependent on specific types of drugs more problematic than others? If so, which ones?

3. What type of challenges does the current opioid crises present?

4. What can the drug courts do better to improve the outcomes for opioid addicts?

5. How long have you worked at your current position?

6. Describe your job duties?

7. Could you describe some of the selection criteria used to determine who is eligible to enter the drug court system? What are some of the main reasons why offenders are not allowed to enter into the program?

8. Do you tend to get more cases from certain parts of the county? Could you describe some of these cases and why you think more problems arise from these areas?

9. What kind of rules and regulations are you expected to comply with from state-level management, such as the state supreme court, drug court coordinator, etc?

10. Are these regulations difficult to comply with? What are some of the toughest challenges you face when trying to comply with these regulations?

11. Do state-level personnel provide you with the necessary resources to meet their requests?

12. Describe the overall relationship between you and the rest of the drug court personnel have with the state-level personnel?

13. What could the state-level personnel do to help you improve your drug court?

14. Who are some of the community members whom you have partnered with to support your drug courts?

15. What type of resources do these people/organizations provide?

16. May I contact you if I think of any additional questions?

\section{Judges}


1. Do you believe the community is largely supportive of drug courts? Who are these supporters and how do they help? Who are some of the most vocal critics of the drug court programs? Are there any attempts to address some of these concerns?

2. Are addicts who are addicted to specific types of drugs more problematic than others? If so, which ones?

3. What type of challenges does the current opioid crises present?

4. What can the drug courts do better to improve the outcomes for opioid addicts?

5. Could you describe some of the selection criteria used to determine who is eligible to enter the drug court system? What are some of the main reasons why offenders are not allowed to enter into the program?

6. Do you tend to get more cases from certain parts of the county? Could you describe some of these cases and why you think more problems arise from these areas?

7. How long have you worked at your current position?

8. How would you describe what you do a drug court judge, and how does this differ from the role of a regular criminal law judge?

9. Which role provides for greater flexibility?

10. Which role is more personally satisfying and why?

11. How would you describe the relationship between yourself and the members of the West Virginia Supreme Court's drug court division?

12. Has it been difficult to comply with some of the legislative mandates and supreme court rules that govern the state drug courts?

13. Do these rules hinder your autonomy as a judge? Does this make your job more difficult? What changes would you make, if any, to these laws and regulations?

\section{Treatment Counselors}

1. Do you believe the community is largely supportive of drug courts? Who are these supporters and how do they help? Who are some of the most vocal critics of the drug court programs? Are there any attempts to address some of these concerns?

2. Are addicts who are addicted to specific types of drugs more problematic than others? If so, which ones?

3. What type of challenges does the current opioid crises present?

4. What can the drug courts do better to improve the outcomes for opioid addicts?

5. Do you tend to get more cases from certain parts of the county? Could you describe some of these cases and why you think more problems arise from these areas? 
6. How long have you worked at your current position?

7. Do you or have you also worked as a treatment counselor outside of the drug court? If so, how would you describe the difference?

8. What are some of the things you like about the drug court model of treatment?

9. What are some of the things about drug court treatment that could be improved upon?

10. Are individuals with certain types of addictions less likely to succeed in drug courts than others? If so, could you please describe the most challenging type of cases?

11. Are the drug courts the proper venue for criminal addicts to receive the best treatment?

\section{Law Enforcement}

1. Do you believe the community is largely supportive of drug courts? Who are these supporters and how do they help? Who are some of the most vocal critics of the drug court programs? Are there any attempts to address some of these concerns?

2. Are addicts who are addicted to specific types of drugs more problematic than others? If so, which ones?

3. What type of challenges does the current opioid crises present?

4. What can the drug courts do better to improve the outcomes for opioid addicts?

5. Do you tend to get more cases from certain parts of the county? Could you describe some of these cases and why you think more problems arise from these areas?

6. How long have you worked at your current position?

7. Describe the ways in which your job as a law enforcement officer involves interaction with the drug court system.

8. Do you believe the drug courts are an effective way to deal with drug offenders? Why or why not?

9. Are there instances where drug courts are too lenient? Please describe these cases.

10. How could drug courts be improved to reduce criminal offending?

11. Are there ways other than drug courts to better address drug crimes? If so, what would these be?

12. Are there specific types of drugs that have become more problematic in the area?

13. Would you say there are certain laws/rules to make it more difficult for you and members of your department to fight drug crimes? If so, what would these be, and how could these things be improved?

Prosecutors 
1. Do you believe the community is largely supportive of drug courts? Who are these supporters and how do they help? Who are some of the most vocal critics of the drug court programs? Are there any attempts to address some of these concerns?

2. Are addicts who are addicted to specific types of drugs more problematic than others? If so, which ones?

3. What type of challenges does the current opioid crises present?

4. What can the drug courts do better to improve the outcomes for opioid addicts?

5. Could you describe some of the selection criteria used to determine who is eligible to enter the drug court system? What are some of the main reasons why offenders are not allowed to enter into the program?

6. Do you tend to get more cases from certain parts of the county? Could you describe some of these cases and why you think more problems arise from these areas?

7. How long have you worked at your current position?

8. Compare your role as normal criminal prosecutor to your one in the drug court?

9. How do you decide which cases are referred to drug courts?

10. Has the legislature and/or state supreme court's mandates made it easier or more difficult for you when it comes to recommending drug treatment courts to offenders? How so?

11. How have the drug courts made a difference in curbing drug abuse?

12. How could the drug courts be improved?

\section{Defense Attorneys}

1. Do you believe the community is largely supportive of drug courts? Who are these supporters and how do they help? Who are some of the most vocal critics of the drug court programs? Are there any attempts to address some of these concerns?

2. Are addicts who are addicted to specific types of drugs more problematic than others? If so, which ones?

3. What type of challenges does the current opioid crises present?

4. What can the drug courts do better to improve the outcomes for opioid addicts?

5. Could you describe some of the selection criteria used to determine who is eligible to enter the drug court system? What are some of the main reasons why offenders are not allowed to enter into the program? 
6. Do you tend to get more cases from certain parts of the county? Could you describe some of these cases and why you think more problems arise from these areas?

7. How long have you worked at your current position?

8. Describe when and why the drug court would be a better option than the regular judicial approach for your client.

9. In what ways could the drug court system be unfair to a potential client?

10. Have you experienced the drug courts helping your clients? If so, how?

11. Do drug courts provide adequate rehabilitative treatment for addicted clients, or would another approach better serve them?

12. In what ways could the drug court system be improved? 


\section{References}

A West Virginia Summit on Prescription Drug Abuse: Report and Recommendations (February 25, 2011. Retrieved from http://www.justice.gov/sites/default/files/usao-sdwv/legacy/201 1/legacy/2011/08/11/Summit_Report.pdf

Alabama Drug Offender Accountability Act. Alabama Code Title 12. Courts and 12-23-1

Aos, S., Miller, M., and Drake E. (2006). Evidence-based public policy options to reduce future prison construction, criminal justice costs, and crime rates. Olympia: Washington State Institute for Public Policy.

Andrews, D. A., and Bonta, J. (2010). Rehabilitating criminal justice policy and practice. Psychology, Public Policy, and Law, 16(1), 39.

Bachrach, P. and Baratz, M. (1962). The two faces of power. American Political Science Review, 56(04), pp. 947-952.

Barkow, R. E. (2011). Sentencing Guidelines at the Crossroads of Politics and Expertise. U. Pa. L. Rev., 160, 1599 .

Basinger, Scott, and Mark Hallerberg. 2004. Remodeling the competition for capital: how domestic politics erases the race to the bottom. American Political Science Review 98 (2): 26176.

Baum, L. (2006). Judges and their audiences: A perspective on judicial behavior. Princeton University Press.

Baum, L. (2011). Specializing the courts. university of Chicago Press.

Baum, L. (1997). The puzzle of judicial behavior. University of Michigan Press.

Baumgartner and Jones (1993). Agendas and instability in American politics. The University of Chicago Press.

Beaver, A. (2010). Getting a fix on cocaine sentencing policy: reforming the sentencing scheme of the anti-drug abuse act of 1986. Fordam Law Review. (78)2531-2575.

Beckett, K. and Western, B. (2001). Governing social marginality: Welfare, incarceration, and the transformation of state policy. Punishment and Society (3) 43-59.

Belenko, S. (2001) Research on Drug Courts: A critical review. New York,: The National Center on Addiction and Substance Abuse at Columbia University.

Benesh, S. C., and Martinek, W. L. (2002). State Supreme Court decision making in confession cases. Justice System Journal, 23(1), 109-133. 
Birkland, T. (1998). Focusing events, mobilization, and agenda setting. Cambridge University Press.

Boles, S. and Miotto, K (2003). Aggression and violent behavior. A Review Journal, 8(2) pp 155-174.

Brace, P., and Hall, M. G. (1995). Studying courts comparatively: The view from the American states. Political Research Quarterly, 48(1), 5-29.

Brace, P., Hall, M. G., and Langer, L. (2001). Placing state Supreme Courts in state politics. State Politics and Policy Quarterly, 1(1), 81-110.

Brehm, J. and Gates, S. (1997). Working, Shirking, and Sabotage: Bureaucratic Response to a Democratic Public. Ann Arbor, MI: University of Michigan Press.

Bureau of Justice Statistics (2009). Retrieved from www.bjs.gov.

Burke, D. andBuchanich, J (2018). Drug overdoses in Pennsylvania: Measuring, tracking, and forecasting the epidemic. Commonwealth 20(1) pp 24-37.

Carey, S. M., Finigan, M. W., and Pukstas, K. (2008). Exploring the key components of Drug Courts: A comparative study of 18 adult Drug Courts on practices, outcomes and costs. Portland, OR: NPC Research.

Cartier, J., Farabee, D., and Pendergast, M. L. (2006). Methamphetamine use, self-reported violent crime, and recidivism among offenders in California who abuse substances. Journal of Interpersonal Violence, 21, 435-445

Centers for Disease Control and Prevention (2017). Drug overdose death data, February 7 , 2018. Retrieved from https://www.cdc.gov/drugoverdose/data/statedeaths.html.

Cohen, A (2015). How white users made heroin a public-health problem (2015 August 12). Retrieved from https://www.theatlantic.com/politics/archive/2015/08/crack-heroin-and-race/401015/

Coppolo, G (2006). Drug court. OLR Research Report. Retrieved from https://www.cga.ct.gov/2006/rpt/2006-r-0012.htm

Cross, F. (2008). Judicial Independence in Caldeira, G., Kelemen, R., and Whittington, K. (2008).

The Oxford Handbook of Law and Politics: Oxford University Press.

Daley, D., Smith, E., Balogh, D., and Toscolani, J (2018). Forgotten but not gone: the impact of the opioid epidemic and other substance use disorders on families and children. Commonwealth 20(1) pp 94-121. 
Dannerbeck, A., Sundet, P., and Lloyd, K. (2002). Drug courts: Gender differences and their implications for treatment strategies. Corrections Compendium, 27 (12), 1-10.

Davey, J. (1998). The politics of prison expansion: Winning elections by waging war on crime. Westport, CT: Praeger.

Davies, L. (2010). Rock, powder, sentencing - making disparate impact evidence relevant in crack cocaine sentencing. Gender, Race and Just.

Dawe, S., Davis, P., Lapworth, K., and McKetin, R. (2009). Mechanisms underlying aggressive and hostile behavior in amphetamine users. Current Opinion in Psychiatry, 22, 269-273.

Drug Courts (September 15, 2017). National Institute of Justice (September 15, 2017). Retrieved from https://www.nij.gov/topics/courts/drug-courts/Pages/welcome.aspx

Drug Courts are not the answer: toward a health-centered approach to drug use. www.drugpolicy.org.

Drug Offender and Treatment Act $(62-15-3,2009)$ in WV Supreme Court website (October 23, 2014). Retrieved from http://www.courtswv.gov/lower-courts/adult-drug-courts/adult-drugcourts.html

Eckrich, J. and Loudenburg, R (2012). Answering the call: drug courts in South Dakota. South Dakota Law Review.

Epstein, L., and Knight, J. (1997). The choices justices make. SAGE.

Fairchild, E. (1981). Interest groups in the criminal justice process. Journal of Criminal Justice, Volume 9, 2.

Fayette County, PA Drug Treatment Court Manual (2017).

Fox, A., and Wolf, R. V. (2004). The future of drug courts: How states are mainstreaming the drug court model. Center for Court Innovation.

Franco, C (2010). Drug courts: background, effectiveness, and policy issues for congress. CRS Report for Congress.

Frankel, M. E. (1973). Criminal sentences: Law without order.

Frase, R. (2007). The Apprendi-Blakely cases: sentencing reform counter-revolution. Criminology and Public Policy, 6(3), pp. 403-432.

Gilardi, F. (2016). Four ways we can improve policy diffusion research. State Politics \& Policy Quaterly 16(1) 8-21. 
Goldstein, P.J. 1985. The drugs/violence nexus: A tripartite conceptual framework. Journal of Drug Issues 15:493-506.

Gottfredson, Najaka, and Kearley (2003). Effectiveness of drug treatment courts: evidence from a randomized trial. Criminology and Public Policy, (2), 2, 171-196.

Graham, K (2011). Sorry seems to be the hardest word: the fair sentencing act of 2010, crack, and methamphetamine. University of Richmond Law Review, 45 pp 765-799.

Grann, M. and Fazel, S (2004). Substance misuse and violent crime: Swedish population study. $B M J$

Gray, A. and Saum, C (2005). Mental health, gender, and drug court completion. American Journal of Criminal Justice 30(1) pp. 55-69.

Gross, J. (2010). The effects of net-widening on minority and indigent drug offenders: a critique of drug courts. University of Maryland L.J, Race, Religion, Gender, and Class, (10), 161-178.

Häggård-Grann U, Hallqvist J, Långström N, Möller J. The role of alcohol and drugs in triggering criminal violence: a case-crossover study. Addiction. 2006;101:100-108

Hall, M. G. (2001, June). State Supreme Courts in American democracy: Probing the myths of judicial reform. In American Political Science Association (Vol. 95, No. 02, pp. 315-330). Cambridge University Press.

Hartley, R. and Phillips, R (2001). Who graduates from drug courts? Correlates of client success. American Journal of Criminal Justice 26(1) pp 107-119.

HHS awards over $\$ 1$ billion to combat the opioid crisis (2018 September 19). Retrieved from https://www.hhs.gov/about/news/2018/09/19/hhs-awards-over-1-billion-combat-opioid-crisis.html

Hickert, A., Boyle, S., Tollefson, D (2009). Factors that predict drug court completion and drop out: findings from an evaluation of Salt Lake county's adult felony drug court. Journal of Social Service Research, 35 pp. 149-162.

Hora, P. F., Schma, W. G., and Rosenthal, J. T. (1999). Therapeutic jurisprudence and the drug treatment court movement: Revolutionizing the criminal justice system's response to drug abuse and crime in America. Notre Dame L. Rev., 74, 439.

Hora, P. F., and Stalcup, T. (2007). Drug treatment courts in the twenty-first century: The evolution of the revolution in problem-solving courts. Ga. L. Rev., 42, 717.

Huddleston, W. and Marlowe, D (2011). Painting the current picture: a national report on drug courts and other problem-solving court programs in the United States. National Association of Drug Court Professionals. 
Lau, T (2018). Historic criminal justice reform legislation signed into law (2018 December 21). Retrieved from https://www.brennancenter.org/blog/historic-criminal-justice-reform-legislationsigned-law

Lewis-Beck, M., Northpoth, H., Jacoby, W., Weisberg, H (2008). The American voter revisited. The University of Chicago Press.

Liang, B., and Long, M.A. (2013). Testing the gender effect in drug and alcohol treatment: Women's participation in Tulsa County drug and DUI programs. Journal of Drug Issues, 43(3), 270-288.

Lipsky, M. (1980) Street-Level Bureaucracy: The Dilemmas of Individuals in Public Service, New York, Russell Sage Foundation.

Lindquist, C. H., Krebs, C. P., and Lattimore, P. K. (2006). Sanctions and rewards in drug court programs: Implementation, perceived efficacy, and decision making. Journal of Drug Issues, $36(1), 119-146$.

Lin, A. (2000). Reform in the Making: The Implementation of Social Policy in Prison. Princeton, NJ: Princeton University Press.

Louisiana Drug Courts. In Louisiana Supreme Court website (March 31, 2015). Retrieved from http://www.lasc.org/court_managed_prog/drug_courts.asp

MacKenzie, D. L. (2006). What Works in Corrections: Reducing the Criminal Activities of Offenders and Deliquents. Cambridge University Press.

Mateyoke-Scrivner, A., Webster, J. M., Staton, M., and Leukefeld, C. (2004). Treatment retention predictors of drug court participants in a rural state.American Journal of Drug and Alcohol Abuse, 30, 605-626.

Marcus, M. (2005). Blakely, Booker, and the future of sentencing. Federal Sentencing Reporter, 17(4).

Marcus, P., and Waye, V. (2010). Australia and the United States: two common criminal justice systems uncommonly at odds part 2. 18 Tul. J. Int'l and Comp.

Marion, N., and Oliver, W. (2003). The public policy of crime and criminal justice. Pearson, Prentice Hall. Upper Saddle River, NJ.

Marlowe, D. (2010). Research update on adult drug courts. National Association of Drug Court Professionals, 1-8.

Marlowe, D., Hardin, C., Fox, C (2016). Painting the current picture. A national report on drug courts and other problem-solving courts in the United States. National Association of Drug Court Professionals. 
Martinson, R. (1974). What works? - questions and answers about prison reform. The Public Interest, 35, 22-54.

Massing, M. (2000). The fix. Univ of California Press.

Meier, K. (1994). The politics of sin: Drugs, alcohol, and public policy. Armonk, NY: M.E. Sharpe.

Miller, L (2008). The perils of federalism: race, poverty, and the politics of crime control. Oxford University Press.

Miller, M., and Wright, R. (1999). Your cheatin' heart(land): the long search for administrative sentencing justice. Buffalo Criminal Law Review. (2) 725-815.

Monongalia County, WV Drug Court Treatment Manual (2008).

Mooney, C. (2000). The decline of federalism and the rise of morality-policy conflict in the United States. Journal of Federalism (30), 171-188.

Mooney, C. (2001). The public clash of private values. In C. Z. Mooney (Ed.), The public clash of private values: The politics of morality policy (pp. 3-17). New York: Chatham House Publishers.

Morone, J. (1998). The Democratic wish: popular participation and the limits of American government. Yale University Press.

National Institute of Health (2018). Overdose death rates.

National Institute of Justice (2017, August 21). Retrieved from https://www.ncjrs.gov/spotlight/drug courts/Summary.html

National Association of Drug Court Professionals (2014, Dec 18). Retrieved from http://www.nadcp.org/

NADCP All Rise 2019 (2019 June 15, 2019). Retrieved from https://ndcrc.org/event/nadcpannual-training-conference-all-rise-2019/

Nolan, J. L. (2001). Reinventing justice: The American drug court movement. Princeton University Press.

North Carolina Drug Treatment Court Act of 1995. (1995, c. 507, s. 21.6(a); 1998-23, s. 9; 1998-212, s. 16.15(a).) 
Olson, A. E., Lurigio, A. J., and Albertson, S. (2001). Implementing the key components of specialized drug treatment courts: Practice and policy considerations. Law and Policy, 23, 171196.

Omori, M. (2013). Moral panics and morality policy: the impact of media, political ideology, drug use, and manufacturing on methamphetamine legislation in the united states. Sage 43(4) 517-534.

Pagano, A. (March 2, 2018). The racist origins of marijuana prohibition. Retrieved from https://www.businessinsider.com/racist-origins-marijuana-prohibition-legalization-2018-2

Peters R.H, Haas A.L, Murrin M.R. Predictors of retention and arrest in drug court. National Drug Court Institute Review. 1999;2:33-60.

Petersilia, J. (2003). When prisoners come home: parole and prisoner re-entry. New York: Oxford University Press.

Piquero, A. (2010). Cost-benefit analysis for jail alternatives and jail. Retrieved November 28, 2012.

Porter, Nicole D. (2010). The state of sentencing 2009: developments in policy and practice. Washington, DC: The Sentencing Project.

Powers, K (2012). Arkansas drug courts. Report to the Eighty-ninth Arkansas General Assembly.

Ryan, K. (1998). Clinging to failure: the rise and continued life of U.S. drug policy. Law and Society Review, Volume 32, 1.

Schattschneider, E. (1960). The semi-sovereign people: a realist's view of democracy in America. New York: Holt, Rinehart, Winston.

Schiff, M., and Terry, W. C., III. (1997). Predicting graduation from Broward County's dedicated drug treatment court. Justice System Journal, 19, 291-310.

Schmidt, John, Kris Warner and Sarika Gupta. (2010). The high budgetary cost of incarceration. Center for Economic and Policy Research.

Segal, J. A., Spaeth, H. J., and Benesh, S. C. (2005). The Supreme Court in the American legal system. Cambridge University Press.

Senjo, S. and Leip, L (2001). Testing therapeutic jurisprudence theory: an empirical assessment of the drug court process. Western Criminology Review, 3(1).

Sevigny, E., Fuleihan, B., Ferdik, F (2013). Do drug courts reduce the use of incarceration? A meta-analysis. Journal of Criminal Justice, 41(6) pp 416-425. 
Shaffer, D. (2011). Looking inside the black box of drug courts: a meta-analytic review. Justice Quarterly 28(3) pp 493-521.

Shepard, R. T. (2006). New Role of State Supreme Courts as Engines of Court Reform. NYUL Rev., 81, 1535.

Somerset County, PA Drug Treatment Court Manual (2017).

Spohn, C. (2009). How do judges decide cases? The search for fairness and justice in punishment. Sage Publications.

Steadman, H., Morris., S, and Dennis, D. (1995). The diversity of mentally ill persons from jails to community-based services: a profile of programs. American Journal of Public Health, 85(12) 1630-1635.

Stein, D., Deberard, S., and Homan, K (2012). Predicting success and failure in juvenile drug treatment court: A meta-analytic review. Journal of Substance Abuse Treatment, 44 159-168.

Stith, K., and Cabranes, J. (1998). Fear of judging: sentencing guidelines in the federal courts. The University of Chicago Press.

Stolz, B. (1999). Congress, symbolic politics and the evolution of 1994 "violence against women act." Criminal Justice Policy Review 10.

Stuckey, T., Heimer, K., \& Lang, J. (2005). Partisan politics, electoral competition and imprisonment: an analysis of states over time. Criminology (43) 1, 211-248.

Tatalovich, R., \& Daynes, B. W. (1998). Moral controversies in American politics: Cases in social regulatory policy. New York, NY: M. E. Sharpe.

The Treatment Court Movement (2019 July 3). Retrieved from https://www.nadcp.org/testtimeline/

Tiger, R. (2013). Judging addicts: Drug courts and coercion in the justice system. NYU Press.

Tiger, R. (2011). Drug courts and the logic of coerced treatment. Sociological Forum, (26), 1, 169-182.

Tonry, M. 1996. Sentencing matters. New York: Oxford.

Uelmen, G. F. (1996). Crocodiles in the bathtub: Maintaining the independence of state Supreme Courts in an era of judicial politicization. Notre Dame L. Rev., 72, 1133.

VoldenVolden, Craig. 2006. States as policy laboratories: emulating success in the children's health insurance program. American Journal of Political Science 50 (2): 294-312 
Wagner, P. and Walsh, A (2016 June 16). States of incarceration: the global context. Retrieved from www.prisonpolicy.org/global/2016html

Walmsley, R (2015). World prison brief. London: Institute for Criminal Policy Research. Available online: http://www. prisonstudies.org/world-prison-brief

Weatherburn, D., Jones, C., Snowball, L., Hua, J. (2008). The NSW Drug Court: A re-evaluation of its effectiveness. Contempory Issues in Crime 121.

Wenzel, S., Longshore, D., Turner, S., Ridgely, S. (2001). Drug courts: a bridge between criminal justice and health services. Journal of Criminal Justice, (29), 241-253.

West Virginia Drug Offender and Accountability Act (2009). §62-15-4.

White, C. (2018 November 18). World War I Played Key Role in Passage of Prohibition. Retrieved from https://themobmuseum.org/blog/world-war-played-key-role-passage-prohibition/

Winter, S. (2001). Information asymmetry and political control of street-level bureaucrats: Danish agro-environmental regulation. Paper prepared for the Annual Research Meeting of the Association for Public Policy Analysis and Management, Seattle, WV (November 3, 2000).

Wilson, J. (1975). Thinking about crime. New York: Vintage Books.

Wolf, R (2009). Race, biad, and problem-solving courts. National Black Law Journal 26 pp 2752 .

Zimring, F. (2007). Protect individual punishment decisions from mandatory penalties. Criminology and Public Policy 6(4) pp. 881-886. 